Supporting Information for:

\title{
Design, Synthesis, and Biological Evaluation of Novel 1,3-Oxazole Sulfonamides as Tubulin Polymerization Inhibitors
}

\author{
Edward Sisco, Korry L. Barnes* \\ National Institute of Standards and Technology, Gaithersburg, MD 20899 \\ Department of Chemistry, United States Naval Academy, Annapolis, MD 21402 \\ Table of Contents \\ General experimental information $\quad$ S2 \\ Synthesis and tabulated characterization data S3-S41

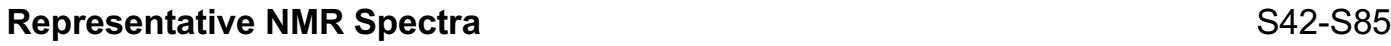 \\ Tubulin polymerization assay information/data $\quad$ S86-S90
}




\section{Experimental:}

All reactions were carried out under atmospheric conditions in oven-dried glassware with magnetic stirring, unless otherwise specified. All reagents and solvents were purchased from Sigma-Aldrich Chemical Company, Fisher Scientific, or Accela Chembio and used without any further purification. TLC analyses were recorded on Silicycle plastic-backed $60 \mathrm{~F}_{254}$ plates and developed as specified followed visualization under UV light. Purification of reaction products was carried out by flash column chromatography using Silicycle Siliaflash ${ }^{\circ}$ P60 (230-400 mesh). ${ }^{1} \mathrm{H}-$ NMR spectra were measured on a JEOL $400(400 \mathrm{MHz})$ spectrometer with chemical shifts $(\delta)$ reported in ppm ( $\mathrm{s}=$ singlet, $\mathrm{d}=$ doublet, $\mathrm{t}=$ triplet, $\mathrm{q}=$ quartet, $\mathrm{m}=$ multiplet, $\mathrm{br}=$ broad; integration; coupling constant(s) $(J)$ in $\mathrm{Hz})$ using the solvent peak as an internal standard $\left(\mathrm{CDCl}_{3}\right.$ at $\left.7.26 \mathrm{ppm}\right)$ or (DMSO- $d_{6}$ at $\left.2.50 \mathrm{ppm}\right) .{ }^{13} \mathrm{C}-\mathrm{NMR}$ spectra were recorded on a JEOL 400 spectrometer with chemical shifts $(\delta)$ reported in ppm using the solvent as an internal standard $\left(\mathrm{CDCl}_{3}\right.$ at $\left.77.16 \mathrm{ppm}\right)$ or (DMSO- $d_{6}$ at $\left.39.52 \mathrm{ppm}\right)$. High-resolution mass spectra were obtained using a Thermo UltiMate 3000 liquid chromatography (LC) system (Thermo Scientific, Waltham, MA, USA) in combination with a JEOL AccuTOF 4G LC-plus (JEOL USA). Parameters used for the LC system included a $50 \%$ methanol $50 \%$ acetonitrile isocratic mobile phase at $0.5 \mathrm{~mL} \mathrm{~min}^{-1}$ a $25 \mu \mathrm{L}$ injection, and the use of a Restek Raptor Biphenyl ( $2.7 \mu \mathrm{m} \times 5 \mathrm{~mm} \times 3 \mathrm{~mm})$ guard column. MS parameters included an electrospray voltage of $-3500 \mathrm{~V}$, a desolvating temperature of $250{ }^{\circ} \mathrm{C}$, an orifice temperature of $110{ }^{\circ} \mathrm{C}$, a detector voltage of $2325 \mathrm{~V}$, an orifice 1 voltage of $-20 \mathrm{~V}$, a ring lens and orifice 2 voltage

of $-5 \mathrm{~V}$, and an ion guide voltage of $500 \mathrm{~V}$. Full scan mass spectra from 60 to $650 \mathrm{~m} / \mathrm{z}$ were collected at 3 scans s$^{-1}$. The mass tolerance on the MS system is $\pm 0.005 \mathrm{Da}$. All samples were analyzed as $0.1 \mathrm{mg} \mathrm{mL}^{-1}$ solutions in methanol or acetonitrile. The purity of all biologically evaluated compounds was assessed via LC-MS and NMR and found to be $>90 \%$ for all compounds. 


\section{2-Bromoacetophenone (7) (known compound):}<smiles>CC(=O)c1ccccc1</smiles>

To a solution of acetophenone $(29.2 \mathrm{~mL}, 0.250 \mathrm{~mol})$ in methyl tert-butyl ether $(275 \mathrm{~mL})$ was added bromine $(12.9 \mathrm{~mL}, 0.250 \mathrm{~mol})$ and the resulting mixture was stirred at room temperature overnight. After completion the reaction mixture was poured into water and the aqueous layer was extracted with ether. The combined organic extracts were washed with brine, dried over anhydrous sodium sulfate, and concentrated under reduced pressure. The resulting residue was placed in an ice bath and the crystals that formed were washed with cold hexanes and filtered to afford the $\alpha$ bromo ketone as white crystals $(42.5 \mathrm{~g}, 0.214 \mathrm{~mol}, 85 \%$ yield $)$. M.P. $=48-51{ }^{\circ} \mathrm{C} ;{ }^{1} \mathrm{H}$ NMR $(400$ $\left.\mathrm{MHz}, \mathrm{CDCl}_{3}\right) \delta 7.97(\mathrm{dt}, J=8.3,1.5 \mathrm{~Hz}, 2 \mathrm{H}), 7.62-7.57(\mathrm{~m}, 1 \mathrm{H}), 7.50-7.46(\mathrm{~m}, 2 \mathrm{H})$, and $4.45(\mathrm{~s}$, $2 \mathrm{H}) ;{ }^{13} \mathrm{C}$ NMR $\left(101 \mathrm{MHz}, \mathrm{CDCl}_{3}\right) \delta 191.3,134.0,133.9,129.3,128.9$, and 31.2; IR (neat) 3423, 3064, 1682 (s), 1596, 1580, 1449, 1427, 1391, 1279 (s), 1195, 1013, 990, 750, and $710 \mathrm{~cm}^{-1}$; HRMS calculated for $\mathrm{C}_{8} \mathrm{H}_{6} \mathrm{BrO}[\mathrm{M}-\mathrm{H}]^{-}$196.9608; found 196.9605.

\section{2-Aminoacetophenone hydrochloride (8) (known compound):}<smiles>[B]CC(=O)c1ccccc1</smiles>

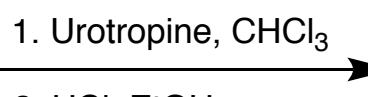
2. $\mathrm{HCl}, \mathrm{EtOH}$<smiles>NCC(=O)c1ccccc1</smiles>

To a solution of 2-bromoacetophenone $(7)(17.7 \mathrm{~g}, 90.0 \mathrm{mmol})$ in chloroform (360 mL) was added hexamethylenetetramine $(13.2 \mathrm{~g}, 94.5 \mathrm{mmol})$ all at once and the resulting solution was stirred at room temperature overnight. After the reaction was complete, the mixture was filtered to remove the precipitated quaternary ammonium salt and washed with small portions of chloroform. The precipitate was then taken up in ethanol $(600 \mathrm{~mL})$ and concentrated hydrochloric acid (90.0 $\mathrm{mL}$ ) was added drop wise via a pressure-equalizing addition funnel followed by stirring of the resulting reaction mixture for 16 hours. The reaction was then filtered to remove a white precipitate 
Supporting Information

$\left(\mathrm{NH}_{4} \mathrm{Cl}\right)$ and the filtrate was concentrated under reduced pressure to give a yellow residue. The residue was cooled in an ice bath and triturated with THF followed by collection of the resulting white solid by filtration to afford the desired primary amine as its $\mathrm{HCl}$ salt $(14.5 \mathrm{~g}, 84.5 \mathrm{mmol}, 94 \%$ yield over two steps). M.P. $=194{ }^{\circ} \mathrm{C}$ (dec.); ${ }^{1} \mathrm{H}$ NMR $\left(400 \mathrm{MHz}, \mathrm{D}_{2} \mathrm{O}\right) \delta 7.95(\mathrm{~d}, J=7.6 \mathrm{~Hz}, 2 \mathrm{H})$, $7.71(\mathrm{t}, J=7.4 \mathrm{~Hz}, 1 \mathrm{H}), 7.55(\mathrm{t}, J=7.7 \mathrm{~Hz}, 2 \mathrm{H})$, and $4.67(\mathrm{~s}, 2 \mathrm{H}) ;{ }^{13} \mathrm{C}$ NMR $\left(101 \mathrm{MHz}, \mathrm{D}_{2} \mathrm{O}\right) \delta$ 194.03, 135.39, 133.11, 129.27, 128.35, and 45.37; IR (neat) 3127, 3040, 1697 (s), 1502, 1399 (s), 1242, 965, 902, and $761 \mathrm{~cm}^{-1}$; HRMS calculated for $\mathrm{C}_{8} \mathrm{H}_{9} \mathrm{NOCl}[\mathrm{M}-\mathrm{H}]^{-}$170.0378; found 170.0374 .

\section{N-(2-Oxo-2-phenylethyl)-cyclopropanecarboxamide (9) (known compound):}<smiles>NCC(=O)c1ccccc1</smiles>

A suspension of 2-aminoacetophenone hydrochloride

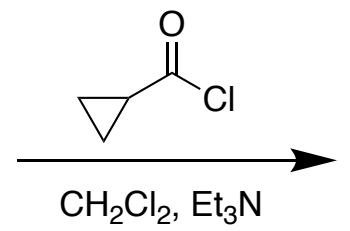

$0{ }^{\circ} \mathrm{C}$ to R.T.

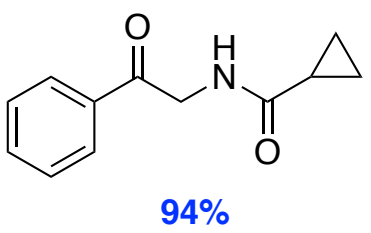

(8) $(10.00 \mathrm{~g}, 58.2 \mathrm{mmol})$ in chloroform $(232 \mathrm{~mL})$ and triethylamine $(16.2 \mathrm{~mL}, 116.4 \mathrm{mmol})$ was cooled to $0{ }^{\circ} \mathrm{C}$ in an ice bath. Cyclopropanecarbonyl chloride $(5.2 \mathrm{~mL}, 58.2 \mathrm{mmol})$ was added dropwise via syringe and the resulting reaction mixture was stirred overnight at room temperature. After quenching the reaction with water, the aqueous layer was extracted with chloroform. The combined organic extracts were washed with brine, dried over anhydrous sodium sulfate, and concentrated under reduced pressure to give a light yellow solid. Recrystallization from methanol:water provided the pure amide as colorless crystals $\left(11.1 \mathrm{~g}, 54.6 \mathrm{mmol}, 94 \%\right.$ yield). M.P. $=129-131^{\circ} \mathrm{C} ;{ }^{1} \mathrm{H}$ NMR $\left(400 \mathrm{MHz}, \mathrm{CDCl}_{3}\right)$ $\delta 7.94(\mathrm{~d}, J=8.0 \mathrm{~Hz}, 2 \mathrm{H}), 7.59-7.55(\mathrm{~m}, 1 \mathrm{H}), 7.45(\mathrm{t}, J=7.7 \mathrm{~Hz}, 2 \mathrm{H}), 6.94(\mathrm{br} \mathrm{s}, 1 \mathrm{H}), 4.77(\mathrm{~d}, J=$ 4.6 Hz, 2H), 1.59-1.53 (m, 1H), 0.98-0.94 (m, 2H), and 0.77-0.72 (m, 2H); ${ }^{13} \mathrm{C}$ NMR $(101 \mathrm{MHz}$, $\left.\mathrm{CDCl}_{3}\right) \delta 194.5,173.8,134.4,134.1,128.9,127.9,46.7,14.6$, and 7.4 ; IR (neat) 3274, 1689, 1657, 1636, 1595, 1549, 1452, 1413, 1392, 1363, 1266, 1253, 1222, 1196, 1185, 1092, 1076, 1060, 1031, 1000, 981, 931, 910, 891, 850, 820, 754, 687, 672, 644, 560, 538, and $526 \mathrm{~cm}^{-1}$; HRMS calculated for $\mathrm{C}_{12} \mathrm{H}_{12} \mathrm{NO}_{2}[\mathrm{M}-\mathrm{H}]^{-} 202.0868$; found 202.0864 . 


\section{2-Cyclopropyl-5-phenyloxazole (10):}

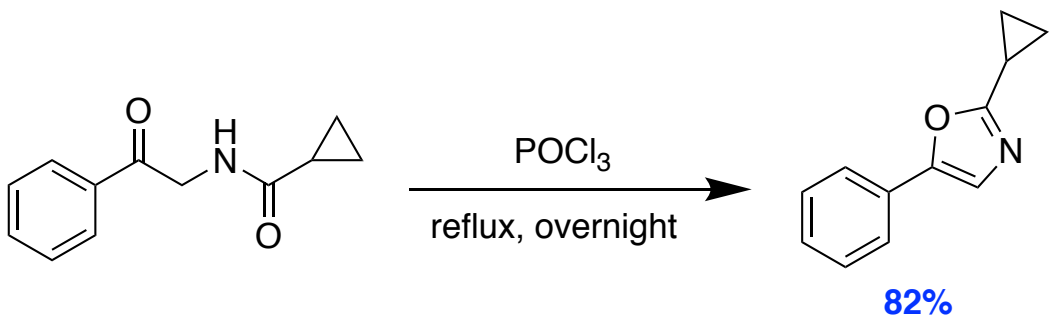

The starting amide (9) $(7.00 \mathrm{~g}, 34.4 \mathrm{mmol})$ was added to phosphoryl chloride $(41.8 \mathrm{~mL}$, $447.2 \mathrm{mmol}$ ) at room temperature and the resulting mixture was refluxed overnight. The next day, after cooling to room temperature, the mixture was carefully transferred to an ice and concentrated ammonium hydroxide mixture with additional ammonium hydroxide being added to make the solution basic as needed. Upon completion the aqueous layer was exhaustively extracted with chloroform. The combined organic extracts were washed with brine, dried over anhydrous sodium sulfate, and concentrated under reduced pressure to give an amber oil. Purification by flash column chromatography $\left(\mathrm{SiO}_{2}\right.$, gradient, $4: 1$ to $3: 1$ hexanes:ethyl acetate) afforded the pure 1,3-oxazole as a pale yellow oil $\left(5.26 \mathrm{~g}, 28.4 \mathrm{mmol}, 82 \%\right.$ yield). $R_{\mathrm{f}}=0.45$ (3:1 hexanes:ethyl acetate); ${ }^{1} \mathrm{H}$ NMR (400 MHz, $\left.\mathrm{CDCl}_{3}\right)$ ס 7.54-7.51 (m, 2H), 7.36-7.31 (m, 2H), 7.26-7.21 (m, 1H), $7.14(\mathrm{t}, J=1.7 \mathrm{~Hz}$, 1H), 2.12-2.04 (m, 1H), and 1.13-1.00 (m, 4H); $\left.{ }^{13} \mathrm{C} \mathrm{NMR} \mathrm{(101} \mathrm{MHz,} \mathrm{CDCl}_{3}\right) \delta$ 165.6, 150.1, 128.7, 128.1, 127.8, 123.7, 121.8, 9.0, and 8.3; IR (neat) 3012, 1693, 1577, 1562, 1489, 1449, 1398, $1314,1259,1177,1143,1120,1061,1026,967,944,879,818,760,729,713,689,656,581,569$, 551, 542, and $534 \mathrm{~cm}^{-1}$; HRMS calculated for $\mathrm{C}_{12} \mathrm{H}_{10} \mathrm{NO}[\mathrm{M}-\mathrm{H}]^{-}$184.0762; found 184.0762. 


\section{4-(2-Cyclopropyl-5-oxazolyl)-benzenesulfonyl chloride (11):}

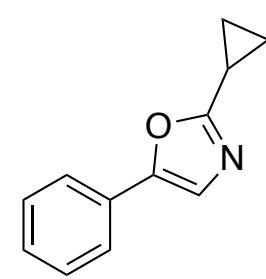

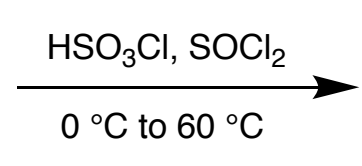

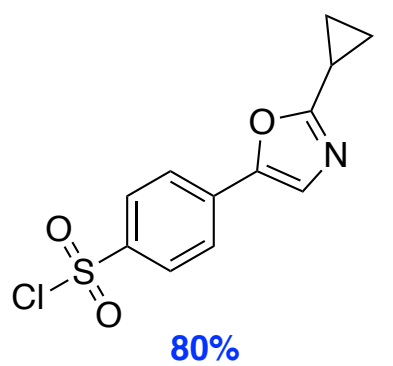

To an ice-cooled solution of chlorosulfonic acid $(18.5 \mathrm{~mL}, 277.7 \mathrm{mmol})$ and thionyl chloride (2.01 $\mathrm{mL}, 27.7 \mathrm{mmol})$ was added the 1,3-oxazole (10) $(5.14 \mathrm{~g}, 27.7 \mathrm{mmol})$ in small portions. The resulting reaction mixture was then warmed to $60^{\circ} \mathrm{C}$ and stirred for three hours. After the starting material had been consumed as observed by TLC, the mixture was cooled to room temperature and carefully transferred by Pasteur pipette to an Erlenmeyer flask containing crushed ice. The aqueous layer was then exhaustively extracted with chloroform. The combined organic extracts were washed with $10 \%$ sodium carbonate, brine, dried over anhydrous sodium sulfate, and concentrated under reduced pressure to afford the sulfonyl chloride as a light brown solid which was used without further purification $(6.27 \mathrm{~g}, 22.1 \mathrm{mmol}, 80 \%$ yield $)$. M.P. $=$ dec.; ${ }^{1} \mathrm{H}$ NMR $(400$ $\left.\mathrm{MHz}, \mathrm{CDCl}_{3}\right) \delta 8.04(\mathrm{~d}, J=8.7 \mathrm{~Hz}, 2 \mathrm{H}), 7.77(\mathrm{~d}, J=8.7 \mathrm{~Hz}, 2 \mathrm{H}), 7.43(\mathrm{~s}, 1 \mathrm{H}), 2.20-2.14(\mathrm{~m}, 1 \mathrm{H})$, and 1.20-1.14 (m, 4H); ${ }^{13} \mathrm{C}$ NMR $\left(101 \mathrm{MHz}, \mathrm{CDCl}_{3}\right) \delta 168.2,148.1,142.7,134.4,128.0,125.9$, 124.3, 9.3, and 9.2; IR (neat) 3007, 2236, 1875, 1604, 1586, 1565, 1553, 1412, 1373, 1326, 1303 , $1233,1190,1162,1130,1080,1063,1022,1009,966,939,879,828,810,744,716,671,625$, 578 , and $553 \mathrm{~cm}^{-1}$; HRMS unable to be acquired due to compound not being mass spec amenable.

General Procedure A: for the synthesis of 1,3-oxazole sulfonamides 12-59.

To a solution of the amine (1.0 equiv.) in chloroform $(0.20 \mathrm{M})$ and pyridine (2.5 equiv.) at 0 ${ }^{\circ} \mathrm{C}$ was added the 1,3-oxazole sulfonyl chloride (11) (1.0 equiv.) in small portions. The resulting reaction solution was then warmed to room temperature and stirred overnight. The next day the reaction was quenched with water and the aqueous layer extracted with chloroform. The combined organic extracts were washed with $10 \% \mathrm{HCl}$, brine, and dried over anhydrous sodium sulfate. After removal of the solvent under reduced pressure the crude residues were purified via flash column 
chromatography $\left(\mathrm{SiO}_{2}\right.$, DCM:MeOH or Hex:EtOAC) or recrystallized from $\mathrm{MeOH}: \mathrm{H}_{2} \mathrm{O}$ to provide the corresponding sulfonamides as solids.

\section{N-(4-fluorophenyl)-4-(2-cyclopropyl-5-oxazolyl)-benzenesulfonamide (12):}<smiles>O=S(=O)(Cl)c1ccc(-c2cnc(C3CC3)o2)cc1</smiles>

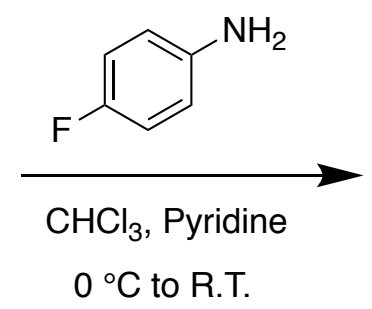<smiles>O=S(=O)(Nc1ccc(F)cc1)c1ccc(-c2cnc(C3CC3)o2)cc1</smiles>

White solid, prepared in $73 \%$ yield $(1.93 \mathrm{mmol}, 0.690 \mathrm{~g})$ from the reaction of 4-fluoroaniline $(2.64 \mathrm{mmol}, 0.25 \mathrm{~mL})$ with $11(2.64 \mathrm{mmol}, 0.750 \mathrm{~g})$ via general procedure $\mathrm{A}$, crude product was purified by column chromatography $\left(\mathrm{SiO}_{2}\right.$, gradient, $1 \%$ to $\left.5 \% \mathrm{DCM}: \mathrm{MeOH}\right) \cdot \mathrm{R}_{\mathrm{f}}=0.35(5 \%$ DCM:MeOH); M.P. $=143-145^{\circ} \mathrm{C} ;{ }^{1} \mathrm{H}$ NMR $\left(400 \mathrm{MHz}, \mathrm{CDCl}_{3}\right) \delta 7.73(\mathrm{dd}, J=6.9,1.8 \mathrm{~Hz}, 2 \mathrm{H}), 7.61$ (dd, $J=6.9,1.8 \mathrm{~Hz}, 2 \mathrm{H}), 7.30(\mathrm{~s}, 1 \mathrm{H}), 7.09-7.03(\mathrm{~m}, 3 \mathrm{H}), 6.97-6.91(\mathrm{~m}, 2 \mathrm{H}), 2.16-2.09(\mathrm{~m}, 1 \mathrm{H})$, and 1.15-1.09 (m, 4H); ${ }^{13} \mathrm{C}$ NMR (101 MHz, $\left.\mathrm{CDCl}_{3}\right) \delta 167.4,161.0$ (d, $\left.J=246.8 \mathrm{~Hz}\right), 148.5,137.4$, 132.6, 132.1, 128.1, $125.1(\mathrm{~d}, J=8.8 \mathrm{~Hz}), 124.8,124.0,116.4(\mathrm{~d}, J=23.2 \mathrm{~Hz}), 9.2$, and 8.9; IR (neat) $3063,2856,1611,1591,1567,1555,1505,1417,1403,1336,1297,1212,1153,1092$, $1064,1050,1014,982,946,933,884,828,752,719,704,659,637,603,581,566,532$, and 526 $\mathrm{cm}^{-1}$; HRMS calculated for $\mathrm{C}_{18} \mathrm{H}_{13} \mathrm{~N}_{2} \mathrm{O}_{3} \mathrm{SF}[\mathrm{M}-\mathrm{H}]^{-}$357.0709; found 357.0692; Purity: 90\%. 


\section{4-[[4-(2-cyclopropyl-5-oxazoyl)phenyl]sulfonyl]-morpholine (13):}<smiles>O=S(=O)(Cl)c1ccc(-c2cnc(C3CC3)o2)cc1</smiles>

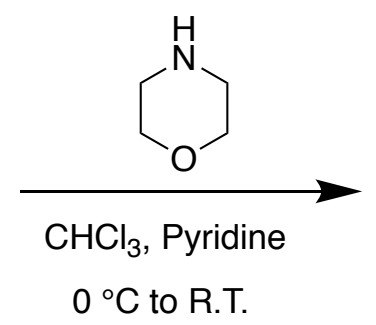<smiles>O=S(=O)(c1ccc(-c2cnc(C3CC3)o2)cc1)N1CCOCC1</smiles>

White solid, prepared in $79 \%$ yield $(1.41 \mathrm{mmol}, 0.47 \mathrm{~g})$ from the reaction of morpholine $(1.76 \mathrm{mmol}, 0.16 \mathrm{~mL})$ with $11(1.76 \mathrm{mmol}, 0.500 \mathrm{~g})$ via general procedure $\mathrm{A}$, crude product was purified by column chromatography $\left(\mathrm{SiO}_{2}\right.$, gradient, $1 \%$ to $\left.5 \% \mathrm{DCM}: \mathrm{MeOH}\right) \cdot \mathrm{R}_{\mathrm{f}}=0.54(5 \%$ DCM:MeOH); M.P. $=181-183{ }^{\circ} \mathrm{C} ;{ }^{1} \mathrm{H}$ NMR $\left(400 \mathrm{MHz}, \mathrm{CDCl}_{3}\right) \delta$ 7.77-7.70 (m, 4H), 7.33 (s, 1H), $3.73(\mathrm{t}, J=4.7 \mathrm{~Hz}, 4 \mathrm{H}), 3.00(\mathrm{t}, J=4.7 \mathrm{~Hz}, 4 \mathrm{H}), 2.17-2.11(\mathrm{~m}, 1 \mathrm{H})$, and 1.16-1.10 $(\mathrm{m}, 4 \mathrm{H}) ;{ }^{13} \mathrm{C} \mathrm{NMR}$ $\left(101 \mathrm{MHz}, \mathrm{CDCl}_{3}\right) \delta 167.4,148.6,133.8,132.6,128.6,124.1,124.0,66.1,46.1,9.2$, and 8.9; IR (neat) 2971, 2916, 2852, 1603, 1566, 1549, 1451, 1413, 1393, 1364, 1347, 1332, 1310, 1299, $1264,1218,1195,1161,1112,1095,1066,1049,1030,1012,966,939,926,889,873,844,823$, $755,735,723,714,655,612,597,569$, and $541 \mathrm{~cm}^{-1} ; \mathrm{HRMS}$ calculated for $\mathrm{C}_{16} \mathrm{H}_{19} \mathrm{~N}_{2} \mathrm{O}_{4} \mathrm{~S}[\mathrm{M}+\mathrm{H}]^{+}$ 335.1065; found 335.1066; Purity: 92\%.

\section{N-(4-chlorophenyl)-4-(2-cyclopropyl-5-oxazolyl)-benzenesulfonamide (14):}<smiles>O=S(=O)(Cl)c1ccc(-c2cnc(C3CC3)o2)cc1</smiles><smiles>Nc1ccc(Cl)cc1</smiles><smiles>O=[R6]S(=O)(=O)c1ccc(-c2cnc(C3CC3)o2)cc1</smiles>

White solid, prepared in $72 \%$ yield $(1.91 \mathrm{mmol}, 0.715 \mathrm{~g})$ from the reaction of 4-chloroaniline $(2.64 \mathrm{mmol}, 0.34 \mathrm{~g})$ with $11(2.64 \mathrm{mmol}, 0.750 \mathrm{~g})$ via general procedure $\mathrm{A}$, crude product was purified by column chromatography $\left(\mathrm{SiO}_{2}\right.$, gradient, $1 \%$ to $\left.5 \% \mathrm{DCM}: \mathrm{MeOH}\right) . \mathrm{Rf}_{\mathrm{f}}=0.37(5 \%$ DCM:MeOH); M.P. $=136-137{ }^{\circ} \mathrm{C} ;{ }^{1} \mathrm{H}$ NMR $\left(400 \mathrm{MHz}, \mathrm{CDCl}_{3}\right) \delta 7.92(\mathrm{~s}, 1 \mathrm{H}), 7.77(\mathrm{~d}, J=7.8 \mathrm{~Hz}$, 
2H), 7.60 (d, J = 7.8 Hz, 2H), $7.29(\mathrm{~s}, 1 \mathrm{H}), 7.18(\mathrm{~d}, J=7.8 \mathrm{~Hz}, 2 \mathrm{H}), 7.06$ (d, J = 7.5 Hz, 2H), 2.26$1.95(\mathrm{~m}, 1 \mathrm{H})$, and 1.12-1.09 (m, 4H); ${ }^{13} \mathrm{C}$ NMR (101 MHz, $\left.\mathrm{CDCl}_{3}\right) \delta$ 167.4, 148.5, 137.4, 135.1, $132.5,131.2,129.7,128.0,124.6,124.0,123.2,9.2$, and 9.0; IR (neat) 3019, 2773, 1556, 1488, $1337,1305,1228,1179,1153,1090,1050,1013,946,933,888,828,743,733,721,633,602$, 568, 549, and $532 \mathrm{~cm}^{-1}$; HRMS calculated for $\mathrm{C}_{18} \mathrm{H}_{14} \mathrm{~N}_{2} \mathrm{O}_{3} \mathrm{SCl}[\mathrm{M}-\mathrm{H}]^{-} 373.0414$; found 373.0417; Purity: $91 \%$.

\section{N-(2,2-difluoroethyl)-4-(2-cyclopropyl-5-oxazolyl)-benzenesulfonamide (15):}
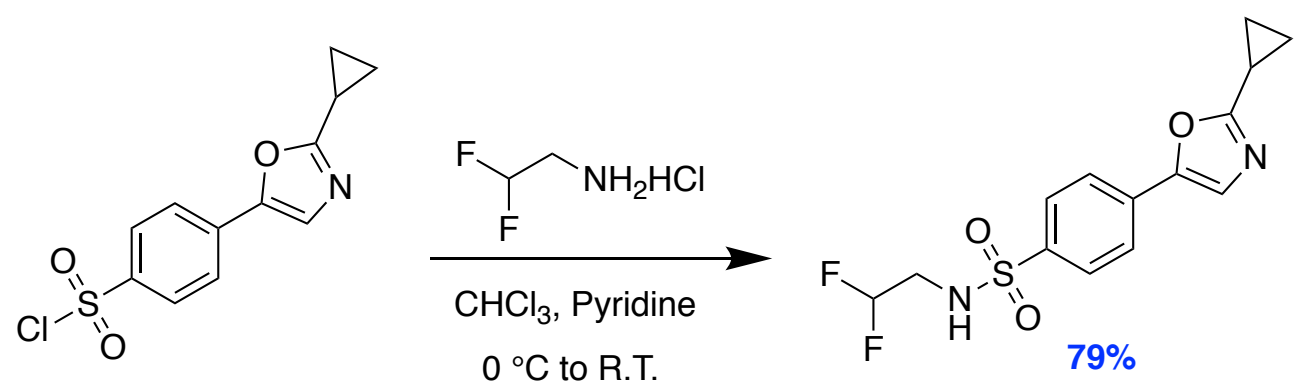

Light yellow needles, prepared in $79 \%$ yield $(1.37 \mathrm{mmol}, 0.45 \mathrm{~g})$ from the reaction of 2,2difluoroethan-1-amine hydrochloride $(1.76 \mathrm{mmol}, 0.21 \mathrm{~g})$ with $11(1.76 \mathrm{mmol}, 0.500 \mathrm{~g})$ via general procedure $\mathrm{A}$, crude product was purified by column chromatography $\left(\mathrm{SiO}_{2}\right.$, gradient, $1 \%$ to $5 \%$ DCM:MeOH). $R_{f}=0.4\left(5 \%\right.$ DCM:MeOH); M.P. $=138-139{ }^{\circ} \mathrm{C} ;{ }^{1} \mathrm{H}$ NMR $(400 \mathrm{MHz}$, DMSO-d $) \delta 8.31$ (q, $J=6.3 \mathrm{~Hz}, 1 \mathrm{H}), 7.89-7.83(\mathrm{~m}, 4 \mathrm{H}), 7.71(\mathrm{~s}, 1 \mathrm{H}), 5.99$ (tt, $J=55.3,3.5 \mathrm{~Hz}, 1 \mathrm{H}), 3.23$ (tdd, $J=$ 15.7, 6.3, 3.7 Hz, 2H), 2.24-2.14 (m, 1H), and 1.12-1.02 (m, 4H); ${ }^{13} \mathrm{C}$ NMR (101 MHz, DMSO-d 6 ) $\delta$ 166.4, 148.3, 139.2, 131.3, 127.4, 125.2, 124.0, 114.5 (t, $J=241.9 \mathrm{~Hz}), 44.3$ (t, $J=26.3 \mathrm{~Hz}), 8.7$, and 8.4 ; IR (neat) $3079,2883,1614,1593,1577,1560,1488,1410,1390,1359,1330,1158,1133$, 1084, 1059, 979, 941, 913, 894, 880, 828, 815, 769, 748, 721, 700, 649, 600, 557, and $526 \mathrm{~cm}^{-1}$; HRMS calculated for $\mathrm{C}_{14} \mathrm{H}_{13} \mathrm{~N}_{2} \mathrm{O}_{3} \mathrm{SF}_{2}[\mathrm{M}-\mathrm{H}]-327.0615$; found 327.0615; Purity: 90\%. 


\section{$N$-[4-chloro-3-trifluoromethyl)phenyl]-4-(2-cyclopropyl-5-oxazoyl)-benzenesulfonamide}

(16):<smiles>O=S(=O)(Cl)c1ccc(-c2cnc(C3CC3)o2)cc1</smiles><smiles>Nc1ccc(Cl)c(C(F)(F)F)c1</smiles>

$0{ }^{\circ} \mathrm{C}$ to R.T.<smiles>O=S(=O)(Nc1ccc(Cl)c(C(F)(F)F)c1)c1ccc(-c2cnc(C3CC3)o2)cc1</smiles>

White crystals, prepared in $73 \%$ yield $(1.29 \mathrm{mmol}, 0.57 \mathrm{~g})$ from the reaction of 4-chloro-3(trifluoromethyl)aniline $(1.76 \mathrm{mmol}, 0.344 \mathrm{~g})$ with $11(1.76 \mathrm{mmol}, 0.500 \mathrm{~g})$ via general procedure $\mathrm{A}$, crude product was purified by column chromatography $\left(\mathrm{SiO}_{2}\right.$, gradient, $1 \%$ to $\left.5 \% \mathrm{DCM}: \mathrm{MeOH}\right)$. $\mathrm{R}_{\mathrm{f}}$ $=0.3\left(5 \%\right.$ DCM:MeOH); M.P. $=176-177{ }^{\circ} \mathrm{C} ;{ }^{1} \mathrm{H}$ NMR $\left(400 \mathrm{MHz}, \mathrm{DMSO}-d_{6}\right) \delta 10.91(\mathrm{~s}, 1 \mathrm{H}), 7.85-$ $7.79(\mathrm{~m}, 4 \mathrm{H}), 7.66(\mathrm{~s}, 1 \mathrm{H}), 7.58(\mathrm{~d}, J=8.9 \mathrm{~Hz}, 1 \mathrm{H}), 7.51$ (d, $J=2.5 \mathrm{~Hz}, 1 \mathrm{H}), 7.39$ (dd, $J=8.9,2.5$ $\mathrm{Hz}, 1 \mathrm{H}), 2.17-2.11(\mathrm{~m}, 1 \mathrm{H})$, and 1.09-0.98 $(\mathrm{m}, 4 \mathrm{H}) ;{ }^{13} \mathrm{C}$ NMR $(101 \mathrm{MHz}$, DMSO-d 6$) \delta$ 166.6, 148.0, $137.4(\mathrm{~d}, J=7.1 \mathrm{~Hz}), 132.8,132.0,127.6,127.3(\mathrm{~d}, J=31.9 \mathrm{~Hz}), 125.7,125.4,124.5,124.1,122.4$ (d, $J=274.9 \mathrm{~Hz}$ ), 118.3 (q, $J=5.8 \mathrm{~Hz}$ ), 8.7, and 8.5; IR (neat) 3064, 2870, 1609, 1589, 1567, 1555, $1495,1477,1460,1408,1350,1327,1306,1279,1257,1232,1179,1161,1136,1112,1090$, 1051, 1030, 1012, 984, 948, 936, 892, 873, 819, 749, 736, 718, 690, 659, 602, 567, and $534 \mathrm{~cm}^{-1}$; HRMS calculated for $\mathrm{C}_{19} \mathrm{H}_{13} \mathrm{~N}_{2} \mathrm{O}_{3} \mathrm{SCIF}_{3}[\mathrm{M}-\mathrm{H}]^{-}$441.0287; found 441.0301; Purity: 96\%.

\section{N-(2-naphthyl)-4-(2-cyclopropyl-5-oxazolyl)-benzenesulfonamide (17):}<smiles>O=S(=O)(Cl)c1ccc(-c2cnc(C3CC3)o2)cc1</smiles><smiles>Nc1ccc2ccccc2c1</smiles>

$0{ }^{\circ} \mathrm{C}$ to R.T.

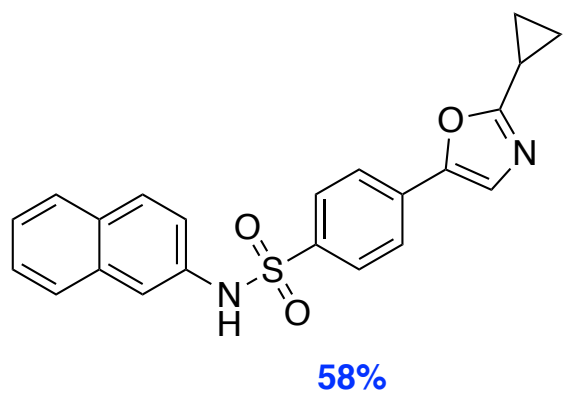

Pink solid, prepared in $58 \%$ yield $(1.54 \mathrm{mmol}, 0.60 \mathrm{~g})$ from the reaction of 2-naphthylamine $(2.64 \mathrm{mmol}, 0.378 \mathrm{~g})$ with $11(2.64 \mathrm{mmol}, 0.750 \mathrm{~g})$ via general procedure $\mathrm{A}$, crude product was 
purified by recrystallization from $\mathrm{MeOH}: \mathrm{H}_{2} \mathrm{O} . \mathrm{M} . \mathrm{P} .=192-193{ }^{\circ} \mathrm{C} ;{ }^{1} \mathrm{H}$ NMR $\left(400 \mathrm{MHz}, \mathrm{DMSO}-d_{6}\right) \delta$ $10.56(\mathrm{~s}, 1 \mathrm{H}), 7.84$ (d, J = 8.5 Hz, 2H), 7.80-7.74 (m, 5H), 7.61 (s, 1H), 7.58 (d, J = 1.6 Hz, 1H), 7.45-7.36 (m, 2H), $7.29(\mathrm{dd}, J=8.7,1.8 \mathrm{~Hz}, 1 \mathrm{H}), 2.17-2.08(\mathrm{~m}, 1 \mathrm{H})$, and 1.07-0.96 (m, 4H); ${ }^{13} \mathrm{C}$ NMR (101 MHz, DMSO- $\left.d_{6}\right) \delta$ 166.3, 148.0, 138.0, 135.2, 133.2, 131.5, 130.1, 129.1, 127.7, 127.5, 127.2, 126.7, 125.4, 125.2, 123.9, 120.5, 116.3, 8.6, and 8.4; IR (neat) 3004, 1609, 1589, 1570, $1553,1508,1455,1415,1351,1326,1244,1209,1159,1136,1110,1092,1060,1014,960,947$, $914,896,863,842,828,788,748,734,711,651,629,604,572,549$, and $533 \mathrm{~cm}^{-1}$; HRMS calculated for $\mathrm{C}_{22} \mathrm{H}_{17} \mathrm{~N}_{2} \mathrm{O}_{3} \mathrm{~S}$ [M-H]-389.0954; found 389.0960; Purity: 91\%.

\section{N-(4-bromophenyl)-4-(2-cyclopropyl-5-oxazolyl)-benzenesulfonamide (18):}<smiles>O=S(=O)(Cl)c1ccc(-c2cnc(C3CC3)o2)cc1</smiles>

$\mathrm{O}$

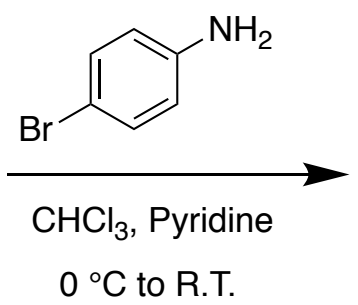

$0{ }^{\circ} \mathrm{C}$ to R.T.<smiles>O=S(=O)(Nc1ccc(Br)cc1)c1ccc(-c2cnc(C3CC3)o2)cc1</smiles>

$69 \%$

Light yellow solid, prepared in $69 \%$ yield $(1.81 \mathrm{mmol}, 0.76 \mathrm{~g})$ from the reaction of 4-bromoaniline (2.64 mmol, $0.454 \mathrm{~g})$ with $11(2.64 \mathrm{mmol}, 0.750 \mathrm{~g})$ via general procedure $\mathrm{A}$, crude product was purified by column chromatography $\left(\mathrm{SiO}_{2}\right.$, gradient, $1 \%$ to $\left.5 \% \mathrm{DCM}: \mathrm{MeOH}\right)$. $\mathrm{R}_{\mathrm{f}}=0.4$ (5\% DCM:MeOH); M.P. = 62-63 ${ }^{\circ} \mathrm{C} ;{ }^{1} \mathrm{H}$ NMR $\left(400 \mathrm{MHz}, \mathrm{CDCl}_{3}\right) \delta 7.78(\mathrm{dd}, J=6.9,1.8 \mathrm{~Hz}, 2 \mathrm{H})$, $7.61(\mathrm{~m}, 3 \mathrm{H}), 7.34(\mathrm{dd}, J=6.7,1.9 \mathrm{~Hz}, 2 \mathrm{H}), 7.29(\mathrm{~s}, 1 \mathrm{H}), 7.01-6.98(\mathrm{~m}, 2 \mathrm{H}), 2.16-2.09(\mathrm{~m}, 1 \mathrm{H})$, and 1.16-1.08 (m, 4H); ${ }^{13} \mathrm{C}$ NMR (101 MHz, $\left.\mathrm{CDCl}_{3}\right) \delta$ 167.4, 148.5, 137.3, 135.6, 132.6, 132.6, 128.0, 124.8, 124.1, 123.5, 119.0, 9.2, and 9.0; IR (neat) 3090, 1607, 1588, 1568, 1555, 1487, 1410, $1389,1327,1293,1225,1157,1092,1061,1010,921,822,745,721,707,657,630,599$, and 562 $\mathrm{cm}^{-1}$; HRMS calculated for $\mathrm{C}_{18} \mathrm{H}_{14} \mathrm{~N}_{2} \mathrm{O}_{3} \mathrm{SBr}$ [M-H] 416.9909 ; found 416.9910; Purity: $90 \%$. 


\section{$N$-[2-(methylsulfonyl)ethyl]-4-(2-cyclopropyl-5-oxazolyl)-benzenesulfonamide (19):}<smiles>O=S(=O)(Cl)c1ccc(-c2cnc(C3CC3)o2)cc1</smiles><smiles>CS(=O)(=O)CCN</smiles><smiles>CS(=O)(=O)CCNS(=O)(=O)c1ccc(-c2cnc(C3CC3)o2)cc1</smiles>

Off-white solid, prepared in $65 \%$ yield $(1.28 \mathrm{mmol}, 0.476 \mathrm{~g})$ from the reaction of 2 (methylamino)-1-(methylsulfonyl)ethane $(1.76 \mathrm{mmol}, 0.217 \mathrm{~g})$ with $11(1.76 \mathrm{mmol}, 0.500 \mathrm{~g})$ via general procedure $\mathrm{A}$, crude product was purified by column chromatography $\left(\mathrm{SiO}_{2}\right.$, gradient, $1 \%$ to $5 \%$ DCM:MeOH). $R_{f}=0.35\left(5 \%\right.$ DCM:MeOH); M.P. $=173{ }^{\circ} \mathrm{C}(\mathrm{dec}.) ;{ }^{1} \mathrm{H} \mathrm{NMR}\left(400 \mathrm{MHz}, \mathrm{CDCl}_{3}\right)$ ס 8.03-7.85 (m, 4H), $7.72(\mathrm{~s}, 1 \mathrm{H}), 3.26(\mathrm{t}, J=6.9 \mathrm{~Hz}, 2 \mathrm{H}), 3.15$ (dd, $J=13.4,5.8 \mathrm{~Hz}, 2 \mathrm{H}), 3.01$ (s, $3 \mathrm{H}), 2.24-2.14(\mathrm{~m}, 1 \mathrm{H})$, and 1.12-1.02 $(\mathrm{m}, 4 \mathrm{H})(\mathrm{NH}$ proton absent due to exchange with solvent); ${ }^{13} \mathrm{C}$ NMR $\left(101 \mathrm{MHz}, \mathrm{CDCl}_{3}\right) \delta 166.4,148.2,138.8,138.4,131.2,127.6,125.3,124.1,53.4,40.6$, 36.6, 8.7, and 8.5; IR (neat) 3071, 2862, 1612, 1577, 1558, 1409, 1335, 1313, 1296, 1249, 1186, 1152, 1133, 1111, 1085, 1060, 1025, 986, 976, 966, 944, 888, 841, 821, 769, 746, 731, 721, 675, 648, 601, 559, and $536 \mathrm{~cm}^{-1}$; HRMS calculated for $\left.\mathrm{C}_{15} \mathrm{H}_{17} \mathrm{~N}_{2} \mathrm{O}_{5} \mathrm{~S}_{2}[\mathrm{M}-\mathrm{H}]\right]^{-369.0579}$; found 369.0579; Purity: $90 \%$.

\section{$N$-(4-methylphenyl)-4-(2-cyclopropyl-5-oxazolyl)-benzenesulfonamide (20):}<smiles>O=S(=O)(Cl)c1ccc(-c2cnc(C3CC3)o2)cc1</smiles>

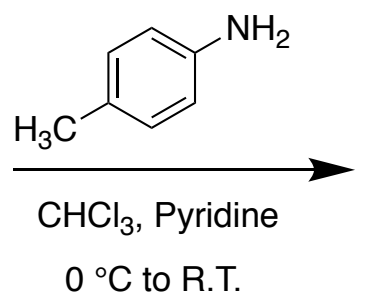

$0{ }^{\circ} \mathrm{C}$ to R.T.<smiles>Cc1ccc(NS(=O)(=O)c2ccc(-c3cnc(C4CC4)o3)cc2)cc1</smiles>

Off-white solid, prepared in $86 \%$ yield $(2.26 \mathrm{mmol}, 0.80 \mathrm{~g})$ from the reaction of p-toluidine $(2.64 \mathrm{mmol}, 0.283 \mathrm{~g})$ with $11(2.64 \mathrm{mmol}, 0.750 \mathrm{~g})$ via general procedure $\mathrm{A}$, crude product was purified by column chromatography $\left(\mathrm{SiO}_{2}\right.$, gradient, $33 \%$ to $50 \%$ Hex:EtOAc). $\mathrm{R}_{\mathrm{f}}=0.3(50 \%$ 
Hex:EtOAc); M.P. $=150{ }^{\circ} \mathrm{C} ;{ }^{1} \mathrm{H}$ NMR $\left(400 \mathrm{MHz}, \mathrm{CDCl}_{3}\right) \delta 7.76(\mathrm{~d}, J=8.5 \mathrm{~Hz}, 2 \mathrm{H}), 7.58(\mathrm{~d}, J=8.5$ $\mathrm{Hz}, 2 \mathrm{H}), 7.33$ (s, 1H), 7.28 (s, 1H), 7.03 (d, J = 8.5 Hz, 2H), 6.98 (d, J = 8.5 Hz, 2H), $2.26(\mathrm{~s}, 3 \mathrm{H})$, 2.09-2.16 $(\mathrm{m}, 1 \mathrm{H})$, and 1.09-1.14 (m, 4H); ${ }^{13} \mathrm{C}$ NMR $\left(101 \mathrm{MHz}, \mathrm{CDCl}_{3}\right) \delta$ 167.27, 148.68, 137.85, $135.74,133.64,132.21,130.06,130.02,128.07,123.90,122.63,20.97,9.21$, and 8.92; IR (neat) $3020,1611,1573,1561,1507,1413,1396,1341,1303,1219,1191,1161,1127,1109,1095$, $1061,1041,1018,981,945,891,843,818,785,753,734,720,701,654,643,629,603,580$, and $533 \mathrm{~cm}^{-1}$; HRMS calculated for $\mathrm{C}_{19} \mathrm{H}_{17} \mathrm{~N}_{2} \mathrm{O}_{3} \mathrm{~S}$ [M-H]- 353.0960; found 353.0974; Purity: 98\%.

\section{N-(4-methoxyphenyl)-4-(2-cyclopropyl-5-oxazolyl)-benzenesulfonamide (21):}

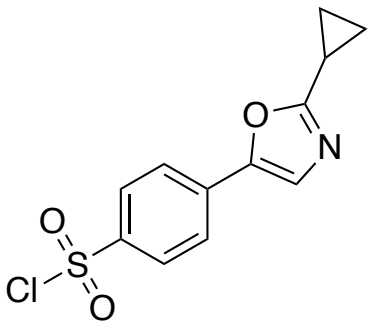

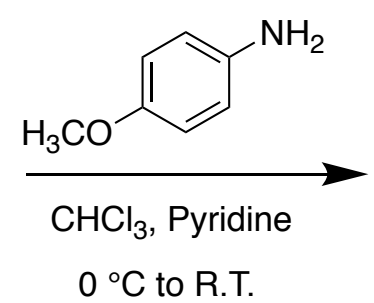

$0{ }^{\circ} \mathrm{C}$ to R.T.<smiles>COc1ccc(NS(=O)(=O)c2ccc(-c3cnc(C4CC4)o3)cc2)cc1</smiles>

$90 \%$

Off-white crystals, prepared in $90 \%$ yield $(2.38 \mathrm{mmol}, 0.88 \mathrm{~g})$ from the reaction of $4-$ methoxyaniline $(2.64 \mathrm{mmol}, 0.325 \mathrm{~g})$ with $11(2.64 \mathrm{mmol}, 0.750 \mathrm{~g})$ via general procedure $\mathrm{A}$, crude product was purified by column chromatography $\left(\mathrm{SiO}_{2}\right.$, gradient, $25 \%$ to $50 \%$ Hex:EtOAc). $\mathrm{R}_{\mathrm{f}}=0.3$ (50\% Hex:EtOAc); M.P. $=139{ }^{\circ} \mathrm{C} ;{ }^{1} \mathrm{H}$ NMR $\left(400 \mathrm{MHz}, \mathrm{CDCl}_{3}\right) \delta 7.71(\mathrm{dd}, J=6.9,1.8 \mathrm{~Hz}, 2 \mathrm{H}), 7.58$ (dd, $J=6.7,1.9 \mathrm{~Hz}, 2 \mathrm{H}), 7.28(\mathrm{~s}, 1 \mathrm{H}), 7.17(\mathrm{~s}, 1 \mathrm{H}), 7.00$ (dd, $J=6.7,2.2 \mathrm{~Hz}, 2 \mathrm{H}), 6.75$ (dd, $J=6.7$, 2.2 Hz, 2H), $3.74(\mathrm{~s}, 3 \mathrm{H}), 2.15-2.09(\mathrm{~m}, 1 \mathrm{H})$, and 1.15-1.07 (m, 4H); ${ }^{13} \mathrm{C} \mathrm{NMR}\left(101 \mathrm{MHz}, \mathrm{CDCl}_{3}\right) \delta$ $167.2,158.1,148.7,137.7,132.2,128.7,128.1,125.7,124.6,123.9,114.6,55.5,9.2$, and 8.9 ; IR (neat) $2837,1608,1589,1568,1556,1507,1463,1409,1328,1300,1247,1220,1155,1092$, $1060,1030,967,943,827,746,721,638,599$, and $543 \mathrm{~cm}^{-1}$; HRMS calculated for $\mathrm{C}_{19} \mathrm{H}_{17} \mathrm{~N}_{2} \mathrm{O}_{4} \mathrm{~S}$ [M-H] 369.0909; found 369.0916; Purity: 98\%. 


\section{$N$-(3,4-dichlorophenyl)-4-(2-cyclopropyl-5-oxazolyl)-benzenesulfonamide (22):}<smiles>O=S(=O)(Cl)c1ccc(-c2cnc(C3CC3)o2)cc1</smiles><smiles>Nc1ccc(Cl)c(Cl)c1</smiles><smiles>O=S(=O)(Nc1ccc(Cl)c(Cl)c1)c1ccc(-c2cnc(C3CC3)o2)cc1</smiles>

Light pink solid, prepared in $70 \%$ yield $(1.86 \mathrm{mmol}, 0.76 \mathrm{~g})$ from the reaction of $3,4-$ dichloroaniline $(2.64 \mathrm{mmol}, 0.428 \mathrm{~g})$ with $11(2.64 \mathrm{mmol}, 0.750 \mathrm{~g})$ via general procedure $\mathrm{A}$, crude product was purified by column chromatography $\left(\mathrm{SiO}_{2}\right.$, gradient, $1 \%$ to $\left.5 \% \mathrm{DCM}: \mathrm{MeOH}\right) . \mathrm{R}_{\mathrm{f}}=0.55$ (5\% DCM:MeOH); M.P. = $198{ }^{\circ} \mathrm{C} ;{ }^{1} \mathrm{H}$ NMR $(400 \mathrm{MHz}$, DMSO-d 6 ) $\delta 10.74$ (s, $1 \mathrm{H}), 7.81$ (d, $J=1.6$ $\mathrm{Hz}, 4 \mathrm{H}), 7.67$ (d, J = 1.6 Hz, 1H), 7.50 (dd, J = 8.8, $1.5 \mathrm{~Hz}, 1 \mathrm{H}), 7.28$ (d, J = 1.8 Hz, 1H), 7.09 (dd, $J=8.7,1.6 \mathrm{~Hz}, 1 \mathrm{H}), 2.19-2.12(\mathrm{~m}, 1 \mathrm{H})$, and 1.10-0.99 (m, 4H); ${ }^{13} \mathrm{C}$ NMR $(101 \mathrm{MHz}$, DMSO-d 6 ) $\delta$ $166.5,148.0,137.9,137.4,131.9,131.5,131.3,127.6,126.2,125.6,124.1,121.1,119.8,8.7$, and 8.5; IR (neat) 2985, 2761, 1610, 1590, 1570, 1463, 1413, 1379, 1336, 1189, 1166, 1123, 1093, $1062,1044,1029,982,944,916,876,831,770,742,733,722,684,629,610,589,556$, and 541 $\mathrm{cm}^{-1}$; HRMS calculated for $\mathrm{C}_{18} \mathrm{H}_{13} \mathrm{~N}_{2} \mathrm{O}_{3} \mathrm{SCl}_{2}[\mathrm{M}-\mathrm{H}]^{-}$407.0024; found 407.0024; Purity: 97\%.

\section{$N$-(4-cyanophenyl)-4-(2-cyclopropyl-5-oxazolyl)-benzenesulfonamide (23):}<smiles>O=S(=O)(Cl)c1ccc(-c2cnc(C3CC3)o2)cc1</smiles><smiles>N#Cc1ccc(N)cc1</smiles><smiles>N#Cc1ccc(NS(=O)(=O)c2ccc(-c3cnc(C4CC4)o3)cc2)cc1</smiles>

Off-white crystals, prepared in $66 \%$ yield $(1.74 \mathrm{mmol}, 0.63 \mathrm{~g})$ from the reaction of 4 aminobenzonitrile $(2.64 \mathrm{mmol}, 0.312 \mathrm{~g})$ with $11(2.64 \mathrm{mmol}, 0.750 \mathrm{~g})$ via general procedure A, crude product was purified by column chromatography $\left(\mathrm{SiO}_{2}\right.$, gradient, $25 \%$ to $50 \%$ Hex:EtOAc). 
$R_{f}=0.2\left(50 \%\right.$ Hex:EtOAc); M.P. $=182{ }^{\circ} \mathrm{C} ;{ }^{1} \mathrm{H}$ NMR $\left(400 \mathrm{MHz}, \mathrm{DMSO}-\mathrm{d}_{6}\right) \delta 11.08(\mathrm{~s}, 1 \mathrm{H}), 7.87(\mathrm{~d}$, $J=8.7 \mathrm{~Hz}, 2 \mathrm{H}), 7.81(\mathrm{~d}, J=8.7 \mathrm{~Hz}, 2 \mathrm{H}), 7.70(\mathrm{~d}, J=8.7 \mathrm{~Hz}, 2 \mathrm{H}), 7.67(\mathrm{~s}, 1 \mathrm{H}), 7.26(\mathrm{dd}, J=6.9$, $1.8 \mathrm{~Hz}, 2 \mathrm{H}), 2.12-2.18(\mathrm{~m}, 1 \mathrm{H})$, and 0.99-1.10 (m, 4H); ${ }^{13} \mathrm{C}$ NMR (101 MHz, DMSO- $\left.d_{6}\right) \delta$ 166.56, 147.96, 142.14, 137.59, 133.76, 131.96, 127.68, 125.68, 124.16, 119.17, 118.71, 105.62, 8.69, and 8.47 IR (neat) 3090, 1607, 1588, 1568, 1555, 1487, 1410, 1389, 1327, 1293, 1225, 1157, 1092, 1061, 1010, 921, 822, 745, 721, 707, 657, 630, 599, and $562 \mathrm{~cm}^{-1}$; HRMS calculated for $\mathrm{C}_{19} \mathrm{H}_{14} \mathrm{~N}_{3} \mathrm{O}_{3} \mathrm{~S}[\mathrm{M}-\mathrm{H}]^{-3}$ 364.0756; found 364.0766; Purity: 96\%.

\section{N-(2,4-dichlorophenyl)-4-(2-cyclopropyl-5-oxazolyl)-benzenesulfonamide (24):}
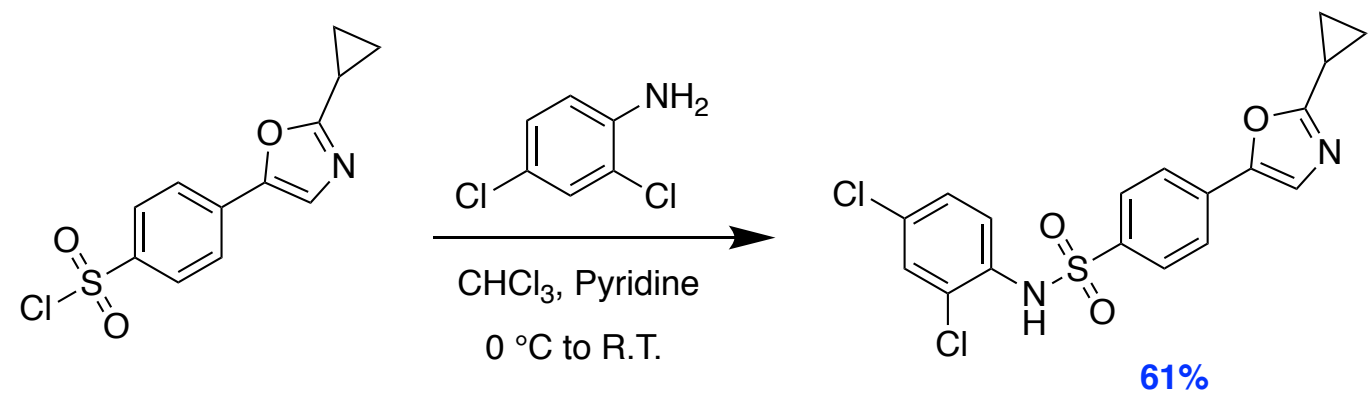

White solid, prepared in $61 \%$ yield $(2.14 \mathrm{mmol}, 0.87 \mathrm{~g})$ from the reaction of $2,4-$ dichloroaniline $(3.52 \mathrm{mmol}, 0.571 \mathrm{~g})$ with $11(3.52 \mathrm{mmol}, 1.00 \mathrm{~g})$ via general procedure $A$, crude product was purified by column chromatography $\left(\mathrm{SiO}_{2}\right.$, gradient, $1 \%$ to $\left.5 \% \mathrm{DCM}: \mathrm{MeOH}\right)$. $\mathrm{R}_{\mathrm{f}}=0.38$ (5\% DCM:MeOH); M.P. = 155-158 ${ }^{\circ} \mathrm{C} ;{ }^{1} \mathrm{H}$ NMR $\left(400 \mathrm{MHz}, \mathrm{CDCl}_{3}\right) \delta 7.74(\mathrm{~d}, \mathrm{~J}=8.7 \mathrm{~Hz}, 2 \mathrm{H}), 7.61$ $(\mathrm{dd}, J=8.6,6.7 \mathrm{~Hz}, 3 \mathrm{H}), 7.30(\mathrm{~s}, 1 \mathrm{H}), 7.25-7.21(\mathrm{~m}, 2 \mathrm{H}), 7.11(\mathrm{~s}, 1 \mathrm{H}), 2.16-2.08(\mathrm{~m}, 1 \mathrm{H})$, and 1.16$1.08(\mathrm{~m}, 4 \mathrm{H}) ;{ }^{13} \mathrm{C}$ NMR $\left(101 \mathrm{MHz}, \mathrm{CDCl}_{3}\right) \delta 167.4,148.4,137.2,132.9,132.0,131.5,129.3,128.3$, 128.0, 126.6, 125.1, 124.4, 124.0, 9.2, and 8.9; IR (neat) 3244, 1609, 1573, 1558, 1471, 1411, 1366, 1336, 1324, 1190, 1171, 1125, 1092, 1060, 1024, 967, 941, 896, 859, 837, 830, 812, 772, $747,733,723,703,672,651,624,599,580$, and $550 \mathrm{~cm}^{-1}$; HRMS calculated for $\mathrm{C}_{18} \mathrm{H}_{13} \mathrm{~N}_{2} \mathrm{O}_{3} \mathrm{SCl}_{2}$ [M-H]- 407.0024; found 407.0033; Purity: 90\%. 
$N$-(4-trifluoromethylphenyl)-4-(2-cyclopropyl-5-oxazolyl)-benzenesulfonamide (25):<smiles>O=S(=O)(Cl)c1ccc(-c2cnc(C3CC3)o2)cc1</smiles>

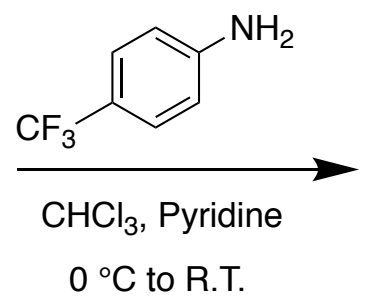<smiles>O=S(=O)(Nc1ccc(C(F)(F)F)cc1)c1ccc(-c2cnc(C3CC3)o2)cc1</smiles>

$77 \%$

Off-white solid, prepared in $77 \%$ yield $(2.04 \mathrm{mmol}, 0.84 \mathrm{~g})$ from the reaction of 4 aminobenzotrifluoride $(2.64 \mathrm{mmol}, 0.33 \mathrm{~mL})$ with $11(2.64 \mathrm{mmol}, 0.750 \mathrm{~g})$ via general procedure $\mathrm{A}$, crude product was purified by column chromatography ( $\mathrm{SiO}_{2}$, gradient, $33 \%$ to $50 \%$ Hex:EtOAc). $R_{f}=0.3\left(50 \%\right.$ Hex:EtOAc); M.P. $=159{ }^{\circ} \mathrm{C} ;{ }^{1} \mathrm{H}$ NMR $\left(400 \mathrm{MHz}, \mathrm{CDCl}_{3}\right) \delta 8.34(\mathrm{~s}, 1 \mathrm{H}), 7.86(\mathrm{~d}, \mathrm{~J}=$ $8.5 \mathrm{~Hz}, 2 \mathrm{H}), 7.63(\mathrm{~d}, J=8.7 \mathrm{~Hz}, 2 \mathrm{H}), 7.47(\mathrm{~d}, J=8.5 \mathrm{~Hz}, 2 \mathrm{H}), 7.31(\mathrm{~s}, 1 \mathrm{H}), 7.24(\mathrm{~d}, J=8.5 \mathrm{~Hz}, 2 \mathrm{H})$, 2.10-2.17 (m, 1H), and 1.08-1.15 (m, 4H); ${ }^{13} \mathrm{C}$ NMR (101 MHz, $\left.\mathrm{CDCl}_{3}\right) \delta 167.55,148.47,140.00$, $137.44,132.75,128.03,126.84,126.72,125.30,124.97,124.65,124.30,124.24,124.14,122.60$, 120.14, 120.07, 119.83, 9.23, and 9.02; IR (neat) 3040, 2863, 1614, 1592, 1573, 1557, 1519, 1490, 1409, 1323, 1294, 1234, 1158, 1115, 1094, 1069, 1015, 984, 945, 918, 892, 845, 834, 781, 750, $729,721,649,634,609,598,561$, and $526 \mathrm{~cm}^{-1}$; HRMS calculated for $\mathrm{C}_{19} \mathrm{H}_{14} \mathrm{~N}_{2} \mathrm{O}_{3} \mathrm{SF}_{3}[\mathrm{M}-\mathrm{H}]^{-}$ 407.0685; found 407.0685; Purity: 97\%.

\section{N-(2-chlorophenyl)-4-(2-cyclopropyl-5-oxazolyl)-benzenesulfonamide (26):}<smiles>O=S(=O)(Cl)c1ccc(-c2cnc(C3CC3)o2)cc1</smiles><smiles>Nc1ccccc1Cl</smiles><smiles></smiles>

White solid, prepared in $84 \%$ yield $(2.16 \mathrm{mmol}, 0.81 \mathrm{~g})$ from the reaction of 2-chloroaniline $(2.58 \mathrm{mmol}, 0.27 \mathrm{~mL})$ with $11(2.58 \mathrm{mmol}, 0.731 \mathrm{~g})$ via general procedure $\mathrm{A}$, crude product was purified by column chromatography $\left(\mathrm{SiO}_{2}\right.$, gradient, $33 \%$ to $50 \%$ Hex:EtOAc). $\mathrm{R}_{\mathrm{f}}=0.2(33 \%$ 
Hex:EtOAc); M.P. $=148{ }^{\circ} \mathrm{C} ;{ }^{1} \mathrm{H} \mathrm{NMR}\left(400 \mathrm{MHz}, \mathrm{CDCl}_{3}\right) \delta 7.75(\mathrm{dd}, \mathrm{J}=6.9,1.8 \mathrm{~Hz}, 2 \mathrm{H}), 7.67$ (dd, $J=8.5,1.6 \mathrm{~Hz}, 1 \mathrm{H}), 7.56-7.59(\mathrm{~m}, 2 \mathrm{H}), 7.28(\mathrm{~s}, 1 \mathrm{H}), 7.23(\mathrm{dd}, J=8.0,1.6 \mathrm{~Hz}, 2 \mathrm{H}), 7.14(\mathrm{~s}, 1 \mathrm{H})$, 7.03-7.07 (m, 1H), 2.08-2.15 (m, 1H), and 1.06-1.15 (m, 4H); ${ }^{13} \mathrm{C} \mathrm{NMR}\left(101 \mathrm{MHz}, \mathrm{CDCl}_{3}\right) \delta$ 167.32, $148.49,137.50,133.22,132.64,129.47,128.04,126.39,125.76,124.87,124.76,123.90,123.29$, 9.18, and 8.90; IR (neat) 3004, 2794, 1610, 1591, 1570, 1557, 1483, 1410, 1342, 1285, 1228, $1164,1128,1094,1063,1034,983,947,922,895,866,846,828,819,758,746,725,679,631$, $618,606,573,556$, and $526 \mathrm{~cm}^{-1}$; HRMS calculated for $\mathrm{C}_{18} \mathrm{H}_{14} \mathrm{~N}_{2} \mathrm{O}_{3} \mathrm{SCl}[\mathrm{M}-\mathrm{H}]^{-} 373.0414$; found 373.0431; Purity: 94\%.

\section{$N$-(3-chloro-4-fluorophenyl)-4-(2-cyclopropyl-5-oxazolyl)-benzenesulfonamide (27):}<smiles>O=S(=O)(Cl)c1ccc(-c2cnc(C3CC3)o2)cc1</smiles><smiles>Nc1ccc(F)c(Cl)c1</smiles><smiles>O=S(=O)(Nc1ccc(F)c(Cl)c1)c1ccc(-c2cnc(C3CC3)o2)cc1</smiles>

White solid, prepared in $61 \%$ yield $(2.13 \mathrm{mmol}, 0.835 \mathrm{~g})$ from the reaction of 3-chloro-4fluoroaniline $(3.52 \mathrm{mmol}, 0.513 \mathrm{~g})$ with $11(3.52 \mathrm{mmol}, 1.00 \mathrm{~g})$ via general procedure $A$, crude product was purified by column chromatography $\left(\mathrm{SiO}_{2}\right.$, gradient, $2 \%$ to $\left.5 \% \mathrm{DCM}: \mathrm{MeOH}\right)$. $\mathrm{R}_{\mathrm{f}}=0.28$ (5\% DCM:MeOH); M.P. = 175-176 ${ }^{\circ} \mathrm{C} ;{ }^{1} \mathrm{H}$ NMR $\left(400 \mathrm{MHz}, \mathrm{CDCl}_{3}\right) \delta 7.82(\mathrm{~s}, 1 \mathrm{H}), 7.78(\mathrm{~d}, J=8.7$ $\mathrm{Hz}, 2 \mathrm{H}), 7.63(\mathrm{~d}, J=8.5 \mathrm{~Hz}, 2 \mathrm{H}), 7.31(\mathrm{~s}, 1 \mathrm{H}), 7.22-7.21(\mathrm{~m}, 1 \mathrm{H}), 7.00-6.97(\mathrm{~m}, 2 \mathrm{H}), 2.16-2.09(\mathrm{~m}$, 1H), and 1.16-1.07 (m, 4H); $\left.{ }^{13} \mathrm{C} \mathrm{NMR} \mathrm{(101} \mathrm{MHz,} \mathrm{CDCl}_{3}\right) \delta 167.5,156.2(\mathrm{~d}, J=249.8 \mathrm{~Hz}), 148.5$, $137.2,133.0(\mathrm{~d}, J=3.9 \mathrm{~Hz}), 132.7,128.0,124.9,124.6,124.1,122.2(\mathrm{~d}, J=7.8 \mathrm{~Hz}), 121.8(\mathrm{~d}, J=$ 18.4 Hz), 117.2 (d, $J=22.2 \mathrm{~Hz}$ ), 9.2, and 9.0; IR (neat) 3010, 2763, 1611, 1591, 1571, 1559, 1488, $1413,1387,1337,1263,1191,1165,1131,1122,1094,1061,1015,981,944,926,878,850,834$, $802,759,734,721,710,688,619,600,577$, and $544 \mathrm{~cm}^{-1} ;$ HRMS calculated for $\mathrm{C}_{18} \mathrm{H}_{13} \mathrm{~N}_{2} \mathrm{O}_{3} \mathrm{SCIF}$ [M-H]- 391.0319; found 391.0320; Purity: 91\%. 
N-(4-chloro-3-fluorophenyl)-4-(2-cyclopropyl-5-oxazolyl)-benzenesulfonamide (28):
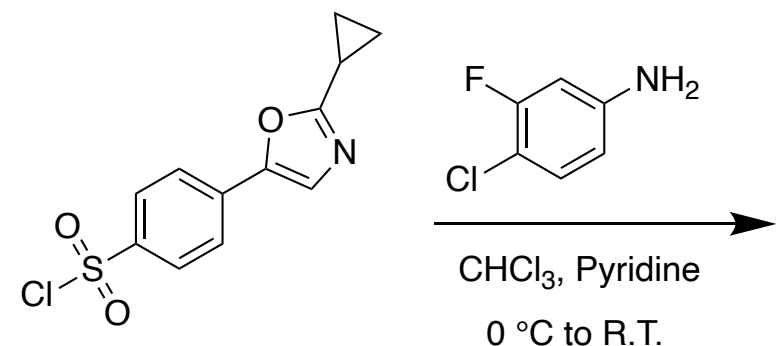<smiles>O=S(=O)(Nc1ccc(Cl)c(F)c1)c1ccc(-c2cnc(C3CC3)o2)cc1</smiles>

$62 \%$

White solid, prepared in $62 \%$ yield $(1.10 \mathrm{mmol}, 0.432 \mathrm{~g})$ from the reaction of 4-chloro-3fluoroaniline $(1.76 \mathrm{mmol}, 0.257 \mathrm{~g})$ with $11(1.76 \mathrm{mmol}, 0.500 \mathrm{~g})$ via general procedure $\mathrm{A}$, crude product was purified by column chromatography $\left(\mathrm{SiO}_{2}\right.$, gradient, $1 \%$ to $\left.5 \% \mathrm{DCM}: \mathrm{MeOH}\right) . \mathrm{R}_{\mathrm{f}}=0.35$ (5\% DCM:MeOH); M.P. = 148-149 ${ }^{\circ} \mathrm{C} ;{ }^{1} \mathrm{H}$ NMR (400 MHz, DMSO-d $)$ $\delta 10.76(\mathrm{~s}, 1 \mathrm{H}), 7.84-7.79$ (m, 4H), $7.67(\mathrm{~s}, 1 \mathrm{H}), 7.45(\mathrm{t}, J=8.6 \mathrm{~Hz}, 1 \mathrm{H}), 7.09(\mathrm{~d}, J=11.0 \mathrm{~Hz}, 1 \mathrm{H}), 6.94(\mathrm{~d}, J=8.7 \mathrm{~Hz}, 1 \mathrm{H})$, 2.19-2.12 $(\mathrm{m}, 1 \mathrm{H})$, and 1.13-0.99 $(\mathrm{m}, 4 \mathrm{H}) ;{ }^{13} \mathrm{C}$ NMR $\left(101 \mathrm{MHz}, \mathrm{DMSO}-\mathrm{d}_{6}\right) \delta 166.5,157.1(\mathrm{~d}, J=$ $247.8 \mathrm{~Hz}$ ), 148.0, 138.3 (d, J = 9.7 Hz), 137.5, 131.8, 131.2, 127.6, 125.6, 124.1, 116.6, 114.4 (d, $J=17.4 \mathrm{~Hz}$ ), 107.9 (d, $J=24.1 \mathrm{~Hz}$ ), 8.7, and 8.4; IR (neat) 3059, 2855, 1610, 1593, 1566, 1554, 1482, 1416, 1336, 1303, 1281, 1246, 1169, 1150, 1092, 1062, 1050, 1033, 1014, 979, 946, 862, $841,827,791,752,719,696,672,657,604,579,553$, and $533 \mathrm{~cm}^{-1}$; HRMS calculated for $\mathrm{C}_{18} \mathrm{H}_{13} \mathrm{~N}_{2} \mathrm{O}_{3} \mathrm{SCIF}[\mathrm{M}-\mathrm{H}]^{-}$391.0319; found 391.0306; Purity: 92\%.

\section{N-(3-chloro-phenyl)-4-(2-cyclopropyl-5-oxazolyl)-benzenesulfonamide (29):}<smiles>O=S(=O)(Cl)c1ccc(-c2cnc(C3CC3)o2)cc1</smiles><smiles>O=S(=O)(Nc1cccc(Cl)c1)c1ccc(-c2cnc(C3CC3)o2)cc1</smiles>

$73 \%$

Off-white solid, prepared in $73 \%$ yield $(1.29 \mathrm{mmol}, 0.482 \mathrm{~g})$ from the reaction of 3chloroaniline $(1.76 \mathrm{mmol}, 0.186 \mathrm{~mL})$ with $11(1.76 \mathrm{mmol}, 0.500 \mathrm{~g})$ via general procedure $\mathrm{A}$, crude product was purified by column chromatography $\left(\mathrm{SiO}_{2}\right.$, gradient, $1 \%$ to $\left.5 \% \mathrm{DCM}: \mathrm{MeOH}\right)$. $\mathrm{R}_{\mathrm{f}}=0.3$ 
(5\% DCM:MeOH); M.P. = 64-65 ${ }^{\circ} \mathrm{C} ;{ }^{1} \mathrm{H}$ NMR $\left(400 \mathrm{MHz}, \mathrm{CDCl}_{3}\right) \delta 7.85(\mathrm{~s}, 1 \mathrm{H}), 7.82(\mathrm{dt}, J=8.7$, $1.8 \mathrm{~Hz}, 2 \mathrm{H}), 7.62(\mathrm{dt}, J=8.6,1.9 \mathrm{~Hz}, 2 \mathrm{H}), 7.30(\mathrm{~s}, 1 \mathrm{H}), 7.17-7.13(\mathrm{~m}, 2 \mathrm{H}), 7.06(\mathrm{dq}, J=8.1,1.0$ $\mathrm{Hz}, 1 \mathrm{H}), 7.01(\mathrm{dq}, J=8.0,1.0 \mathrm{~Hz}, 1 \mathrm{H}), 2.16-2.09(\mathrm{~m}, 1 \mathrm{H})$, and $1.15-1.09(\mathrm{~m}, 4 \mathrm{H}) ;{ }^{13} \mathrm{C}$ NMR $(101$ $\left.\mathrm{MHz}, \mathrm{CDCl}_{3}\right) \delta 167.4,148.5,137.8,137.5,135.1,132.6,130.5,128.0,125.5,124.8,124.1,121.3$ 119.2, 9.2, and 9.0; IR (neat) 3074, 2856, 1593, 1568, 1556, 1474, 1410, 1327, 1222, 1156, 1129, 1092, 1061, 1029, 1015, 997, 941, 829, 779, 745, 721, 678, 599, and $553 \mathrm{~cm}^{-1}$; HRMS calculated for $\mathrm{C}_{18} \mathrm{H}_{14} \mathrm{~N}_{2} \mathrm{O}_{3} \mathrm{SCl}[\mathrm{M}-\mathrm{H}]^{-} 373.0414$; found 373.0438; Purity: $92 \%$.

\section{N-(4-chloro-3-methyl-phenyl)-4-(2-cyclopropyl-5-oxazolyl)-benzenesulfonamide (30):}

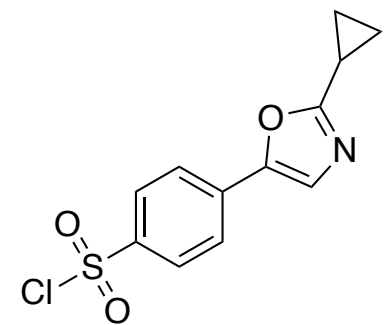

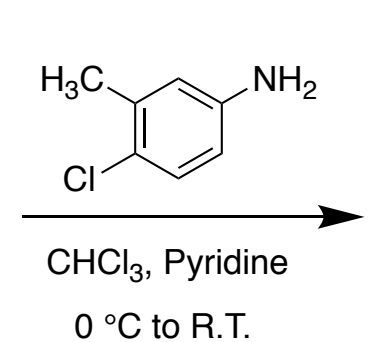

$0{ }^{\circ} \mathrm{C}$ to R.T.<smiles>Cc1cc(NS(=O)(=O)c2ccc(-c3cnc(C4CC4)o3)cc2)ccc1Cl</smiles>

$69 \%$

White solid, prepared in $69 \%$ yield $(1.21 \mathrm{mmol}, 0.472 \mathrm{~g})$ from the reaction of 4-chloro-3methylaniline $(1.76 \mathrm{mmol}, 0.250 \mathrm{~g})$ with $11(1.76 \mathrm{mmol}, 0.500 \mathrm{~g})$ via general procedure $A$, crude product was purified by column chromatography $\left(\mathrm{SiO}_{2}\right.$, gradient, $2 \%$ to $\left.5 \% \mathrm{DCM}: \mathrm{MeOH}\right)$. $\mathrm{R}_{\mathrm{f}}=0.33$ (5\% DCM:MeOH); M.P. = 192-194 ${ }^{\circ} \mathrm{C} ;{ }^{1} \mathrm{H}$ NMR $\left(400 \mathrm{MHz}, \mathrm{DMSO}-d_{6}\right) \delta 10.41(\mathrm{~s}, 1 \mathrm{H}), 7.79(\mathrm{~s}, 4 \mathrm{H})$, 7.66 (s, 1H), 7.26 (d, J = 8.5 Hz, 1H), 7.06 (d, J = 2.3 Hz, 1H), 6.94 (dd, J = 8.6, 2.4 Hz, 1H), 2.20 (s, 3H), 2.18-2.12 (m, 1H), and 1.10-0.99 (m, 4H); ${ }^{13} \mathrm{C}$ NMR (101 MHz, DMSO-d $) \delta$ 166.4, 148.1, $137.9,136.5,136.3,131.6,129.5,128.7,127.6,125.4,124.0,122.6,119.2,40.1,39.9,39.7,39.5$, $39.3,39.1,38.9,19.8,8.7$, and 8.4; IR (neat) $3004,1610,1590,1571,1475,1412,1389,1334$, 1286, 1233, 1189, 1168, 1154, 1131, 1093, 1054, 1015, 1000, 981, 948, 879, 828, 783, 752, 734, $718,708,671,629,608,584,569,562$, and $538 \mathrm{~cm}^{-1}$; HRMS calculated for $\mathrm{C}_{19} \mathrm{H}_{16} \mathrm{~N}_{2} \mathrm{O}_{3} \mathrm{SCl}[\mathrm{M}-\mathrm{H}]^{-}$ 387.0570; found 387.0570; Purity: 93\%. 
N-(2-fluoro-4-iodo-phenyl)-4-(2-cyclopropyl-5-oxazolyl)-benzenesulfonamide (31):<smiles>O=S(=O)(Cl)c1ccc(-c2cnc(C3CC3)o2)cc1</smiles>

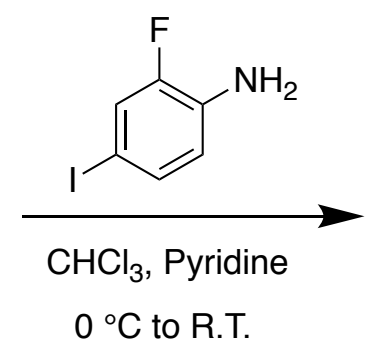<smiles>O=S(=O)(Nc1ccc(I)cc1F)c1ccc(-c2cnc(C3CC3)o2)cc1</smiles>

Off-white solid, prepared in $60 \%$ yield $(1.06 \mathrm{mmol}, 0.512 \mathrm{~g})$ from the reaction of 2-fluoro-4iodoaniline $(1.76 \mathrm{mmol}, 0.418 \mathrm{~g})$ with $11(1.76 \mathrm{mmol}, 0.500 \mathrm{~g})$ via general procedure $\mathrm{A}$, crude product was purified by column chromatography $\left(\mathrm{SiO}_{2}\right.$, gradient, $2 \%$ to $\left.5 \% \mathrm{DCM}: \mathrm{MeOH}\right)$. $\mathrm{R}_{\mathrm{f}}=0.33$ (5\% DCM:MeOH); M.P. = 162-163 ${ }^{\circ} \mathrm{C} ;{ }^{1} \mathrm{H}$ NMR $\left(400 \mathrm{MHz}, \mathrm{CDCl}_{3}\right) \delta 7.77(\mathrm{~d}, J=8.5 \mathrm{~Hz}, 2 \mathrm{H}), 7.62$ $(\mathrm{d}, J=8.5 \mathrm{~Hz}, 2 \mathrm{H}), 7.43(\mathrm{~d}, J=8.2 \mathrm{~Hz}, 1 \mathrm{H}), 7.36(\mathrm{~d}, J=8.2 \mathrm{~Hz}, 1 \mathrm{H}), 7.33-7.29(\mathrm{~m}, 2 \mathrm{H}), 7.07(\mathrm{~d}, J$ $=1.8 \mathrm{~Hz}, 1 \mathrm{H}), 2.17-2.10(\mathrm{~m}, 1 \mathrm{H})$, and 1.16-1.09 $(\mathrm{m}, 4 \mathrm{H}) ;{ }^{13} \mathrm{C} \mathrm{NMR}\left(101 \mathrm{MHz}, \mathrm{CDCl}_{3}\right) \delta 167.4,153.8$ $(\mathrm{d}, J=251.6 \mathrm{~Hz}), 148.4,137.3,134.2,132.8,128.0,125.4,125.2,124.9,124.6(\mathrm{~d}, J=11.6 \mathrm{~Hz})$ 124.1, 88.5, 9.2, and 8.9; IR (neat) 3260, 1604, 1568, 1552, 1489, 1426, 1400, 1346, 1294, 1265, $1243,1187,1160,1113,1091,1062,1048,944,926,910,870,848,832,811,745,733,722,660$, $639,613,576,568,554$, and $534 \mathrm{~cm}^{-1}$; HRMS calculated for $\mathrm{C}_{18} \mathrm{H}_{13} \mathrm{~N}_{2} \mathrm{O}_{3} \mathrm{SFI}[\mathrm{M}-\mathrm{H}]^{-} 482.9676$; found 482.9694; Purity: 90\%.

\section{N-(4-bromo-3-chloro-phenyl)-4-(2-cyclopropyl-5-oxazolyl)-benzenesulfonamide (32):}<smiles>O=S(=O)(Cl)c1ccc(-c2cnc(C3CC3)o2)cc1</smiles><smiles>Nc1ccc(Br)c(Cl)c1</smiles><smiles>O=S(=O)(Nc1ccc(Br)c(Cl)c1)c1ccc(-c2cnc(C3CC3)o2)cc1</smiles>

Off-white solid, prepared in $60 \%$ yield $(1.06 \mathrm{mmol}, 0.482 \mathrm{~g})$ from the reaction of 4-bromo3-chloroaniline $(1.76 \mathrm{mmol}, 0.363 \mathrm{~g})$ with $11(1.76 \mathrm{mmol}, 0.500 \mathrm{~g})$ via general procedure $\mathrm{A}$, crude product was purified by column chromatography $\left(\mathrm{SiO}_{2}\right.$, gradient, $2 \%$ to $\left.5 \% \mathrm{DCM}: \mathrm{MeOH}\right)$. $\mathrm{R}_{\mathrm{f}}=0.4$ 
(5\% DCM:MeOH); M.P. = 202-204 ${ }^{\circ} \mathrm{C} ;{ }^{1} \mathrm{H}$ NMR (400 MHz, DMSO-d $)$ $\delta 10.75(\mathrm{~s}, 1 \mathrm{H}), 7.84-7.78$ (m, 4H), $7.65(\mathrm{~s}, 1 \mathrm{H}), 7.60(\mathrm{~d}, J=8.9 \mathrm{~Hz}, 1 \mathrm{H}), 7.29(\mathrm{~d}, J=2.5 \mathrm{~Hz}, 1 \mathrm{H}), 7.03$ (dd, $J=8.7,2.5 \mathrm{~Hz}$, $1 \mathrm{H}), 2.17-2.10(\mathrm{~m}, 1 \mathrm{H})$, and 1.09-0.98 $(\mathrm{m}, 4 \mathrm{H}) ;{ }^{13} \mathrm{C}$ NMR $\left(101 \mathrm{MHz}\right.$, DMSO-d $\mathrm{d}_{6} \delta$ 166.5, 148.0, $138.4,137.4,134.5,133.5,131.9,127.6,125.5,124.1,120.8,119.9,116.0,8.7$, and 8.5; IR (neat) 2924, 2851, 2756, 1609, 1583, 1549, 1461, 1415, 1374, 1336, 1301, 1217, 1182, 1165, 1150, 1110, 1093, 1062, 1051, 1033, 1019, 982, 948, 913, 896, 872, 831, 817, 798, 756, 732, 721, 682 , $658,629,614,581$, and $538 \mathrm{~cm}^{-1}$; HRMS calculated for $\mathrm{C}_{18} \mathrm{H}_{13} \mathrm{~N}_{2} \mathrm{O}_{3} \mathrm{SBrCl}[\mathrm{M}-\mathrm{H}]^{-} 450.9519$; found 450.9519; Purity: 90\%.

\section{$N$-(3,4-dimethylphenyl)-4-(2-cyclopropyl-5-oxazolyl)-benzenesulfonamide (33):}<smiles>O=S(=O)(Cl)c1ccc(-c2cnc(C3CC3)o2)cc1</smiles>

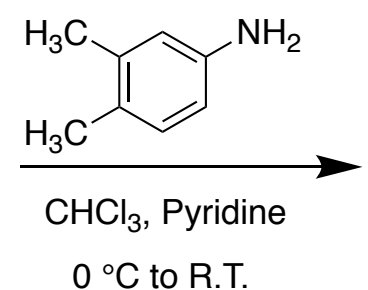

$0{ }^{\circ} \mathrm{C}$ to R.T.<smiles>Cc1ccc(NS(=O)(=O)c2ccc(-c3cnc(C4CC4)o3)cc2)cc1C</smiles>

$72 \%$

Off-white solid, prepared in $72 \%$ yield $(1.26 \mathrm{mmol}, 0.464 \mathrm{~g})$ from the reaction of 3,4dimethylaniline $(1.76 \mathrm{mmol}, 0.213 \mathrm{~g})$ with $11(1.76 \mathrm{mmol}, 0.500 \mathrm{~g})$ via general procedure $\mathrm{A}$, crude product was purified by column chromatography $\left(\mathrm{SiO}_{2}\right.$, gradient, $2 \%$ to $\left.5 \% \mathrm{DCM}: \mathrm{MeOH}\right)$. $\mathrm{R}_{\mathrm{f}}=0.4$ (5\% DCM:MeOH); M.P. $=193-194{ }^{\circ} \mathrm{C} ;{ }^{1} \mathrm{H}$ NMR $\left(400 \mathrm{MHz}, \mathrm{CDCl}_{3}\right) \delta 7.76(\mathrm{~d}, J=8.2 \mathrm{~Hz}, 2 \mathrm{H}), 7.59$ (d, $J=8.5 \mathrm{~Hz}, 2 \mathrm{H}), 7.28(\mathrm{~s}, 1 \mathrm{H}), 6.97(\mathrm{~d}, J=8.1 \mathrm{~Hz}, 1 \mathrm{H}), 6.89(\mathrm{~d}, J=11.9 \mathrm{~Hz}, 2 \mathrm{H}), 6.79(\mathrm{~d}, J=8.0$ $\mathrm{Hz}, 1 \mathrm{H}), 2.16-2.09(\mathrm{~m}, 7 \mathrm{H})$, and 1.14-1.09 $(\mathrm{m}, 4 \mathrm{H}) ;{ }^{13} \mathrm{C} \mathrm{NMR}\left(101 \mathrm{MHz}, \mathrm{CDCl}_{3}\right) \delta 166.4,148.1$, $138.3,137.0,135.1,132.4,131.3,130.0,127.6,125.2,123.8,121.9,118.1,19.5,18.7,8.7$, and 8.4; IR (neat) 3011, 1610, 1571, 1559, 1496, 1441, 1413, 1393, 1376, 1331, 1288, 1189, 1165, $1153,1130,1094,1061,1043,1024,1002,980,947,877,844,832,790,753,734,719,705,629$, 615, 601, 567, and $538 \mathrm{~cm}^{-1}$; HRMS calculated for $\mathrm{C}_{20} \mathrm{H}_{19} \mathrm{~N}_{2} \mathrm{O}_{3} \mathrm{~S}$ [M-H]- 367.1116; found 367.1125; Purity: $91 \%$. 


\section{$\mathrm{N}$-[3-chloro-4-trifluoromethyl)phenyl]-4-(2-cyclopropyl-5-oxazoyl)-benzenesulfonamide}

(34):<smiles>O=S(=O)(Cl)c1ccc(-c2cnc(C3CC3)o2)cc1</smiles><smiles>CC(C)(C)O[Mg]</smiles>

Off-white solid, prepared in $64 \%$ yield $(1.13 \mathrm{mmol}, 0.502 \mathrm{~g})$ from the reaction of 3-chloro4-trifluoromethylaniline $(1.76 \mathrm{mmol}, 0.344 \mathrm{~g})$ with $11(1.76 \mathrm{mmol}, 0.500 \mathrm{~g})$ via general procedure A, crude product was purified by column chromatography $\left(\mathrm{SiO}_{2}\right.$, gradient, $1 \%$ to $\left.2 \% \mathrm{DCM}: \mathrm{MeOH}\right)$. $R_{f}=0.35$ (5\% DCM:MeOH); M.P. = 169-170 ${ }^{\circ} \mathrm{C} ;{ }^{1} \mathrm{H}$ NMR $\left(400 \mathrm{MHz}, \mathrm{DMSO}-d_{6}\right) \delta 11.21(\mathrm{~s}, 1 \mathrm{H})$, $7.89(\mathrm{~d}, J=8.5 \mathrm{~Hz}, 2 \mathrm{H}), 7.83(\mathrm{~d}, J=8.7 \mathrm{~Hz}, 2 \mathrm{H}), 7.72(\mathrm{~d}, J=8.7 \mathrm{~Hz}, 1 \mathrm{H}), 7.68(\mathrm{~s}, 1 \mathrm{H}), 7.33(\mathrm{~d}, J$ $=1.8 \mathrm{~Hz}, 1 \mathrm{H}), 7.25(\mathrm{dd}, J=8.7,1.6 \mathrm{~Hz}, 1 \mathrm{H}), 2.12-2.19(\mathrm{~m}, 1 \mathrm{H})$, and $0.99-1.10(\mathrm{~m}, 4 \mathrm{H}) ;{ }^{13} \mathrm{C} \mathrm{NMR}$ (101 MHz, DMSO-d $\left.d_{6}\right) \delta 166.60,147.93,142.68,137.35,132.10,131.64,129.30,129.25,127.67$, $125.77,124.25,121.49,121.38,121.06,120.22,116.59,8.67$, and 8.47; IR (neat) 2915, 2081, 1606, 1569, 1557, 1505, 1411, 1391, 1337, 1311, 1229, 1161, 1127, 1103, 1091, 1062, 1025, 942, $876,845,828,779,746,721,691,651,628,599,565,548,539$, and $533 \mathrm{~cm}^{-1}$; HRMS calculated for $\mathrm{C}_{19} \mathrm{H}_{13} \mathrm{~N}_{2} \mathrm{O}_{3} \mathrm{SCIF}_{3}[\mathrm{M}-\mathrm{H}]^{-} 441.0287$; found 441.0287 Purity: $90 \%$.

\section{N-(2,4-difluorophenyl)-4-(2-cyclopropyl-5-oxazolyl)-benzenesulfonamide (35):}<smiles>O=S(=O)(Cl)c1ccc(-c2cnc(C3CC3)o2)cc1</smiles><smiles>CC(C)CCCCc1cc(F)ccc1N</smiles><smiles>O=S(=O)(Nc1ccc(F)cc1F)c1ccc(-c2cnc(C3CC3)o2)cc1</smiles>

White solid, prepared in $67 \%$ yield $(1.17 \mathrm{mmol}, 0.442 \mathrm{~g})$ from the reaction of $2,4-$ difluoroaniline $(1.76 \mathrm{mmol}, 0.18 \mathrm{~mL})$ with $11(1.76 \mathrm{mmol}, 0.500 \mathrm{~g})$ via general procedure $A$, crude 
product was purified by column chromatography $\left(\mathrm{SiO}_{2}\right.$, gradient, $2 \%$ to $\left.5 \% \mathrm{DCM}: \mathrm{MeOH}\right)$. $\mathrm{R}_{\mathrm{f}}=0.4$ (5\% DCM:MeOH); M.P. $=142-143{ }^{\circ} \mathrm{C} ;{ }^{1} \mathrm{H}$ NMR $\left(400 \mathrm{MHz}, \mathrm{CDCl}_{3}\right) \delta 7.72(\mathrm{~d}, J=8.7 \mathrm{~Hz}, 2 \mathrm{H}), 7.61-$ $7.54(\mathrm{~m}, 3 \mathrm{H}), 7.30(\mathrm{~s}, 1 \mathrm{H}), 7.16(\mathrm{~s}, 1 \mathrm{H}), 6.89-6.84(\mathrm{~m}, 1 \mathrm{H}), 6.73-6.68(\mathrm{~m}, 1 \mathrm{H}), 2.17-2.10(\mathrm{~m}, 1 \mathrm{H})$, and 1.16-1.07 (m, 4H); ${ }^{13} \mathrm{C}$ NMR (101 MHz, $\left.\mathrm{CDCl}_{3}\right) \delta$ 167.4, $160.6(\mathrm{dd}, J=249.7,10.6 \mathrm{~Hz}), 155.2$ (dd, $J=249.8,12.6 \mathrm{~Hz}), 148.5,137.4,132.7,128.0,126.9$ (d, $J=8.7 \mathrm{~Hz}), 124.9,124.0,120.4$ (d, $J=13.5 \mathrm{~Hz}$ ), $112.0(\mathrm{dd}, J=23.2,3.9 \mathrm{~Hz}), 104.3(\mathrm{t}, J=23.2 \mathrm{~Hz}$ ) 9.2, and 8.9; IR (neat) 3080, 2988, 1982, 1610, 1550, 1504, 1421, 1347, 1299, 1258, 1165, 1096, 1052, 1004, 948, 872, 831, 749, $729,701,607,593,581,560,533$, and $526 \mathrm{~cm}^{-1}$; HRMS calculated for $\mathrm{C}_{18} \mathrm{H}_{13} \mathrm{~N}_{2} \mathrm{O}_{3} \mathrm{SF}_{2}$ [M-H] 375.0615; found 375.0639; Purity: 90\%.

\section{N-(2,5-dichlorophenyl)-4-(2-cyclopropyl-5-oxazolyl)-benzenesulfonamide (36):}

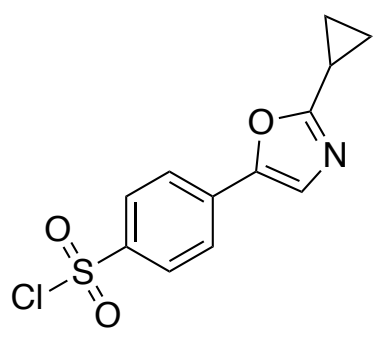

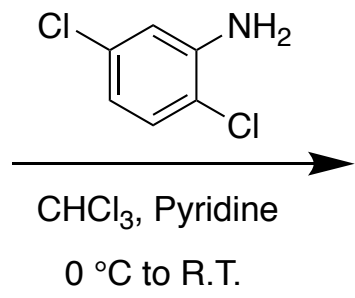

$0{ }^{\circ} \mathrm{C}$ to R.T.

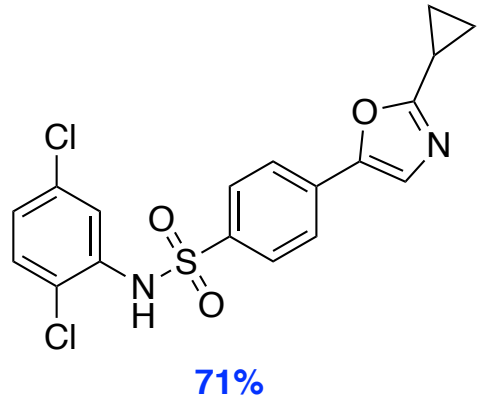

$71 \%$

White solid, prepared in $71 \%$ yield $(1.25 \mathrm{mmol}, 0.512 \mathrm{~g})$ from the reaction of $2,5-$ dichloroaniline $(1.76 \mathrm{mmol}, 0.35 \mathrm{~mL})$ with $11(1.76 \mathrm{mmol}, 0.500 \mathrm{~g})$ via general procedure $\mathrm{A}$, crude product was purified by column chromatography $\left(\mathrm{SiO}_{2}, 2 \% \mathrm{DCM}: \mathrm{MeOH}\right) . \mathrm{R}_{\mathrm{f}}=0.4(5 \%$ DCM:MeOH); M.P. $=170-171{ }^{\circ} \mathrm{C} ;{ }^{1} \mathrm{H}$ NMR $(400 \mathrm{MHz} \text {, DMSO-d })_{6} \delta 10.35(\mathrm{~s}, 1 \mathrm{H}), 7.82(\mathrm{~d}, J=7.8$ $\mathrm{Hz}, 2 \mathrm{H}), 7.75(\mathrm{~d}, J=8.2 \mathrm{~Hz}, 2 \mathrm{H}), 7.70(\mathrm{~s}, 1 \mathrm{H}), 7.44(\mathrm{~d}, J=8.0 \mathrm{~Hz}, 1 \mathrm{H}), 7.30(\mathrm{~d}, J=8.2 \mathrm{~Hz}, 2 \mathrm{H})$, 2.18-2.17 $(\mathrm{m}, 1 \mathrm{H})$, and 1.09-1.04 $(\mathrm{m}, 4 \mathrm{H}) ;{ }^{13} \mathrm{C}$ NMR (101 MHz, DMSO-d $\left.\mathrm{d}_{6}\right) \delta$ 166.5, 148.1, 138.6, $134.8,131.7,131.4,127.7,127.6,127.0,125.5,124.0,8.7$, and 8.5; IR (neat) 2748, 1609, 1574, $1557,1471,1408,1388,1333,1286,1242,1227,1163,1133,1092,1063,1014,986,942,886$, $851,835,816,745,734,719,691,660,629,605,583,557$, and $540 \mathrm{~cm}^{-1}$; HRMS calculated for $\mathrm{C}_{18} \mathrm{H}_{13} \mathrm{~N}_{2} \mathrm{O}_{3} \mathrm{SCl}_{2}[\mathrm{M}-\mathrm{H}]^{-}$407.0024; found 407.0043; Purity: 96\%. 
N-(3,5-difluorophenyl)-4-(2-cyclopropyl-5-oxazolyl)-benzenesulfonamide (37):<smiles>O=S(=O)(Cl)c1ccc(-c2cnc(C3CC3)o2)cc1</smiles><smiles>Nc1cc(F)cc(F)c1</smiles><smiles>O=S(=O)(Nc1cc(F)cc(F)c1)c1ccc(-c2cnc(C3CC3)o2)cc1</smiles>

Off-white solid, prepared in $70 \%$ yield $(1.23 \mathrm{mmol}, 0.464 \mathrm{~g})$ from the reaction of $3,5-$ difluoroaniline $(1.76 \mathrm{mmol}, 0.227 \mathrm{~g})$ with $11(1.76 \mathrm{mmol}, 0.500 \mathrm{~g})$ via general procedure $\mathrm{A}$, crude product was purified by column chromatography $\left(\mathrm{SiO}_{2}\right.$, gradient, $1 \%$ to $\left.5 \% \mathrm{DCM}: \mathrm{MeOH}\right)$. $\mathrm{R}_{\mathrm{f}}=0.3$ (5\% DCM:MeOH); M.P. = 66-69 ${ }^{\circ} \mathrm{C} ;{ }^{1} \mathrm{H}$ NMR $\left(400 \mathrm{MHz}, \mathrm{CDCl}_{3}\right) \delta 8.02$ (s, 1H), 7.86 (dd, $J=7.0$, $1.7 \mathrm{~Hz}, 2 \mathrm{H}), 7.65(\mathrm{dd}, J=6.9,1.8 \mathrm{~Hz}, 2 \mathrm{H}), 7.33(\mathrm{~s}, 1 \mathrm{H}), 6.73-6.67(\mathrm{~m}, 2 \mathrm{H}), 6.51$ (tt, $J=8.8,2.2 \mathrm{~Hz}$, 1H), 2.19-2.11 (m, 1H), and 1.18-1.09 (m, 4H); $\left.{ }^{13} \mathrm{C} \mathrm{NMR} \mathrm{(101} \mathrm{MHz,} \mathrm{CDCl}_{3}\right) \delta 167.6,163.4(\mathrm{dd}, J=$ 249.8, $14.4 \mathrm{~Hz}), 148.5,139.2(\mathrm{t}, J=12.6 \mathrm{~Hz}), 137.2,132.9,128.1,124.9,124.2,103.5$ (dd, $J=$ 20.3, 8.8 Hz), 100.5 (t, $J=26.2 \mathrm{~Hz}$ ), 9.3, and 9.0; IR (neat) 2987, 1625, 1607, 1568, 1556, 1498, $1475,1410,1329,1166,1141,1118,1092,1062,1024,996,945,877,831,745,721,660,629$, 604, 567, and $533 \mathrm{~cm}^{-1}$; HRMS calculated for $\mathrm{C}_{18} \mathrm{H}_{13} \mathrm{~N}_{2} \mathrm{O}_{3} \mathrm{SF}_{2}$ [M-H]- 375.0615; found 375.0615; Purity: 92\%.

\section{N-(4-difluoromethoxyphenyl)-4-(2-cyclopropyl-5-oxazolyl)-benzenesulfonamide (38):}<smiles>O=S(=O)(Cl)c1ccc(-c2cnc(C3CC3)o2)cc1</smiles><smiles>Nc1ccc(OC(F)F)cc1</smiles><smiles>O=S(=O)(Nc1ccc(OC(F)F)cc1)c1ccc(-c2cnc(C3CC3)o2)cc1</smiles>
$58 \%$

Light brown solid, prepared in $58 \%$ yield $(1.02 \mathrm{mmol}, 0.415 \mathrm{~g})$ from the reaction of 4(difluoromethoxy)aniline $(1.76 \mathrm{mmol}, 0.218 \mathrm{~mL})$ with $11(1.76 \mathrm{mmol}, 0.500 \mathrm{~g})$ via general procedure A, crude product was purified by column chromatography $\left(\mathrm{SiO}_{2}, 2 \% \mathrm{DCM}: \mathrm{MeOH}\right) \cdot \mathrm{R}_{\mathrm{f}}=0.35(5 \%$ 
DCM:MeOH); M.P. $=140-142{ }^{\circ} \mathrm{C} ;{ }^{1} \mathrm{H}$ NMR $\left(400 \mathrm{MHz}, \mathrm{CDCl}_{3}\right) \delta 7.75(\mathrm{dd}, J=6.9,1.8 \mathrm{~Hz}, 2 \mathrm{H}), 7.62$ (dd, $J=6.9,1.8 \mathrm{~Hz}, 2 \mathrm{H}), 7.30(\mathrm{~s}, 1 \mathrm{H}), 7.10-7.07(\mathrm{~m}, 2 \mathrm{H}), 7.01(\mathrm{~d}, J=8.9 \mathrm{~Hz}, 2 \mathrm{H}), 6.96(\mathrm{~s}, 1 \mathrm{H})$, $6.44(\mathrm{t}, J=73.5 \mathrm{~Hz}, 1 \mathrm{H}), 2.16-2.09(\mathrm{~m}, 1 \mathrm{H})$, and 1.17-1.08 (m, 4H); ${ }^{13} \mathrm{C} \mathrm{NMR}\left(101 \mathrm{MHz}, \mathrm{CDCl}_{3}\right) \delta$ 167.4, 148.6, 148.5, 137.5, 133.8, 132.4, 128.0, 124.7, 124.0, 123.7, 120.7, 115.8 (t, $J=262.3 \mathrm{~Hz})$, 9.2, and 8.9; IR (neat) 3025, 1616, 1592, 1568, 1557, 1505, 1467, 1407, 1379, 1340, 1305, 1234, $1211,1161,1123,1091,1045,1014,979,945,877,826,761,721,657,638,602,569$, and 543 $\mathrm{cm}^{-1}$; HRMS calculated for $\mathrm{C}_{19} \mathrm{H}_{15} \mathrm{~N}_{2} \mathrm{O}_{4} \mathrm{SF}_{2}[\mathrm{M}-\mathrm{H}]^{-}$405.0721; found 405.0717; Purity: $93 \%$.

\section{N-(4-fluoro-3-methoxyphenyl)-4-(2-cyclopropyl-5-oxazolyl)-benzenesulfonamide (39):}<smiles>O=S(=O)(Cl)c1ccc(-c2cnc(C3CC3)o2)cc1</smiles>

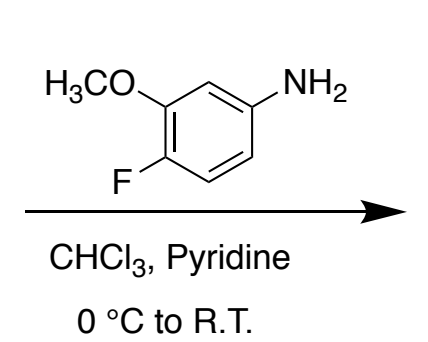

$0{ }^{\circ} \mathrm{C}$ to R.T.<smiles>COc1cc(NS(=O)(=O)c2ccc(-c3cnc(C4CC4)o3)cc2)ccc1F</smiles>

$77 \%$

White solid, prepared in $77 \%$ yield $(1.35 \mathrm{mmol}, 0.526 \mathrm{~g})$ from the reaction of 4 -fluoro-3methoxyaniline $(1.76 \mathrm{mmol}, 0.248 \mathrm{~g})$ with $11(1.76 \mathrm{mmol}, 0.500 \mathrm{~g})$ via general procedure $\mathrm{A}$, crude product was purified by column chromatography $\left(\mathrm{SiO}_{2}\right.$, gradient, $1 \%$ to $\left.5 \% \mathrm{DCM}: \mathrm{MeOH}\right) . \mathrm{R}_{\mathrm{f}}=0.35$ (5\% DCM:MeOH); M.P. $=59-61^{\circ} \mathrm{C} ;{ }^{1} \mathrm{H}$ NMR $\left(400 \mathrm{MHz}, \mathrm{CDCl}_{3}\right)$ ठ 7.76-7.74 (m, 2H), 7.62-7.60 (m, 2H), $7.33(\mathrm{~s}, 1 \mathrm{H}), 7.29(\mathrm{~s}, 1 \mathrm{H}), 6.91-6.84(\mathrm{~m}, 2 \mathrm{H}), 6.49$ (ddd, J = 8.6, 3.5, $2.7 \mathrm{~Hz}, 1 \mathrm{H}), 3.81(\mathrm{~s}, 3 \mathrm{H})$, 2.16-2.09 (m, 1H), and 1.14-1.08 (m, 4H); $\left.{ }^{13} \mathrm{C} \mathrm{NMR} \mathrm{(101} \mathrm{MHz,} \mathrm{CDCl}_{3}\right) \delta$ 167.4, 151.8, 149.4, 148.5, $148.2(\mathrm{~d}, J=11.6 \mathrm{~Hz}), 137.3,132.6,128.1,124.8,124.0,116.3(\mathrm{~d}, J=19.4 \mathrm{~Hz}), 114.9$ (d, $J=6.8$ $\mathrm{Hz}$ ), 109.0, 56.4, 9.2, and 9.0; IR (neat) 3080, 1609, 1568, 1556, 1514, 1410, 1333, 1259, 1217 , $1194,1153,1120,1092,1061,1029,966,945,878,832,748,720,637,600,548$, and $526 \mathrm{~cm}^{-1}$; HRMS calculated for $\mathrm{C}_{19} \mathrm{H}_{16} \mathrm{~N}_{2} \mathrm{O}_{4} \mathrm{SF}[\mathrm{M}-\mathrm{H}]^{-} 387.0814$; found 387.0816; Purity: 95\%. 
N-(3-chloro-5-fluorophenyl)-4-(2-cyclopropyl-5-oxazolyl)-benzenesulfonamide (40):<smiles>O=S(=O)(Cl)c1ccc(-c2cnc(C3CC3)o2)cc1</smiles><smiles>Nc1cc(F)cc(Cl)c1</smiles><smiles>O=S(=O)(Nc1cc(F)cc(Cl)c1)c1ccc(-c2cnc(C3CC3)o2)cc1</smiles>

$66 \%$

Off-white solid, prepared in $66 \%$ yield $(1.16 \mathrm{mmol}, 0.454 \mathrm{~g})$ from the reaction of 3-chloro5-fluoroaniline $(1.76 \mathrm{mmol}, 0.177 \mathrm{~mL})$ with $11(1.76 \mathrm{mmol}, 0.500 \mathrm{~g})$ via general procedure $A$, crude product was purified by column chromatography $\left(\mathrm{SiO}_{2}\right.$, gradient, $1 \%$ to $\left.2 \% \mathrm{DCM}: \mathrm{MeOH}\right) . \mathrm{R}_{\mathrm{f}}=0.4$ (5\% DCM:MeOH); M.P. $=62-65{ }^{\circ} \mathrm{C} ;{ }^{1} \mathrm{H}$ NMR $\left(400 \mathrm{MHz}, \mathrm{CDCl}_{3}\right) \delta 8.74(\mathrm{~s}, 1 \mathrm{H}), 7.86(\mathrm{~d}, J=8.7 \mathrm{~Hz}$, 2H), $7.64(\mathrm{~d}, J=8.5 \mathrm{~Hz}, 2 \mathrm{H}), 7.32(\mathrm{~s}, 1 \mathrm{H}), 6.93(\mathrm{~s}, 1 \mathrm{H}), 6.86(\mathrm{dt}, J=9.8,2.0 \mathrm{~Hz}, 1 \mathrm{H}), 6.76(\mathrm{dt}, J=$ 8.2, $1.8 \mathrm{~Hz}, 1 \mathrm{H}), 2.17-2.10(\mathrm{~m}, 1 \mathrm{H})$, and 1.17-1.08 (m, 4H); $\left.{ }^{13} \mathrm{C} \mathrm{NMR} \mathrm{(101} \mathrm{MHz,} \mathrm{CDCl}_{3}\right) \delta$ 167.5, $162.9(\mathrm{~d}, J=250.7 \mathrm{~Hz}), 148.5,139.2(\mathrm{~d}, J=12.5 \mathrm{~Hz}), 137.3,135.8(\mathrm{~d}, J=11.6 \mathrm{~Hz}), 132.7,128.0$, 124.7, 124.2, 116.1 (d, $J=3.9 \mathrm{~Hz}), 112.6$ (d, $J=25.1 \mathrm{~Hz}), 106.0(\mathrm{~d}, J=26.2 \mathrm{~Hz}), 9.2$, and 9.0; IR (neat) $3093,1606,1568,1556,1487,1456,1410,1328,1165,1141,1091,1061,1011,997,945$, $920,888,830,745,721,691,651,629,600,580,560$, and $542 \mathrm{~cm}^{-1}$; HRMS calculated for $\mathrm{C}_{18} \mathrm{H}_{13} \mathrm{~N}_{2} \mathrm{O}_{3} \mathrm{SCIF}[\mathrm{M}-\mathrm{H}]^{-}$391.0319; found 391.0338; Purity: 92\%.

\section{N-[4-methyl-3-(trifluoromethyl)phenyl]-4-(2-cyclopropyl-5-oxazoyl)-benzenesulfonamide}

(41):<smiles>O=S(=O)(Cl)c1ccc(-c2cnc(C3CC3)o2)cc1</smiles><smiles>Cc1ccc(N)cc1C(F)(F)F</smiles><smiles>Cc1ccc(NS(=O)(=O)c2ccc(-c3cnc(C4CC4)o3)cc2)cc1C(F)(F)F</smiles>

Off-white solid, prepared in $68 \%$ yield $(1.19 \mathrm{mmol}, 0.502 \mathrm{~g})$ from the reaction of 4-methyl3-(trifluoromethyl)aniline $(1.76 \mathrm{mmol}, 0.253 \mathrm{~mL})$ with $11(1.76 \mathrm{mmol}, 0.500 \mathrm{~g})$ via general procedure 
A, crude product was purified by column chromatography $\left(\mathrm{SiO}_{2}\right.$, gradient, $1 \%$ to $\left.5 \% \mathrm{DCM}: \mathrm{MeOH}\right)$. $\mathrm{R}_{\mathrm{f}}=0.33$ (5\% DCM:MeOH); M.P. = 179-181 ${ }^{\circ} \mathrm{C} ;{ }^{1} \mathrm{H}$ NMR $\left(400 \mathrm{MHz}, \mathrm{CDCl}_{3}\right) \delta 7.79(\mathrm{~d}, J=8.5 \mathrm{~Hz}$, 2H), $7.70(\mathrm{~s}, 1 \mathrm{H}), 7.61(\mathrm{~d}, J=8.7 \mathrm{~Hz}, 2 \mathrm{H}), 7.32(\mathrm{~d}, J=2.1 \mathrm{~Hz}, 1 \mathrm{H}), 7.30(\mathrm{~s}, 1 \mathrm{H}), 7.20(\mathrm{dd}, J=8.2$, $2.3 \mathrm{~Hz}, 1 \mathrm{H}), 7.14(\mathrm{~d}, J=8.5 \mathrm{~Hz}, 1 \mathrm{H}), 2.38(\mathrm{~s}, 3 \mathrm{H}), 2.16-2.09(\mathrm{~m}, 1 \mathrm{H})$, and $1.16-1.08(\mathrm{~m}, 4 \mathrm{H}) ;{ }^{13} \mathrm{C}$ NMR $\left(101 \mathrm{MHz}, \mathrm{CDCl}_{3}\right) \delta 167.4,148.5,137.5,134.4,133.9,133.1,132.6,129.9(\mathrm{~d}, J=31.0 \mathrm{~Hz})$, 128.1, 125.3, 124.8, 124.1, 122.6, 119.3 (q, $J=5.8 \mathrm{~Hz}$ ), 18.8, 9.2, and 9.0; IR (neat) 3094, 2867, $1610,1590,1570,1560,1500,1408,1339,1318,1285,1268,1216,1184,1160,1138,1124$, $1113,1093,1068,1055,1032,1015,981,936,893,839,820,793,752,718,670,655,643,628$, 606, 577, 537, and $526 \mathrm{~cm}^{-1}$; HRMS calculated for $\mathrm{C}_{20} \mathrm{H}_{16} \mathrm{~N}_{2} \mathrm{O}_{3} \mathrm{SF}_{3}[\mathrm{M}-\mathrm{H}]^{-}$421.0834; found 421.0829; Purity: 93\%.

\section{$N$-[3-fluoro-4-(morpholino)phenyl]-4-(2-cyclopropyl-5-oxazoyl)-benzenesulfonamide (42):}

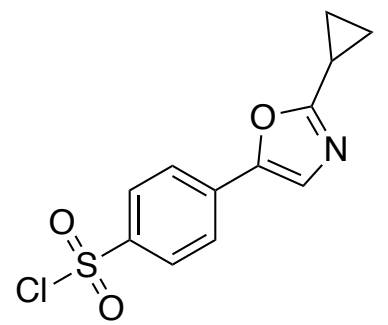

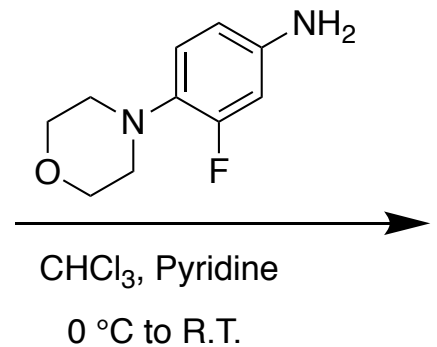

$0{ }^{\circ} \mathrm{C}$ to R.T.

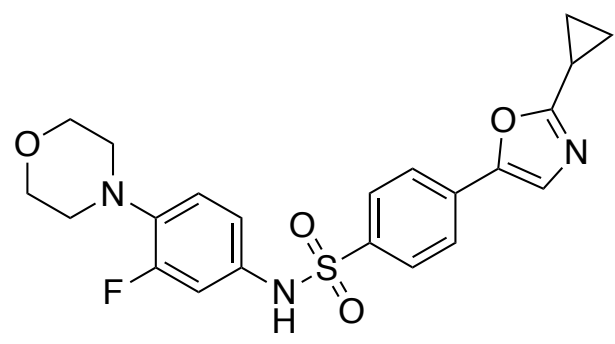

$68 \%$

Off-white solid, prepared in $68 \%$ yield $(1.19 \mathrm{mmol}, 0.527 \mathrm{~g})$ from the reaction of 3-fluoro-4morpholinoaniline $(1.76 \mathrm{mmol}, 0.345 \mathrm{~g})$ with $11(1.76 \mathrm{mmol}, 0.500 \mathrm{~g})$ via general procedure $\mathrm{A}$, crude product was purified by column chromatography $\left(\mathrm{SiO}_{2}\right.$, gradient, $1 \%$ to $\left.5 \% \mathrm{DCM}: \mathrm{MeOH}\right)$. $\mathrm{R}_{\mathrm{f}}$ $=0.35\left(5 \%\right.$ DCM:MeOH); M.P. $=185-187{ }^{\circ} \mathrm{C} ;{ }^{1} \mathrm{H}$ NMR $\left(400 \mathrm{MHz}, \mathrm{CDCl}_{3}\right) \delta 7.76(\mathrm{dd}, J=6.9,1.8$ $\mathrm{Hz}, 2 \mathrm{H}), 7.61(\mathrm{~d}, J=8.7 \mathrm{~Hz}, 2 \mathrm{H}), 7.33(\mathrm{~s}, 1 \mathrm{H}), 7.29(\mathrm{~s}, 1 \mathrm{H}), 6.91-6.87(\mathrm{~m}, 1 \mathrm{H}), 6.80-6.75(\mathrm{~m}, 2 \mathrm{H})$, $3.83(\mathrm{t}, J=4.7 \mathrm{~Hz}, 4 \mathrm{H}), 3.00(\mathrm{t}, J=4.6 \mathrm{~Hz}, 4 \mathrm{H}), 2.16-2.09(\mathrm{~m}, 1 \mathrm{H})$, and 1.16-1.08 $(\mathrm{m}, 4 \mathrm{H}) ;{ }^{13} \mathrm{C} \mathrm{NMR}$ $\left(101 \mathrm{MHz}, \mathrm{CDCl}_{3}\right) \delta 167.4,156.6,154.2,148.6,138.1(\mathrm{~d}, J=7.8 \mathrm{~Hz}), 137.6,132.5,130.8(\mathrm{~d}, J=$ 10.7 Hz), 128.0, 124.8 (d, $J=8.7 \mathrm{~Hz}), 124.0,119.0(\mathrm{~d}, J=9.7 \mathrm{~Hz}), 111.6(\mathrm{~d}, J=24.3 \mathrm{~Hz}), 67.0$, $50.9,9.2$, and 8.9; IR (neat) 2853, 1608, 1568, 1556, 1510, 1450, 1410, 1377, 1332, 1253, 1223 , 
$1150,1118,1092,1062,1049,1030,979,931,876,815,747,721,652,611,581$, and $545 \mathrm{~cm}^{-1}$; HRMS calculated for $\mathrm{C}_{22} \mathrm{H}_{21} \mathrm{~N}_{3} \mathrm{O}_{4} \mathrm{SF}[\mathrm{M}-\mathrm{H}]^{-} 442.1237$; found 442.1236; Purity: $91 \%$.

\section{N-(4-chloro-2-methylphenyl)-4-(2-cyclopropyl-5-oxazolyl)-benzenesulfonamide (43):}<smiles>O=S(=O)(Cl)c1ccc(-c2cnc(C3CC3)o2)cc1</smiles><smiles>Cc1cc(Cl)ccc1N</smiles><smiles></smiles>

Off-white solid, prepared in $72 \%$ yield $(1.26 \mathrm{mmol}, 0.491 \mathrm{~g})$ from the reaction of 4-chloro2-methylaniline $(1.76 \mathrm{mmol}, 0.250 \mathrm{~g})$ with $11(1.76 \mathrm{mmol}, 0.500 \mathrm{~g})$ via general procedure $\mathrm{A}$, crude product was purified by column chromatography $\left(\mathrm{SiO}_{2}\right.$, gradient, $1 \%$ to $\left.5 \% \mathrm{DCM}: \mathrm{MeOH}\right) . \mathrm{R}_{\mathrm{f}}=0.42$ (5\% DCM:MeOH); M.P. $=161-163{ }^{\circ} \mathrm{C} ;{ }^{1} \mathrm{H}$ NMR $\left(400 \mathrm{MHz}, \mathrm{CDCl}_{3}\right) \delta 7.72(\mathrm{~d}, \mathrm{~J}=8.7 \mathrm{~Hz}, 2 \mathrm{H}), 7.62$ (d, $J=8.7 \mathrm{~Hz}, 2 \mathrm{H}), 7.31(\mathrm{~s}, 1 \mathrm{H}), 7.24(\mathrm{~d}, J=8.5 \mathrm{~Hz}, 1 \mathrm{H}), 7.10(\mathrm{td}, J=8.4,2.2 \mathrm{~Hz}, 2 \mathrm{H}), 6.76(\mathrm{~s}$, 1H), 2.16-2.09 (m, 1H), $1.98(\mathrm{~s}, 3 \mathrm{H})$, and 1.17-1.08 (m, 4H); $\left.{ }^{13} \mathrm{C} \mathrm{NMR} \mathrm{(101} \mathrm{MHz,} \mathrm{CDCl}_{3}\right) \delta$ 167.4, $148.5,138.0,134.1,132.8,132.6,132.2,130.8,127.9,127.2,126.5,124.9,124.0,17.7,9.2$, and 8.9; IR (neat) 3267, 1609, 1570, 1558, 1486, 1410, 1365, 1333, 1322, 1168, 1122, 1111, 1092 , $1061,1025,969,940,910,893,869,833,818,802,746,725,681,650,610,579,557,538$, and $532 \mathrm{~cm}^{-1}$; HRMS calculated for $\mathrm{C}_{19} \mathrm{H}_{16} \mathrm{~N}_{2} \mathrm{O}_{3} \mathrm{SCl}[\mathrm{M}-\mathrm{H}]^{-}$387.0570; found 387.0563; Purity: 96\%. 


\section{N-(2-chloro-5-methylphenyl)-4-(2-cyclopropyl-5-oxazolyl)-benzenesulfonamide (44):}<smiles>O=S(=O)(Cl)c1ccc(-c2cnc(C3CC3)o2)cc1</smiles><smiles>Cc1ccc(Cl)c(N)c1</smiles><smiles>Cc1ccc(Cl)c(NS(=O)(=O)c2ccc(-c3cnc(C4CC4)o3)cc2)c1</smiles>

Off-white solid, prepared in $69 \%$ yield $(1.26 \mathrm{mmol}, 0.491 \mathrm{~g})$ from the reaction of 2-chloro5-methylaniline $(1.76 \mathrm{mmol}, 0.250 \mathrm{~g})$ with $11(1.76 \mathrm{mmol}, 0.500 \mathrm{~g})$ via general procedure $\mathrm{A}$, crude product was purified by column chromatography $\left(\mathrm{SiO}_{2}\right.$, gradient, $1 \%$ to $\left.5 \% \mathrm{DCM}: \mathrm{MeOH}\right)$. $\mathrm{R}_{\mathrm{f}}=0.41$ (5\% DCM:MeOH); M.P. = 171-173 ${ }^{\circ} \mathrm{C} ;{ }^{1} \mathrm{H}$ NMR $\left(400 \mathrm{MHz}, \mathrm{CDCl}_{3}\right) \delta 7.74(\mathrm{~d}, J=8.7 \mathrm{~Hz}, 2 \mathrm{H}), 7.59$ (d, $J=8.5 \mathrm{~Hz}, 2 \mathrm{H}), 7.49$ (d, J = 1.1 Hz, 1H), $7.28(\mathrm{~s}, 1 \mathrm{H}), 7.10$ (d, J = 8.0 Hz, 1H), $6.97(\mathrm{~s}, 1 \mathrm{H})$, $6.86(\mathrm{dd}, J=8.2,1.4 \mathrm{~Hz}, 1 \mathrm{H}), 2.32(\mathrm{~s}, 3 \mathrm{H}), 2.15-2.08(\mathrm{~m}, 1 \mathrm{H})$, and 1.14-1.08 $(\mathrm{m}, 4 \mathrm{H}) ;{ }^{13} \mathrm{C} \mathrm{NMR}$ $\left(101 \mathrm{MHz}, \mathrm{CDCl}_{3}\right) \delta 167.3,148.6,138.4,137.6,132.8,132.7,129.1,128.7,128.1,127.4,124.9$, 123.9, 122.7, 21.3, 9.2, and 8.9; IR (neat) 2923, 1609, 1572, 1557, 1486, 1407, 1330, 1285, 1161, $1131,1094,1060,1032,1014,982,965,944,894,834,822,811,745,734,720,700,645,622$, 604, 564, and $548 \mathrm{~cm}^{-1}$; HRMS calculated for $\mathrm{C}_{19} \mathrm{H}_{16} \mathrm{~N}_{2} \mathrm{O}_{3} \mathrm{SCl}[\mathrm{M}-\mathrm{H}]^{-} 387.0570$; found 387.0570; Purity: $90 \%$.

\section{N-(4-iodophenyl)-4-(2-cyclopropyl-5-oxazolyl)-benzenesulfonamide (45):}<smiles>O=S(=O)(Cl)c1ccc(-c2cnc(C3CC3)o2)cc1</smiles><smiles>Nc1ccc(I)cc1</smiles><smiles>O=S(=O)(Nc1ccc(I)cc1)c1ccc(-c2cnc(C3CC3)o2)cc1</smiles>

Light yellow solid, prepared in $63 \%$ yield $(1.10 \mathrm{mmol}, 0.514 \mathrm{~g})$ from the reaction of 4 iodoaniline $(1.76 \mathrm{mmol}, 0.385 \mathrm{~g})$ with $11(1.76 \mathrm{mmol}, 0.500 \mathrm{~g})$ via general procedure $\mathrm{A}$, crude product was purified by column chromatography $\left(\mathrm{SiO}_{2}\right.$, gradient, $1 \%$ to $\left.5 \% \mathrm{DCM}: \mathrm{MeOH}\right)$. $\mathrm{R}_{\mathrm{f}}=0.41$ 
(5\% DCM:MeOH); M.P. = $157-159{ }^{\circ} \mathrm{C} ;{ }^{1} \mathrm{H}$ NMR $\left(400 \mathrm{MHz}, \mathrm{CDCl}_{3}\right) \delta 7.78(\mathrm{dd}, \mathrm{J}=6.9,1.8 \mathrm{~Hz}, 2 \mathrm{H})$, $7.61(\mathrm{dd}, J=8.7,1.8 \mathrm{~Hz}, 2 \mathrm{H}), 7.55-7.52(\mathrm{~m}, 3 \mathrm{H}), 7.30(\mathrm{~s}, 1 \mathrm{H}), 6.88(\mathrm{dd}, J=8.7,1.8 \mathrm{~Hz}, 2 \mathrm{H}), 2.16-$ $2.10(\mathrm{~m}, 1 \mathrm{H})$, and 1.15-1.10 (m, 4H); ${ }^{13} \mathrm{C}$ NMR $\left(101 \mathrm{MHz}, \mathrm{CDCl}_{3}\right) \delta 167.4,148.5,138.5,137.4$, 136.3, 132.6, 128.0, 124.8, 124.1, 123.5, 89.7, 9.2, and 9.0; IR (neat) 3014, 1607, 1568, 1556, $1483,1410,1386,1328,1294,1225,1156,1128,1092,1060,1006,944,919,819,745,720,704$ 653, 626, 598, 561, and $534 \mathrm{~cm}^{-1}$; HRMS calculated for $\mathrm{C}_{18} \mathrm{H}_{14} \mathrm{~N}_{2} \mathrm{O}_{3} \mathrm{SI}$ [M-H]- 464.9770; found 464.9770; Purity: 90\%.

\section{N-[4-(3-oxo-4-morpholinyl)phenyl]-4-(2-cyclopropyl-5-oxazolyl)-benzenesulfonamide (46):}

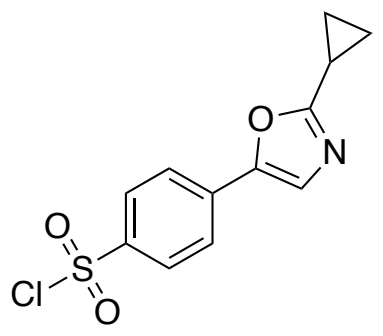

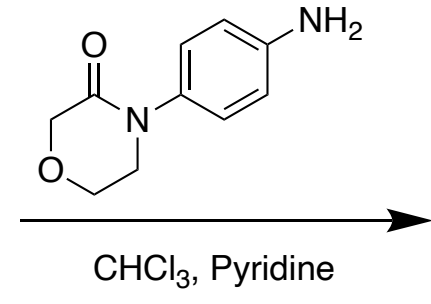

$0{ }^{\circ} \mathrm{C}$ to R.T.<smiles>O=C1COCCN1c1ccc(NS(=O)(=O)c2ccc(-c3cnc(C4CC4)o3)cc2)cc1</smiles>

$62 \%$

Light pink solid, prepared in $62 \%$ yield $(1.09 \mathrm{mmol}, 0.478 \mathrm{~g})$ from the reaction of $\mathrm{N}-4-$ aminophenylmorpholin-3-one $(1.76 \mathrm{mmol}, 0.338 \mathrm{~g})$ with $11(1.76 \mathrm{mmol}, 0.500 \mathrm{~g})$ via general procedure $\mathrm{A}$, crude product was purified by column chromatography $\left(\mathrm{SiO}_{2}\right.$, gradient, $1 \%$ to $5 \%$ DCM:MeOH). $R_{f}=0.3\left(5 \%\right.$ DCM:MeOH); M.P. $=203{ }^{\circ} \mathrm{C}$ (decomposed); ${ }^{1} \mathrm{H}$ NMR $(400 \mathrm{MHz}, \mathrm{DMSO}-$ d6) $\delta 10.43(\mathrm{~s}, 1 \mathrm{H}), 7.79-7.81(\mathrm{~m}, 4 \mathrm{H}), 7.66(\mathrm{~s}, 1 \mathrm{H}), 7.26(\mathrm{~d}, J=8.9 \mathrm{~Hz}, 2 \mathrm{H}), 7.11(\mathrm{~d}, J=8.9 \mathrm{~Hz}$, 2H), $4.14(\mathrm{~s}, 2 \mathrm{H}), 3.89-3.92(\mathrm{~m}, 2 \mathrm{H}), 3.62(\mathrm{t}, J=5.0 \mathrm{~Hz}, 2 \mathrm{H}), 2.13-2.21(\mathrm{~m}, 1 \mathrm{H})$, and 1.00-1.10 (m, $4 \mathrm{H}) ;{ }^{13} \mathrm{C}$ NMR $\left(101 \mathrm{MHz}\right.$, DMSO- $\left.d_{6}\right) \delta 166.43,165.91,148.09,138.18,137.74,135.56,131.55$, $127.60,126.24,125.43,124.03,120.39,67.69,63.45,48.88,8.67$, and 8.43; IR (neat) 2974, 1662, $1609,1556,1508,1463,1417,1381,1349,1335,1323,1304,1294,1258,1228,1161,1151$, $1126,1095,1052,1015,1000,982,963,947,926,894,861,829,751,728,657,641,609$, and $574 \mathrm{~cm}^{-1}$; HRMS calculated for $\mathrm{C}_{22} \mathrm{H}_{20} \mathrm{~N}_{3} \mathrm{O}_{5} \mathrm{~S}$ [M-H] 438.1124; found 438.1129; Purity: $91 \%$. 
N-(4-cyclopropylphenyl)-4-(2-cyclopropyl-5-oxazolyl)-benzenesulfonamide (47):<smiles>O=S(=O)(Cl)c1ccc(-c2cnc(C3CC3)o2)cc1</smiles>
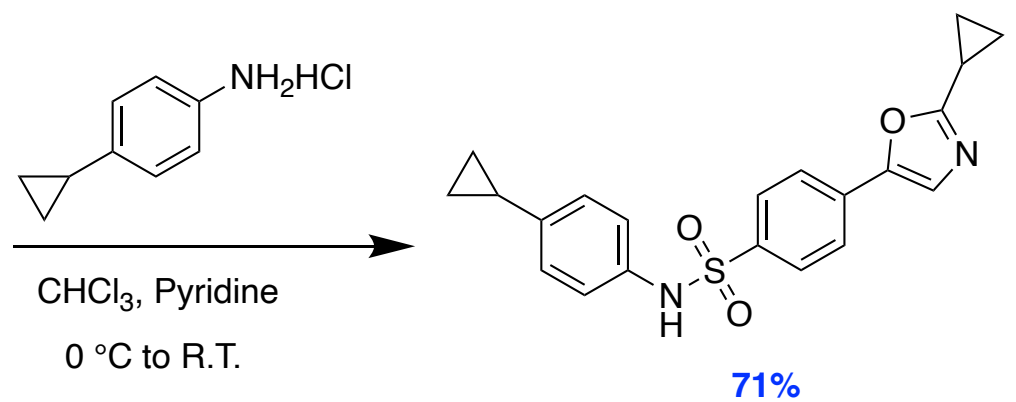

Off-white solid, prepared in $71 \%$ yield $(1.25 \mathrm{mmol}, 0.476 \mathrm{~g})$ from the reaction of 4 cyclopropylaniline hydrochloride $(1.76 \mathrm{mmol}, 0.300 \mathrm{~g})$ with $11(1.76 \mathrm{mmol}, 0.500 \mathrm{~g})$ via general procedure $\mathrm{A}$, crude product was purified by column chromatography $\left(\mathrm{SiO}_{2}\right.$, gradient, $1 \%$ to $2 \%$ DCM:MeOH). $\mathrm{R}_{\mathrm{f}}=0.42(5 \% \mathrm{DCM}: \mathrm{MeOH}) ; \mathrm{M} . \mathrm{P} .=161-163{ }^{\circ} \mathrm{C} ;{ }^{1} \mathrm{H} \mathrm{NMR}\left(400 \mathrm{MHz}, \mathrm{CDCl}_{3}\right) \delta 7.76$ $(\mathrm{d}, J=8.7 \mathrm{~Hz}, 2 \mathrm{H}), 7.57(\mathrm{~d}, J=8.7 \mathrm{~Hz}, 2 \mathrm{H}), 7.35(\mathrm{~s}, 1 \mathrm{H}), 7.27(\mathrm{~s}, 1 \mathrm{H}), 6.97-6.99(\mathrm{~m}, 2 \mathrm{H}), 6.91(\mathrm{dd}$, $J=6.7,1.9 \mathrm{~Hz}, 2 \mathrm{H}), 2.09-2.15(\mathrm{~m}, 1 \mathrm{H}), 1.76-1.83(\mathrm{~m}, 1 \mathrm{H}), 1.07-1.15(\mathrm{~m}, 4 \mathrm{H}), 0.88-0.93(\mathrm{~m}, 2 \mathrm{H})$, and $0.57-0.61(\mathrm{~m}, 2 \mathrm{H}) ;{ }^{13} \mathrm{C}$ NMR $\left(101 \mathrm{MHz}, \mathrm{CDCl}_{3}\right) \delta 167.25,148.70,141.88,137.98,133.60$, 132.26, 128.07, 126.61, 124.59, 123.92, 122.73, 15.01, 9.37, 9.20, and 8.85; IR (neat) 3009, 1609, $1571,1557,1511,1411,1334,1227,1190,1158,1130,1094,1060,1017,981,945,890,877$, $823,753,733,719,689,660,639,605,580,569,563,550$, and $538 \mathrm{~cm}^{-1}$; HRMS calculated for $\mathrm{C}_{21} \mathrm{H}_{19} \mathrm{~N}_{2} \mathrm{O}_{3} \mathrm{~S}[\mathrm{M}-\mathrm{H}]^{-} 379.1116$; found 379.1119; Purity: 94\%.

\section{N-(3-chloro-4-methoxyphenyl)-4-(2-cyclopropyl-5-oxazolyl)-benzenesulfonamide (48):}<smiles>O=S(=O)(Cl)c1ccc(-c2cnc(C3CC3)o2)cc1</smiles><smiles>COc1ccc(N)cc1Cl</smiles><smiles>COc1ccc(NS(=O)(=O)c2ccc(-c3cnc(C4CC4)o3)cc2)cc1Cl</smiles>

Off-white solid, prepared in $73 \%$ yield $(1.29 \mathrm{mmol}, 0.521 \mathrm{~g})$ from the reaction of 3-chloro4-methoxyaniline hydrochloride $(1.76 \mathrm{mmol}, 0.342 \mathrm{~g})$ with $11(1.76 \mathrm{mmol}, 0.500 \mathrm{~g})$ via general procedure $\mathrm{A}$, crude product was purified by column chromatography $\left(\mathrm{SiO}_{2}\right.$, gradient, $1 \%$ to $2 \%$ 
DCM:MeOH). $R_{f}=0.35\left(5 \%\right.$ DCM:MeOH); M.P. = 153-155 ${ }^{\circ} \mathrm{C} ;{ }^{1} \mathrm{H}$ NMR $\left(400 \mathrm{MHz}, \mathrm{DMSO}-d_{6}\right) \delta$ $10.18(\mathrm{~s}, 1 \mathrm{H}), 7.79(\mathrm{~d}, J=8.5 \mathrm{~Hz}, 2 \mathrm{H}), 7.73(\mathrm{~d}, J=6.9 \mathrm{~Hz}, 2 \mathrm{H}), 7.66(\mathrm{~s}, 1 \mathrm{H}), 7.11(\mathrm{~d}, J=2.3 \mathrm{~Hz}$, 1H), $7.01(\mathrm{t}, J=2.4 \mathrm{~Hz}, 2 \mathrm{H}), 3.75(\mathrm{~s}, 3 \mathrm{H}), 2.12-2.19(\mathrm{~m}, 1 \mathrm{H})$, and 1.00-1.10 $(\mathrm{m}, 4 \mathrm{H}) ;{ }^{13} \mathrm{C}$ NMR $(101$ $\left.\mathrm{MHz}, \mathrm{DMSO}-d_{6}\right) \delta 166.43,151.89,148.07,137.72,131.52,130.62,127.61,125.42,123.93$, 123.26, 121.62, 120.94, 113.17, 56.14, 8.66, and 8.42; IR (neat) 3084, 2907, 2840, 1612, 1558, $1493,1462,1439,1411,1390,1337,1289,1259,1209,1180,1159,1111,1093,1061,1023,981$, $946,935,879,842,807,786,752,738,721,680,630,616,600,583$, and $542 \mathrm{~cm}^{-1}$; HRMS calculated for $\mathrm{C}_{19} \mathrm{H}_{16} \mathrm{~N}_{2} \mathrm{O}_{4} \mathrm{SCl}[\mathrm{M}-\mathrm{H}]-403.0519$; found 403.0519; Purity: 97\%.

\section{N-(3-chloro-4-iodophenyl)-4-(2-cyclopropyl-5-oxazolyl)-benzenesulfonamide (49):}<smiles>O=S(=O)(Cl)c1ccc(-c2cnc(C3CC3)o2)cc1</smiles>

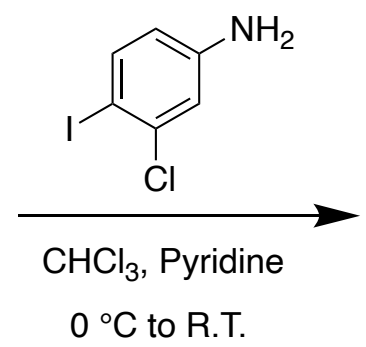

$0{ }^{\circ} \mathrm{C}$ to R.T.

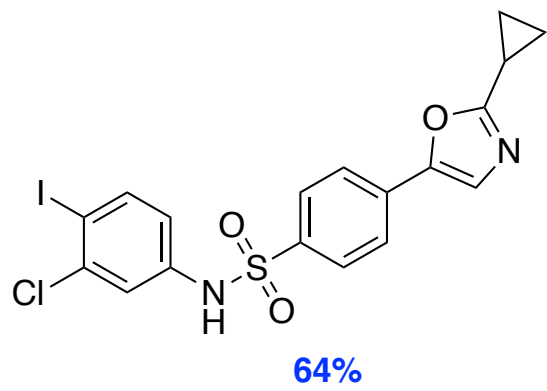

$64 \%$

White solid, prepared in $64 \%$ yield $(1.13 \mathrm{mmol}, 0.564 \mathrm{~g})$ from the reaction of 3-chloro-4iodoaniline $(1.76 \mathrm{mmol}, 0.35 \mathrm{~mL})$ with $11(1.76 \mathrm{mmol}, 0.500 \mathrm{~g})$ via general procedure $A$, crude product was purified by column chromatography $\left(\mathrm{SiO}_{2}\right.$, gradient, $1 \%$ to $\left.5 \% \mathrm{DCM}: \mathrm{MeOH}\right) . \mathrm{R}_{\mathrm{f}}=0.4$ (5\% DCM:MeOH); M.P. = $193{ }^{\circ} \mathrm{C}$ (decomposed); ${ }^{1} \mathrm{H}$ NMR $\left(400 \mathrm{MHz}, \mathrm{DMSO}-d_{6}\right) \delta 10.72(\mathrm{~s}, 1 \mathrm{H})$, 7.76-7.84 (m, 5H), $7.66(\mathrm{~s}, 1 \mathrm{H}), 7.26(\mathrm{~d}, J=2.5 \mathrm{~Hz}, 1 \mathrm{H}), 6.86(\mathrm{dd}, J=8.6,2.4 \mathrm{~Hz}, 1 \mathrm{H}), 2.12-2.18$ (m, 1H), and 0.99-1.10 (m, 4H); ${ }^{13} \mathrm{C}$ NMR (101 MHz, DMSO- $\left.d_{6}\right) \delta$ 166.51, 147.97, 140.68, 139.18, 137.76, 137.46, 131.84, 127.60, 125.61, 124.12, 119.81, 119.74, 92.21, 8.67, and 8.45; IR (neat) 2972, 2751, 1608, 1579, 1566, 1548, 1456, 1415, 1371, 1334, 1310, 1261, 1214, 1181, 1164, $1149,1092,1052,1033,1011,982,948,911,896,871,831,798,756,732,704,681,657,645$, 630, 613, 577, and $537 \mathrm{~cm}^{-1}$; HRMS calculated for $\mathrm{C}_{18} \mathrm{H}_{13} \mathrm{~N}_{2} \mathrm{O}_{3} \mathrm{SCll}$ [M-H] 498.9380; found 498.9380; Purity: 92\%. 


\section{N-(2,2-difluoro-1,3-benzodioxol-5-yl)-4-(2-cyclopropyl-5-oxazolyl)-benzenesulfonamide} (50):<smiles>O=S(=O)(Cl)c1ccc(-c2cnc(C3CC3)o2)cc1</smiles>

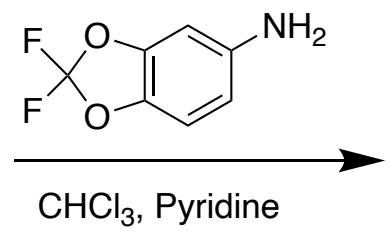

$0{ }^{\circ} \mathrm{C}$ to R.T.<smiles>O=S(=O)(Nc1ccc2c(c1)OC(F)(F)O2)c1ccc(-c2cnc(C3CC3)o2)cc1</smiles>

$76 \%$

White foam, prepared in 76\% yield $(1.34 \mathrm{mmol}, 0.562 \mathrm{~g})$ from the reaction of 5-amino-2,2difluoro-1,3-benzodioxole $(1.76 \mathrm{mmol}, 0.305 \mathrm{~g})$ with $11(1.76 \mathrm{mmol}, 0.500 \mathrm{~g})$ via general procedure A, crude product was purified by column chromatography $\left(\mathrm{SiO}_{2}\right.$, gradient, $1 \%$ to $\left.2 \% \mathrm{DCM}: \mathrm{MeOH}\right)$. $\mathrm{R}_{\mathrm{f}}=0.4\left(5 \%\right.$ DCM:MeOH); M.P. $=58-60{ }^{\circ} \mathrm{C} ;{ }^{1} \mathrm{H}$ NMR $\left(400 \mathrm{MHz}, \mathrm{CDCl}_{3}\right) \delta 8.03(\mathrm{~s}, 1 \mathrm{H}), 7.78(\mathrm{dd}, J$ $=6.9,1.6 \mathrm{~Hz}, 2 \mathrm{H}), 7.62(\mathrm{dd}, J=6.9,1.8 \mathrm{~Hz}, 2 \mathrm{H}), 7.31(\mathrm{~s}, 1 \mathrm{H}), 7.00(\mathrm{~d}, J=2.1 \mathrm{~Hz}, 1 \mathrm{H}), 6.87(\mathrm{~d}, J$ $=8.5 \mathrm{~Hz}, 1 \mathrm{H}), 6.74(\mathrm{dd}, J=8.6,2.2 \mathrm{~Hz}, 1 \mathrm{H}), 2.09-2.16(\mathrm{~m}, 1 \mathrm{H})$, and 1.08-1.16 $(\mathrm{m}, 4 \mathrm{H}) ;{ }^{13} \mathrm{C} \mathrm{NMR}$ $\left(101 \mathrm{MHz}, \mathrm{CDCl}_{3}\right) \delta 167.49,148.50,144.08,141.72,137.22,132.52$ (d, $\left.J=21.3 \mathrm{~Hz}\right), 131.77$, 129.22, 128.06, 124.79, 124.12, 118.06, 109.76, 105.54, 9.23, and 8.98; IR (neat) 3074, 1608, $1568,1557,1494,1411,1350,1323,1235,1147,1092,1061,1036,962,945,892,815,746,721$, $705,664,635,606,587$, and $548 \mathrm{~cm}^{-1}$; HRMS calculated for $\mathrm{C}_{19} \mathrm{H}_{13} \mathrm{~N}_{2} \mathrm{O}_{5} \mathrm{SF}_{2}[\mathrm{M}-\mathrm{H}]^{-}$419.0513; found 419.0513; Purity: 91\%.

\section{N-(3,5-dichlorophenyl)-4-(2-cyclopropyl-5-oxazolyl)-benzenesulfonamide (51):}<smiles>O=S(=O)(Cl)c1ccc(-c2cnc(C3CC3)o2)cc1</smiles><smiles>Nc1cc(Cl)cc(Cl)c1</smiles><smiles>O=[W][Mg]S(=O)(=O)c1ccc(-c2cnc(C3CC3)o2)cc1</smiles>

Light gray solid, prepared in $74 \%$ yield $(1.31 \mathrm{mmol}, 0.535 \mathrm{~g})$ from the reaction of $3,5-$ dichloroaniline $(1.76 \mathrm{mmol}, 0.285 \mathrm{~g})$ with $11(1.76 \mathrm{mmol}, 0.500 \mathrm{~g})$ via general procedure $\mathrm{A}$, crude 
product was purified by column chromatography $\left(\mathrm{SiO}_{2}\right.$, gradient, $1 \%$ to $\left.5 \% \mathrm{DCM}: \mathrm{MeOH}\right)$. $\mathrm{R}_{\mathrm{f}}=0.3$ (5\% DCM:MeOH); M.P. = 183-185 ${ }^{\circ} \mathrm{C} ;{ }^{1} \mathrm{H}$ NMR (400 MHz, DMSO-d6) $\delta 10.92(\mathrm{~s}, 1 \mathrm{H}), 7.81-7.86$ $(\mathrm{m}, 4 \mathrm{H}), 7.67(\mathrm{~s}, 1 \mathrm{H}), 7.24(\mathrm{t}, J=1.8 \mathrm{~Hz}, 1 \mathrm{H}), 7.10(\mathrm{~d}, J=1.6 \mathrm{~Hz}, 2 \mathrm{H}), 2.12-2.19(\mathrm{~m}, 1 \mathrm{H})$, and 0.991.10 (m, 4H); ${ }^{13} \mathrm{C}$ NMR (101 MHz, DMSO-d 6 ) $\delta$ 166.55, 147.94, 140.22, 137.31, 134.60, 131.99, $127.61,125.70,124.18,123.40,117.46,8.67$, and 8.46; IR (neat) 3089, 2872, 1615, 1578, 1560, $1489,1434,1414,1383,1344,1330,1290,1239,1186,1165,1119,1108,1093,1068,1048$, 1036, 1016, 978, 959, 947, 876, 855, 838, 820, 801, 761, 732, 683, 638, 605, 564, and $544 \mathrm{~cm}^{-1}$; HRMS calculated for $\mathrm{C}_{18} \mathrm{H}_{13} \mathrm{~N}_{2} \mathrm{O}_{3} \mathrm{SCl}_{2}$ [M-H]- 407.0024; found 407.0036; Purity: $90 \%$.

\section{$N$-(3,5-dichloro-4-fluorophenyl)-4-(2-cyclopropyl-5-oxazolyl)-benzenesulfonamide (52):}<smiles>O=S(=O)(Cl)c1ccc(-c2cnc(C3CC3)o2)cc1</smiles><smiles>Nc1cc(Cl)c(F)c(Cl)c1</smiles><smiles>O=S(=O)(Nc1cc(Cl)c(F)c(Cl)c1)c1ccc(-c2cnc(C3CC3)o2)cc1</smiles>

White solid, prepared in $76 \%$ yield $(1.34 \mathrm{mmol}, 0.574 \mathrm{~g})$ from the reaction of 3,5-dichloro4-fluoroaniline $(1.76 \mathrm{mmol}, 0.32 \mathrm{~g})$ with $11(1.76 \mathrm{mmol}, 0.500 \mathrm{~g})$ via general procedure $\mathrm{A}$, crude product was purified by column chromatography $\left(\mathrm{SiO}_{2}\right.$, gradient, $1 \%$ to $\left.5 \% \mathrm{DCM}: \mathrm{MeOH}\right)$. $\mathrm{R}_{\mathrm{f}}=0.35$ (5\% DCM:MeOH); M.P. = 198-199 ${ }^{\circ} \mathrm{C}$ (decomposed); ${ }^{1} \mathrm{H}$ NMR $\left(400 \mathrm{MHz}, \mathrm{DMSO}-d_{6}\right) \delta 10.77$ (s, 1H), 7.80-7.84 (m, 4H), $7.67(\mathrm{~s}, 1 \mathrm{H}), 7.20(\mathrm{~d}, J=5.7 \mathrm{~Hz}, 2 \mathrm{H}), 2.11-2.17(\mathrm{~m}, 1 \mathrm{H})$, and 0.99-1.09 (m, 4H); ${ }^{13} \mathrm{C}$ NMR (101 MHz, DMSO- $\left.d_{6}\right) \delta$ 166.55, 150.11 (d, $\left.J=246.7 \mathrm{~Hz}\right), 147.96,137.19,135.01$ (d, $J=3.8 \mathrm{~Hz}), 131.96,127.64,125.68,124.15,121.51(\mathrm{~d}, J=18.4 \mathrm{~Hz}), 120.33,8.67$, and 8.46; IR (neat) $3081,2899,1610,1589,1567,1556,1478,1462,1410,1377,1337,1300,1269,1217$, 1202, 1185, 1164, 1134, 1095, 1063, 1028, 1015, 972, 944, 908, 873, 825, 814, 796, 748, 730, $718,703,647,627,607,590,555,541$, and $526 \mathrm{~cm}^{-1}$; HRMS calculated for $\mathrm{C}_{18} \mathrm{H}_{12} \mathrm{~N}_{2} \mathrm{O}_{3} \mathrm{SCl}_{2} \mathrm{~F}$ [MH] 424.9930; found 424.9954; Purity: 94\%. 
N-(4-iodo-3-methylphenyl)-4-(2-cyclopropyl-5-oxazolyl)-benzenesulfonamide (53):<smiles>O=S(=O)(Cl)c1ccc(-c2cnc(C3CC3)o2)cc1</smiles>

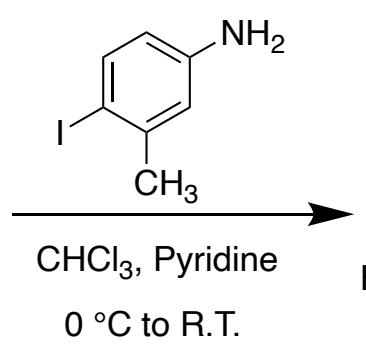

$0{ }^{\circ} \mathrm{C}$ to R.T.<smiles>Cc1cc(NS(=O)(=O)c2ccc(-c3cnc(C4CC4)o3)cc2)ccc1I</smiles>

$63 \%$

Off-white solid, prepared in $63 \%$ yield $(1.12 \mathrm{mmol}, 0.536 \mathrm{~g})$ from the reaction of 4-iodo-3methylaniline $(1.76 \mathrm{mmol}, 0.410 \mathrm{~g})$ with $11(1.76 \mathrm{mmol}, 0.500 \mathrm{~g})$ via general procedure $\mathrm{A}$, crude product was purified by column chromatography $\left(\mathrm{SiO}_{2}\right.$, gradient, $1 \%$ to $\left.2 \% \mathrm{DCM}: \mathrm{MeOH}\right)$. $\mathrm{R}_{\mathrm{f}}=0.35$ (5\% DCM:MeOH); M.P. $=166-168{ }^{\circ} \mathrm{C} ;{ }^{1} \mathrm{H}$ NMR $\left(400 \mathrm{MHz}, \mathrm{CDCl}_{3}\right) \delta 7.79(\mathrm{~d}, \mathrm{~J}=6.9 \mathrm{~Hz}, 2 \mathrm{H}), 7.61$ (d, $J=8.5 \mathrm{~Hz}, 3 \mathrm{H}), 7.36(\mathrm{~s}, 1 \mathrm{H}), 7.30(\mathrm{~s}, 1 \mathrm{H}), 7.00(\mathrm{~d}, J=2.5 \mathrm{~Hz}, 1 \mathrm{H}), 6.65(\mathrm{dd}, J=8.5,2.5 \mathrm{~Hz}$, 1H), $2.32(\mathrm{~s}, 3 \mathrm{H}), 2.11-2.16(\mathrm{~m}, 1 \mathrm{H})$, and 1.10-1.15 (m, 4H); ${ }^{13} \mathrm{C}$ NMR $\left(101 \mathrm{MHz}, \mathrm{CDCl}_{3}\right) \delta 167.42$, $148.56,142.87,139.72,137.53,136.71,132.57,128.04,124.75,124.09,122.75,120.43,96.61$, 28.26, 9.25, and 9.00; IR (neat) 3014, 1608, 1590, 1570, 1467, 1411, 1374, 1333, 1284, 1230, 1190, 1169, 1158, 1127, 1093, 1061, 1015, 980, 946, 875, 848, 829, 812, 783, 750, 734, 718, 697, $642,629,606,572,545$, and $535 \mathrm{~cm}^{-1}$; HRMS calculated for $\mathrm{C}_{19} \mathrm{H}_{16} \mathrm{~N}_{2} \mathrm{O}_{3} \mathrm{SI}$ [M-H] 478.9926 ; found 478.9944; Purity: 90\%.

\section{N-(1,3-benzodioxol-5-yl)-4-(2-cyclopropyl-5-oxazolyl)-benzenesulfonamide (54):}<smiles>O=S(=O)(Cl)c1ccc(-c2cnc(C3CC3)o2)cc1</smiles><smiles>Nc1ccc2c(c1)OCO2</smiles><smiles>O=S(=O)(Nc1ccc2c(c1)OCO2)c1ccc(-c2cnc(C3CC3)o2)cc1</smiles>

$68 \%$

Light brown solid, prepared in $68 \%$ yield $(1.27 \mathrm{mmol}, 0.487 \mathrm{~g})$ from the reaction of 3,4methylenedioxyaniline $(1.76 \mathrm{mmol}, 0.241 \mathrm{~g})$ with $11(1.76 \mathrm{mmol}, 0.500 \mathrm{~g})$ via general procedure $\mathrm{A}$, crude product was purified by column chromatography $\left(\mathrm{SiO}_{2}\right.$, gradient, $1 \%$ to $\left.2 \% \mathrm{DCM}: \mathrm{MeOH}\right)$. $\mathrm{R}_{\mathrm{f}}$ 
$=0.4\left(5 \%\right.$ DCM:MeOH); M.P. $=165-167{ }^{\circ} \mathrm{C} ;{ }^{1} \mathrm{H}$ NMR $\left(400 \mathrm{MHz}, \mathrm{CDCl}_{3}\right) \delta 7.75(\mathrm{~d}, J=8.7 \mathrm{~Hz}, 2 \mathrm{H})$, 7.59 (d, J = 8.7 Hz, 2H), 7.47 (s, 1H), $7.29(\mathrm{~s}, 1 \mathrm{H}), 6.71(\mathrm{~d}, J=2.1 \mathrm{~Hz}, 1 \mathrm{H}), 6.61$ (d, J = $8.5 \mathrm{~Hz}$, 1H), $6.46(\mathrm{dd}, J=10.5,2.3 \mathrm{~Hz}, 1 \mathrm{H}), 5.91(\mathrm{~s}, 2 \mathrm{H}), 2.09-2.16(\mathrm{~m}, 1 \mathrm{H})$, and 1.07-1.16 $(\mathrm{m}, 4 \mathrm{H}) ;{ }^{13} \mathrm{C}$ $\operatorname{NMR}\left(101 \mathrm{MHz}, \mathrm{CDCl}_{3}\right) \delta 167.28,148.65,148.16,146.08,137.59,132.26,130.07,128.11,124.57$, 123.92, 117.04, 108.34, 105.66, 101.64, 9.21, and 8.91; IR (neat) 3017, 1609, 1571, 1558, 1504 , 1483, 1413, 1346, 1326, 1242, 1187, 1161, 1124, 1094, 1061, 1034, 981, 945, 929, 894, 857, 811, 798, 756, 734, 721, 712, 651, 629, 616, 604, 588, 566, 553, and $533 \mathrm{~cm}^{-1}$; HRMS calculated for $\mathrm{C}_{19} \mathrm{H}_{15} \mathrm{~N}_{2} \mathrm{O}_{5} \mathrm{~S}[\mathrm{M}-\mathrm{H}]^{-383.0702 ; ~ f o u n d ~ 383.0702 ; ~ P u r i t y: ~ 92 \% . ~}$

\section{N-(3-chloro-5-methylphenyl)-4-(2-cyclopropyl-5-oxazolyl)-benzenesulfonamide (55):}<smiles>O=S(=O)(Cl)c1ccc(-c2cnc(C3CC3)o2)cc1</smiles><smiles>Cc1cc(N)cc(Cl)c1</smiles>

$0{ }^{\circ} \mathrm{C}$ to R.T.<smiles>Cc1cc(Cl)cc(NS(=O)(=O)c2ccc(-c3cnc(C4CC4)o3)cc2)c1</smiles>

Light tan solid, prepared in $76 \%$ yield $(1.34 \mathrm{mmol}, 0.521 \mathrm{~g})$ from the reaction of 3-chloro5-methylaniline $(1.76 \mathrm{mmol}, 0.250 \mathrm{~g})$ with $11(1.76 \mathrm{mmol}, 0.500 \mathrm{~g})$ via general procedure $\mathrm{A}$, crude product was purified by column chromatography $\left(\mathrm{SiO}_{2}\right.$, gradient, $1 \%$ to $\left.2 \% \mathrm{DCM}: \mathrm{MeOH}\right)$. $\mathrm{R}_{\mathrm{f}}=0.3$ (5\% DCM:MeOH); M.P. = 190-191 ${ }^{\circ} \mathrm{C} ;{ }^{1} \mathrm{H}$ NMR (400 MHz, DMSO-d6) $\delta 10.56$ (s, 1H), 7.78-7.84 (m, 4H), $7.65(\mathrm{~s}, 1 \mathrm{H}), 6.94(\mathrm{~d}, J=1.8 \mathrm{~Hz}, 1 \mathrm{H}), 6.90$ (d, $J=7.5 \mathrm{~Hz}, 2 \mathrm{H}), 2.13-2.18(\mathrm{~m}, 4 \mathrm{H})$, and 0.99-1.09 (m, 4H); ${ }^{13} \mathrm{C}$ NMR (101 MHz, DMSO-d 6 ) $\delta$ 166.48, 148.03, 140.99, 138.98, 137.77, $133.17,131.71,127.60,125.52,124.05,118.87,116.56,115.90,20.83,8.68$, and 8.45; IR (neat) 2886, 1614, 1602, 1582, 1560, 1500, 1456, 1413, 1341, 1290, 1265, 1186, 1167, 1153, 1118, 1094, 1068, 1048, 1036, 1018, 977, 947, 925, 883, 874, 839, 823, 760, 732, 690, 664, 644, 605, 567, 542, and $530 \mathrm{~cm}^{-1}$; HRMS calculated for $\mathrm{C}_{19} \mathrm{H}_{16} \mathrm{~N}_{2} \mathrm{O}_{3} \mathrm{SCl}$ [M-H]- 387.0570; found 387.0570; Purity: 91\%. 
N-(3-fluoro-5-methylphenyl)-4-(2-cyclopropyl-5-oxazolyl)-benzenesulfonamide (56):<smiles>O=S(=O)(Cl)c1ccc(-c2cnc(C3CC3)o2)cc1</smiles><smiles>Cc1cc(N)cc(F)c1</smiles>

$0{ }^{\circ} \mathrm{C}$ to R.T.<smiles>Cc1cc(F)cc(NS(=O)(=O)c2ccc(-c3cnc(C4CC4)o3)cc2)c1</smiles>

Light orange foam, prepared in $79 \%$ yield $(1.39 \mathrm{mmol}, 0.516 \mathrm{~g})$ from the reaction of 3 fluoro-5-methylaniline $(1.76 \mathrm{mmol}, 0.250 \mathrm{~g})$ with $11(1.76 \mathrm{mmol}, 0.500 \mathrm{~g})$ via general procedure A, crude product was purified by column chromatography $\left(\mathrm{SiO}_{2}\right.$, gradient, $1 \%$ to $\left.2 \% \mathrm{DCM}: \mathrm{MeOH}\right)$. $\mathrm{R}_{\mathrm{f}}$ $=0.4\left(5 \%\right.$ DCM:MeOH); M.P. $=68-69{ }^{\circ} \mathrm{C} ;{ }^{1} \mathrm{H}$ NMR $\left(400 \mathrm{MHz}, \mathrm{CDCl}_{3}\right) \delta 7.83(\mathrm{~d}, \mathrm{~J}=8.7 \mathrm{~Hz}, 2 \mathrm{H})$, $7.63(\mathrm{~d}, J=8.7 \mathrm{~Hz}, 2 \mathrm{H}), 7.39(\mathrm{~s}, 1 \mathrm{H}), 7.31(\mathrm{~s}, 1 \mathrm{H}), 6.73(\mathrm{dt}, J=9.9,2.0 \mathrm{~Hz}, 1 \mathrm{H}), 6.65(\mathrm{~s}, 1 \mathrm{H}), 6.61$ $(\mathrm{d}, J=9.1 \mathrm{~Hz}, 1 \mathrm{H}), 2.24(\mathrm{~s}, 3 \mathrm{H}), 2.10-2.17(\mathrm{~m}, 1 \mathrm{H})$, and 1.09-1.17 (m, 4H); ${ }^{13} \mathrm{C}$ NMR $(101 \mathrm{MHz}$, $\left.\mathrm{CDCl}_{3}\right) \delta 167.46,163.04$ (d, $\left.J=246.7 \mathrm{~Hz}\right), 148.60,141.56$ (d, $\left.J=9.7 \mathrm{~Hz}\right), 137.68$ (d, $\left.J=15.5 \mathrm{~Hz}\right)$, 132.57, 128.09, 124.78, 124.12, 117.18, 113.06, 112.88, 105.27, 21.49, 9.24, and 9.05; IR (neat) $3088,1621,1604,1568,1556,1472,1410,1325,1167,1150,1130,1092$, 1061, 1035, 970, 945 , $873,833,745,722,660,629,603$, and $565 \mathrm{~cm}^{-1}$; HRMS calculated for $\mathrm{C}_{19} \mathrm{H}_{16} \mathrm{~N}_{2} \mathrm{O}_{3} \mathrm{SF}$ [M-H] 371.0866; found 371.0866; Purity: 94\%.

\section{N-(2-chloro-4-iodophenyl)-4-(2-cyclopropyl-5-oxazolyl)-benzenesulfonamide (57):}<smiles>O=S(=O)(Cl)c1ccc(-c2cnc(C3CC3)o2)cc1</smiles><smiles>Nc1ccc(I)cc1Cl</smiles><smiles>O=S(=O)(Nc1ccc(I)cc1Cl)c1ccc(-c2cnc(C3CC3)o2)cc1</smiles>

Off-white foam, prepared in $48 \%$ yield $(0.853 \mathrm{mmol}, 0.427 \mathrm{~g})$ from the reaction of 2-chloro4-iodoaniline (1.76 mmol, $0.250 \mathrm{~g})$ with $11(1.76 \mathrm{mmol}, 0.500 \mathrm{~g})$ via general procedure $A$, crude product was purified by column chromatography $\left(\mathrm{SiO}_{2}\right.$, gradient, $1 \%$ to $\left.5 \% \mathrm{DCM}: \mathrm{MeOH}\right) \cdot \mathrm{R}_{\mathrm{f}}=035$ 
(5\% DCM:MeOH); M.P. = 62-63 ${ }^{\circ} \mathrm{C} ;{ }^{1} \mathrm{H}$ NMR $\left(400 \mathrm{MHz}, \mathrm{CDCl}_{3}\right) \delta 7.75(\mathrm{~d}, J=8.5 \mathrm{~Hz}, 2 \mathrm{H}), 7.61$ (d, $J=8.7 \mathrm{~Hz}, 2 \mathrm{H}), 7.52-7.57(\mathrm{~m}, 2 \mathrm{H}), 7.41(\mathrm{~d}, J=8.5 \mathrm{~Hz}, 1 \mathrm{H}), 7.31(\mathrm{~s}, 1 \mathrm{H}), 7.06(\mathrm{~s}, 1 \mathrm{H}), 2.11-2.18$ $(\mathrm{m}, 1 \mathrm{H})$, and 1.10-1.18 $(\mathrm{m}, 4 \mathrm{H}) ;{ }^{13} \mathrm{C}$ NMR $\left(101 \mathrm{MHz}, \mathrm{CDCl}_{3}\right) \delta 167.47,148.44,137.74,137.22$ $133.24,132.90,128.69,128.47,128.04,126.42,124.37,124.07,88.96,9.22$, and 8.97; IR (neat) 2922, 1607, 1567, 1557, 1472, 1411, 1372, 1336, 1225, 1162, 1128, 1093, 1054, 1011, 967, 944, $912,828,745,720,647,606,568,545$, and $533 \mathrm{~cm}^{-1} ;$ HRMS calculated for $\mathrm{C}_{18} \mathrm{H}_{13} \mathrm{~N}_{2} \mathrm{O}_{3} \mathrm{SCII}[\mathrm{M}-\mathrm{H}]^{-}$ 498.9380; found 498.9380; Purity: 90\%.

\section{$N$-(1-naphthyl)-4-(2-cyclopropyl-5-oxazolyl)-benzenesulfonamide (58):}

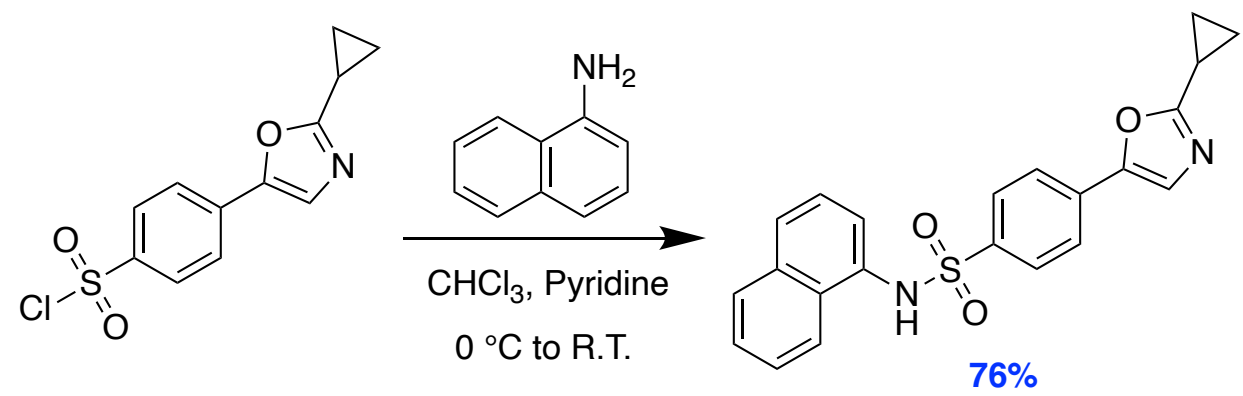

Tan foam, prepared in $76 \%$ yield $(1.34 \mathrm{mmol}, 0.524 \mathrm{~g})$ from the reaction of 1-naphthylamine $(1.76 \mathrm{mmol}, 0.252 \mathrm{~g})$ with $11(1.76 \mathrm{mmol}, 0.500 \mathrm{~g})$ via general procedure $\mathrm{A}$, crude product was purified by column chromatography $\left(\mathrm{SiO}_{2}\right.$, gradient, $1 \%$ to $\left.2 \% \mathrm{DCM}: \mathrm{MeOH}\right) . \mathrm{R}_{\mathrm{f}}=0.4(5 \%$ DCM:MeOH); M.P. $=65-66{ }^{\circ} \mathrm{C} ;{ }^{1} \mathrm{H}$ NMR $\left(400 \mathrm{MHz}, \mathrm{CDCl}_{3}\right) \delta 7.89(\mathrm{~d}, \mathrm{~J}=8.0 \mathrm{~Hz}, 1 \mathrm{H}), 7.71-7.81$ (m, 4H), $7.60(\mathrm{~s}, 1 \mathrm{H}), 7.51(\mathrm{~d}, J=8.5 \mathrm{~Hz}, 2 \mathrm{H}), 7.34-7.45(\mathrm{~m}, 4 \mathrm{H}), 7.24(\mathrm{~s}, 1 \mathrm{H}), 2.07-2.13(\mathrm{~m}, 1 \mathrm{H})$, and 1.05-1.14; $(\mathrm{m}, 4 \mathrm{H}){ }^{13} \mathrm{C}$ NMR $\left(101 \mathrm{MHz}, \mathrm{CDCl}_{3}\right) \delta$ 167.25, 148.60, 138.19, 134.34, 132.19, $131.33,129.25,128.49,128.10,127.61,126.82,126.46,125.52,124.49,123.86,123.44,121.77$ 9.19, and 8.93; IR (neat) $3057,1607,1568,1557,1511,1456,1410,1345,1318,1264,1154$, 1092, 1060, 1016, 968, 944, 919, 830, 799, 774, 746, 720, 653, 603, 564, and $544 \mathrm{~cm}^{-1}$; HRMS calculated for $\mathrm{C}_{22} \mathrm{H}_{19} \mathrm{~N}_{2} \mathrm{O}_{3} \mathrm{~S}[\mathrm{M}+\mathrm{H}]^{+} 391.1116$ found 391.1120; Purity: 95\%. 


\section{$N$-(4-acetylphenyl)-4-(2-cyclopropyl-5-oxazolyl)-benzenesulfonamide (59):}<smiles>O=S(=O)(Cl)c1ccc(-c2cnc(C3CC3)o2)cc1</smiles><smiles>CC(=O)c1ccc(N)cc1</smiles><smiles>CC(=O)c1ccc(NS(=O)(=O)c2ccc(-c3cnc(C4CC4)o3)cc2)cc1</smiles>

Off-white foam, prepared in $82 \%$ yield $(1.45 \mathrm{mmol}, 0.554 \mathrm{~g})$ from the reaction of 4 aminoacetophenone $(1.76 \mathrm{mmol}, 0.238 \mathrm{~g})$ with $11(1.76 \mathrm{mmol}, 0.500 \mathrm{~g})$ via general procedure $\mathrm{A}$, crude product was purified by column chromatography $\left(\mathrm{SiO}_{2}\right.$, gradient, $1 \%$ to $\left.2 \% \mathrm{DCM}: \mathrm{MeOH}\right)$. $\mathrm{R}_{\mathrm{f}}$ $=0.35$ (5\% DCM:MeOH); M.P. = 62-64 ${ }^{\circ} \mathrm{C} ;{ }^{1} \mathrm{H}$ NMR $\left(400 \mathrm{MHz}, \mathrm{CDCl}_{3}\right) \delta 8.18(\mathrm{~s}, 1 \mathrm{H}), 7.85(\mathrm{t}, \mathrm{J}=$ $8.7 \mathrm{~Hz}, 4 \mathrm{H}), 7.61(\mathrm{~d}, J=8.5 \mathrm{~Hz}, 2 \mathrm{H}), 7.30(\mathrm{~s}, 1 \mathrm{H}), 7.21(\mathrm{~d}, J=8.7 \mathrm{~Hz}, 2 \mathrm{H}), 2.52(\mathrm{~s}, 3 \mathrm{H}), 2.10-2.16$ $(\mathrm{m}, 1 \mathrm{H})$, and 1.09-1.14 (m, 4H); ${ }^{13} \mathrm{C}$ NMR $\left(101 \mathrm{MHz}, \mathrm{CDCl}_{3}\right) \delta$ 197.16, 167.53, 148.47, 141.29, $137.55,133.40,132.69,130.15,128.05,124.74,124.17,119.22,26.56,9.22$, and 9.06; IR (neat) $3115,2922,1676,1599,1568,1555,1509,1465,1409,1358,1304,1269,1236,1184,1156$, 1091, 1060, 1013, 963, 945, 914, 827, 744, 720, 656, 634, 596, and $560 \mathrm{~cm}^{-1}$; HRMS calculated for $\mathrm{C}_{20} \mathrm{H}_{19} \mathrm{~N}_{2} \mathrm{O}_{4} \mathrm{~S}[\mathrm{M}+\mathrm{H}]^{+} 383.1065$ found 383.1065; Purity: 96\%.

\section{$N$-(4-fluorophenyl)-N-methyl-4-(2-cyclopropyl-5-oxazolyl)-benzenesulfonamide (60):}<smiles>CNc1ccc(F)cc1C(=O)OCc1ccc(F)cc1</smiles>

Light yellow oil, prepared in $65 \%$ yield $(1.15 \mathrm{mmol}, 0.427 \mathrm{~g})$ from the reaction of 4 -fluoro$\mathrm{N}$-methylaniline $(1.76 \mathrm{mmol}, 0.220 \mathrm{~g})$ with $11(1.76 \mathrm{mmol}, 0.500 \mathrm{~g})$ via general procedure $\mathrm{A}$, crude product was purified by column chromatography $\left(\mathrm{SiO}_{2}\right.$, gradient, $1 \%$ to $\left.2 \% \mathrm{DCM}: \mathrm{MeOH}\right)$. $\mathrm{R}_{\mathrm{f}}=0.6$ 
(5\% DCM:MeOH); ${ }^{1} \mathrm{H}$ NMR (400 MHz, $\left.\mathrm{CDCl}_{3}\right) \delta 7.64$ (d, J = $\left.8.5 \mathrm{~Hz}, 2 \mathrm{H}\right), 7.54$ (d, J = $\left.8.5 \mathrm{~Hz}, 2 \mathrm{H}\right)$, $7.33(\mathrm{~s}, 1 \mathrm{H}), 7.04-7.08(\mathrm{~m}, 2 \mathrm{H}), 6.96-7.01(\mathrm{~m}, 2 \mathrm{H}), 3.17(\mathrm{~s}, 3 \mathrm{H}), 2.11-2.18(\mathrm{~m}, 1 \mathrm{H}), 1.10-1.19(\mathrm{~m}$, 4H) ${ }^{13} \mathrm{C} \mathrm{NMR}\left(101 \mathrm{MHz}, \mathrm{CDCl}_{3}\right) \delta 167.43,161.72(\mathrm{~d}, J=248.8 \mathrm{~Hz}), 148.70,137.35(\mathrm{~d}, J=2.8 \mathrm{~Hz})$, 134.97, 132.35, 128.70, 128.61, 124.56, 123.80, 116.00 (d, $J=23.2 \mathrm{~Hz}), 38.49,9.25$, and 9.04; IR (neat) $3015,1606,1587,1567,1554,1505,1410,1348,1220,1171,1149,1127,1090,1061$, 1014, 967, 943, 872, 835, 806, 747, 722, 662, 595, 560, and $545 \mathrm{~cm}^{-1}$; HRMS calculated for $\mathrm{C}_{19} \mathrm{H}_{18} \mathrm{~N}_{2} \mathrm{O}_{3} \mathrm{SF}[\mathrm{M}+\mathrm{H}]^{+} 373.1028$ found 373.1028; Purity: 94\%.

$N$-(4-chlorophenyl)-N-methyl-4-(2-cyclopropyl-5-oxazolyl)-benzenesulfonamide (61):

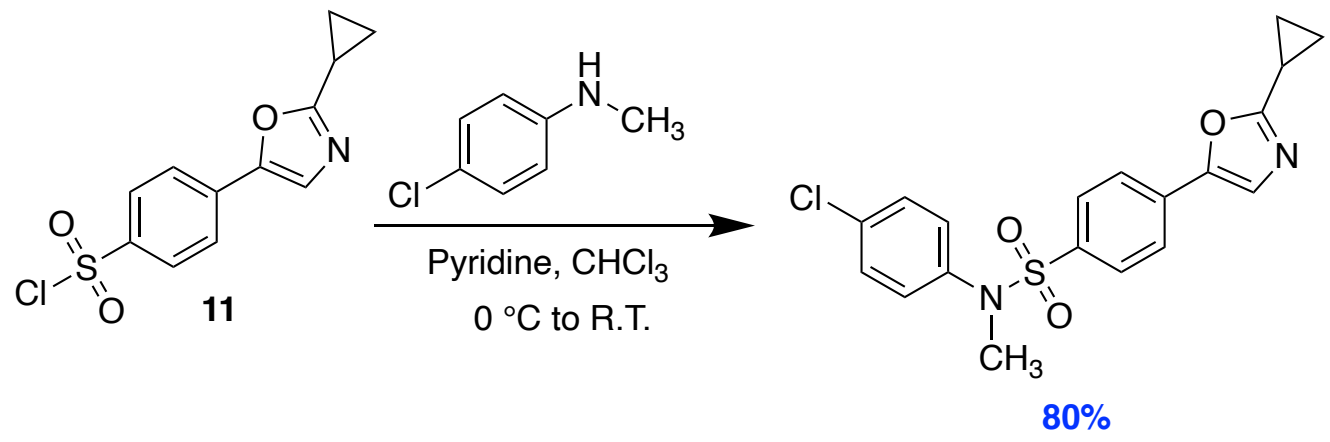

Off-white solid, prepared in $80 \%$ yield $(1.40 \mathrm{mmol}, 0.546 \mathrm{~g})$ from the reaction of 4-chloro$\mathrm{N}$-methylaniline $(1.76 \mathrm{mmol}, 0.250 \mathrm{~g})$ with $11(1.76 \mathrm{mmol}, 0.500 \mathrm{~g})$ via general procedure $\mathrm{A}$, crude product was purified by column chromatography $\left(\mathrm{SiO}_{2}\right.$, gradient, $1 \%$ to $\left.2 \% \mathrm{DCM}: \mathrm{MeOH}\right)$. $\mathrm{R}_{\mathrm{f}}=0.55$ (5\% DCM:MeOH); M.P. = 111-113 ${ }^{\circ} \mathrm{C} ;{ }^{1} \mathrm{H}$ NMR $\left(400 \mathrm{MHz}, \mathrm{CDCl}_{3}\right) \delta 7.62(\mathrm{dd}, J=6.7,1.7 \mathrm{~Hz}, 2 \mathrm{H})$, $7.51(\mathrm{dd}, J=6.9,1.6 \mathrm{~Hz}, 2 \mathrm{H}), 7.30(\mathrm{~s}, 1 \mathrm{H}), 7.25(\mathrm{dd}, J=6.7,1.9 \mathrm{~Hz}, 2 \mathrm{H}), 7.02(\mathrm{dd}, J=6.9,2.1 \mathrm{~Hz}$ 2H), 3.14 (s, 3H), 2.09-2.16 (m, 1H), and 1.07-1.16 (m, 4H); $\left.{ }^{13} \mathrm{C} \mathrm{NMR} \mathrm{(101} \mathrm{MHz,} \mathrm{CDCl}_{3}\right) \delta$ 167.44, $148.65,139.97,134.82,133.34,132.42,129.25,128.64,127.94,124.62,123.82,38.19,9.24$, and 9.02; IR (neat) 2925, 1610, 1589, 1574, 1556, 1489, 1463, 1411, 1350, 1321, 1296, 1265, 1174, $1157,1128,1087,1060,1032,1014,966,940,872,842,826,755,730,719,714,659,632,622$, 587, 557, 545, and $534 \mathrm{~cm}^{-1}$; HRMS calculated for $\mathrm{C}_{19} \mathrm{H}_{18} \mathrm{~N}_{2} \mathrm{O}_{3} \mathrm{SCl}[\mathrm{M}+\mathrm{H}]^{+}$389.0727; found 389.0727; Purity: 95\%. 
N-(4-bromophenyl)-N-methyl-4-(2-cyclopropyl-5-oxazolyl)-benzenesulfonamide (62):

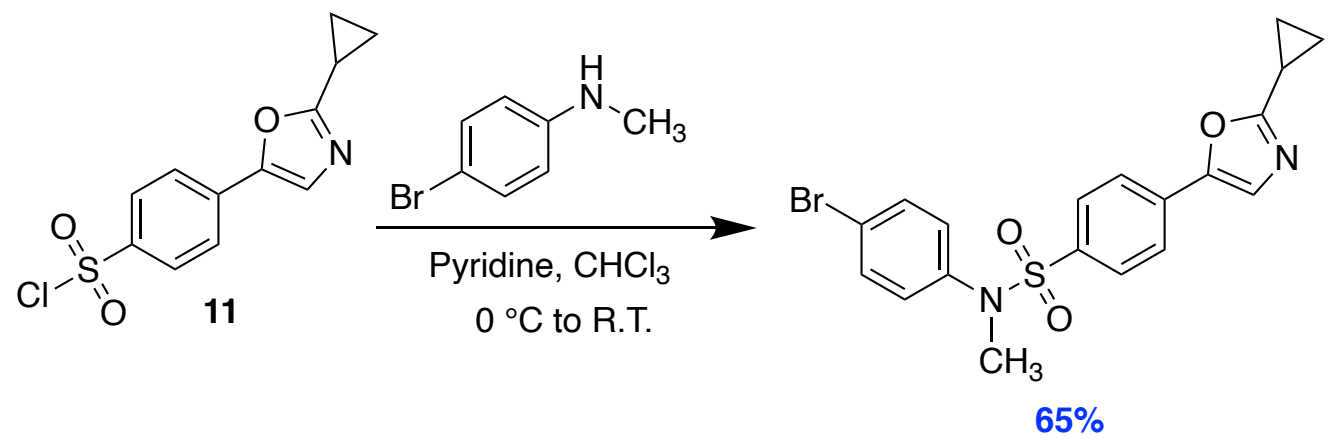

White solid, prepared in $65 \%$ yield $(1.14 \mathrm{mmol}, 0.495 \mathrm{~g})$ from the reaction of 4-bromo- $\mathrm{N}$ methylaniline $(1.76 \mathrm{mmol}, 0.250 \mathrm{~g})$ with $11(1.76 \mathrm{mmol}, 0.500 \mathrm{~g})$ via general procedure $A$, crude product was purified by column chromatography $\left(\mathrm{SiO}_{2}\right.$, gradient, $1 \%$ to $\left.2 \% \mathrm{DCM}: \mathrm{MeOH}\right)$. $\mathrm{R}_{\mathrm{f}}=0.6$ (5\% DCM:MeOH); M.P. = 140-142 ${ }^{\circ} \mathrm{C} ;{ }^{1} \mathrm{H}$ NMR $\left(400 \mathrm{MHz}, \mathrm{CDCl}_{3}\right) \delta 7.63(\mathrm{dd}, J=6.7,1.7 \mathrm{~Hz}, 2 \mathrm{H})$, $7.53(\mathrm{dd}, J=6.9,1.8 \mathrm{~Hz}, 2 \mathrm{H}), 7.42(\mathrm{dd}, J=6.6,2.1 \mathrm{~Hz}, 2 \mathrm{H}), 7.32(\mathrm{~s}, 1 \mathrm{H}), 6.97$ (dd, $J=6.6,2.1 \mathrm{~Hz}$, 2H), $3.15(\mathrm{~s}, 3 \mathrm{H}), 2.10-2.17(\mathrm{~m}, 1 \mathrm{H})$, and 1.09-1.18 $(\mathrm{m}, 4 \mathrm{H}) ;{ }^{13} \mathrm{C} \mathrm{NMR}\left(101 \mathrm{MHz}, \mathrm{CDCl}_{3}\right) \delta 167.38$, $148.59,140.50,134.71,132.45,132.20,128.60,128.22,124.75,123.79,121.29,38.09,9.23$, and 8.95; IR (neat) 2924, 1609, 1589, 1574, 1557, 1486, 1463, 1411, 1349, 1321, 1304, 1263, 1174 , $1157,1128,1090,1059,1033,1011,966,940,872,842,824,753,733,723,707,658,630,613$, 584, 556, and $526 \mathrm{~cm}^{-1}$; HRMS calculated for $\mathrm{C}_{19} \mathrm{H}_{18} \mathrm{~N}_{2} \mathrm{O}_{3} \mathrm{SBr}[\mathrm{M}+\mathrm{H}]^{+}$433.0221; found 433.0222; Purity: $97 \%$. 
Supporting Information<smiles>O=C(CBr)c1ccccc1</smiles>

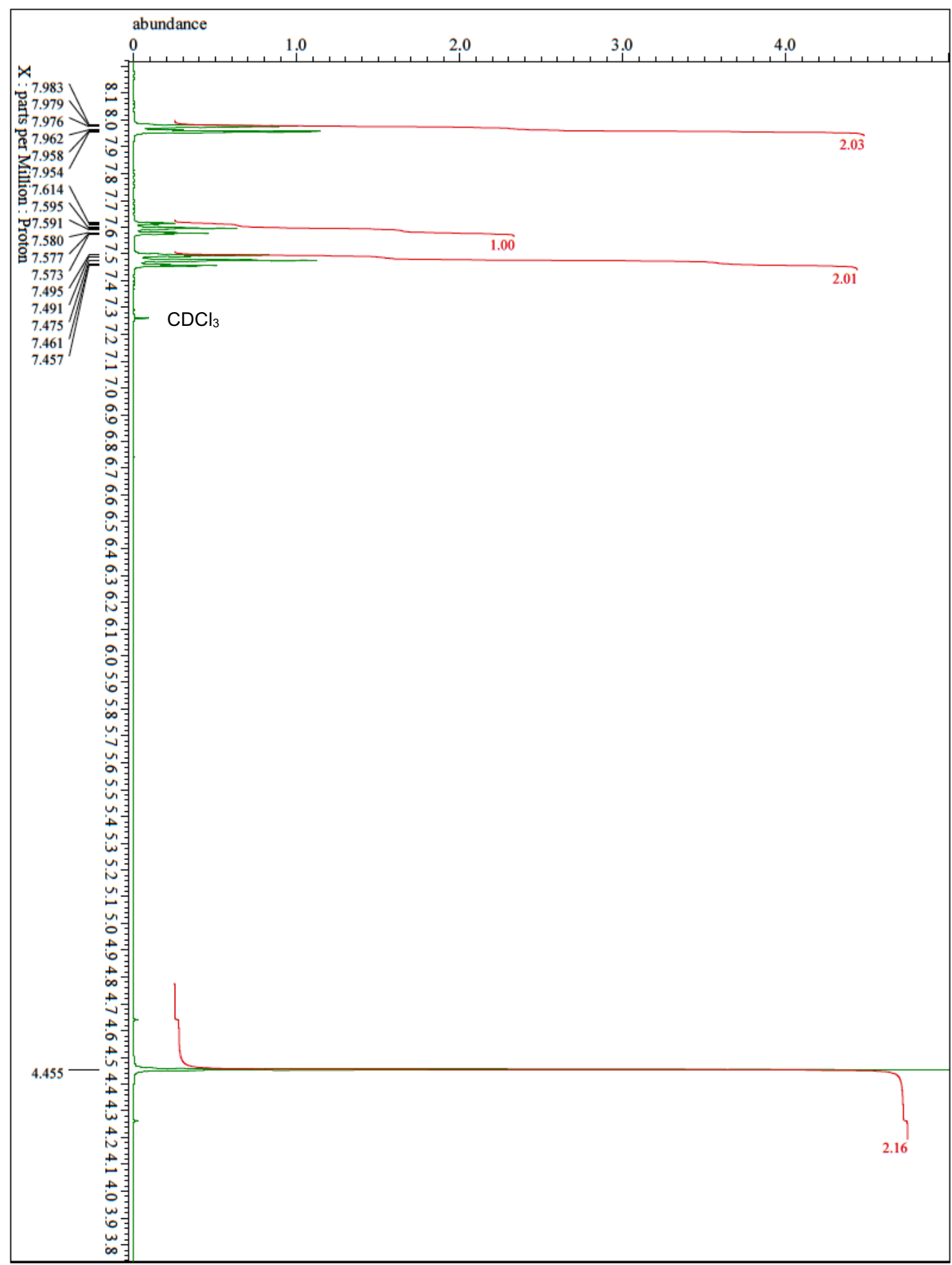


Supporting Information<smiles>O=C(CBr)c1ccccc1</smiles>

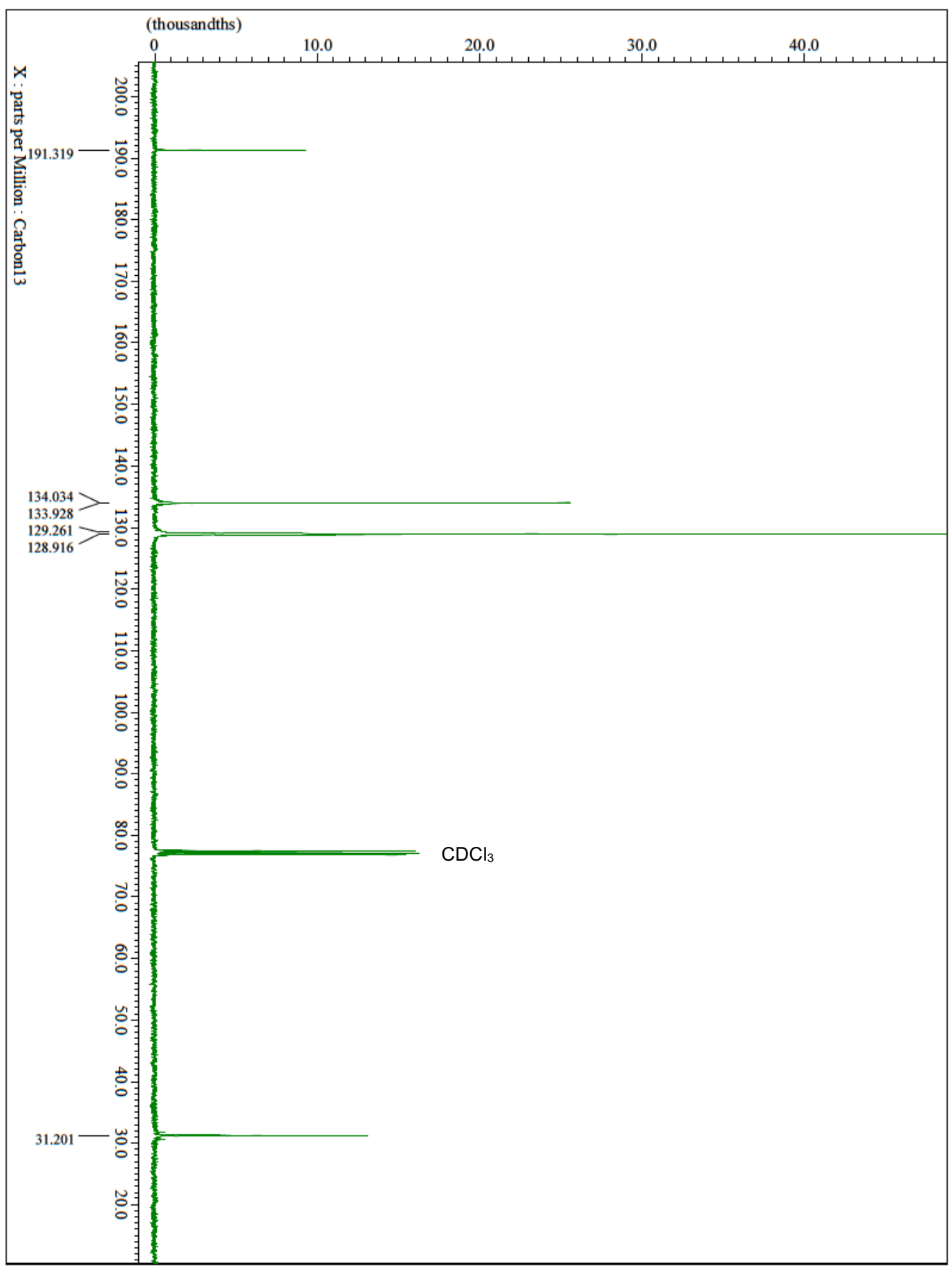


Supporting Information<smiles>NCC(=O)c1ccccc1</smiles>

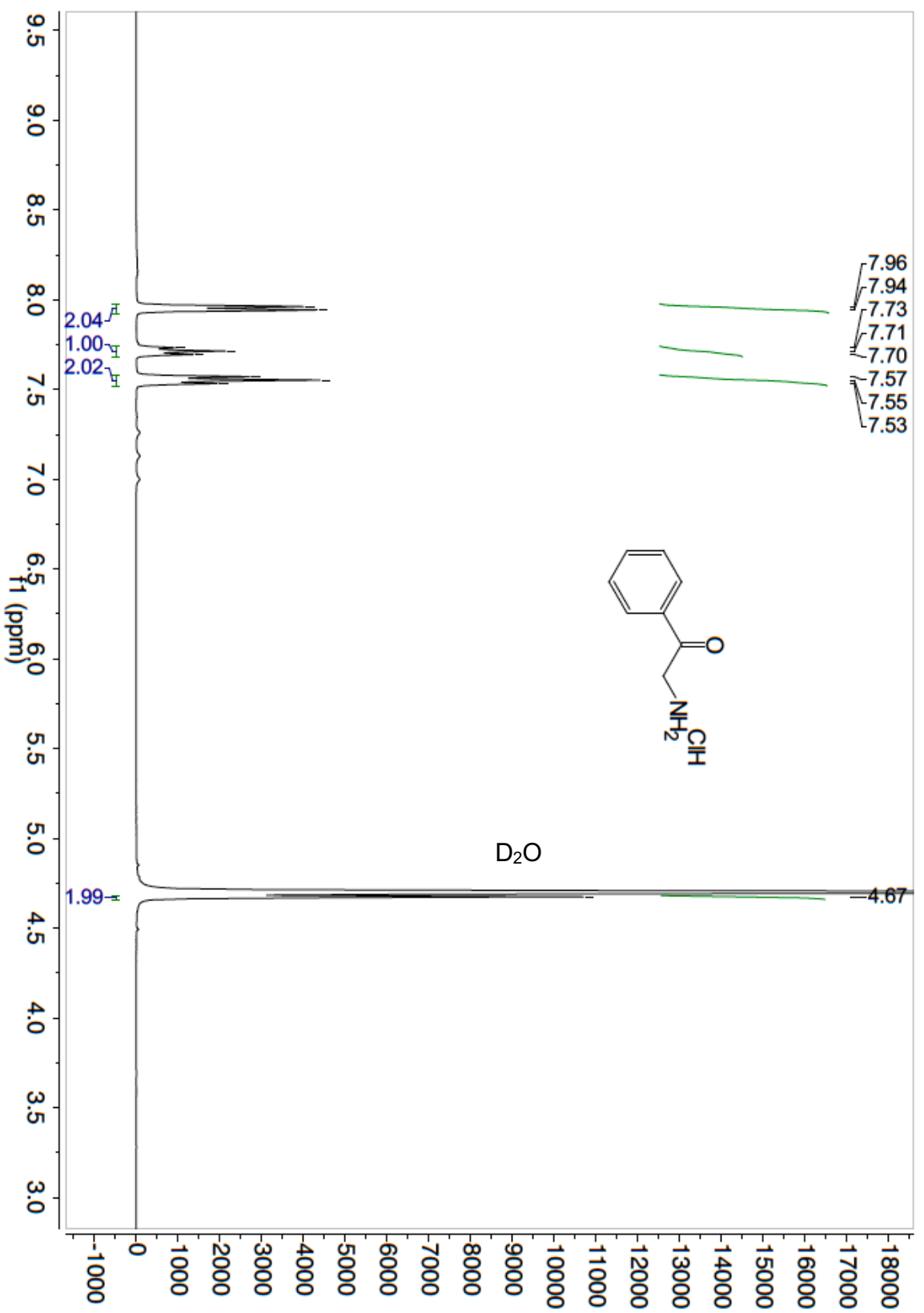


Supporting Information<smiles>NCC(=O)c1ccccc1</smiles>

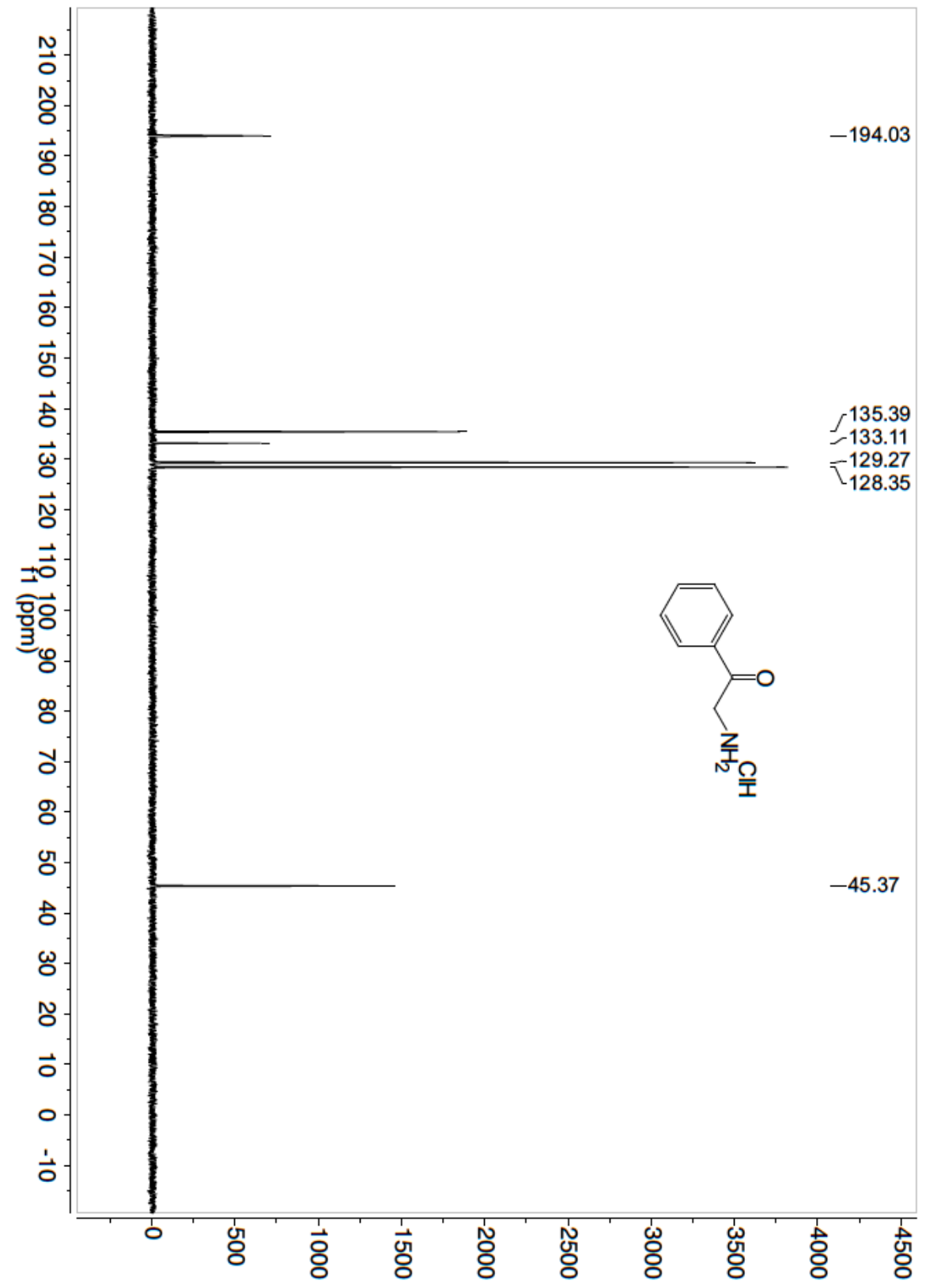


Supporting Information<smiles>O=C(CNC(=O)C1CC1)c1ccccc1</smiles>

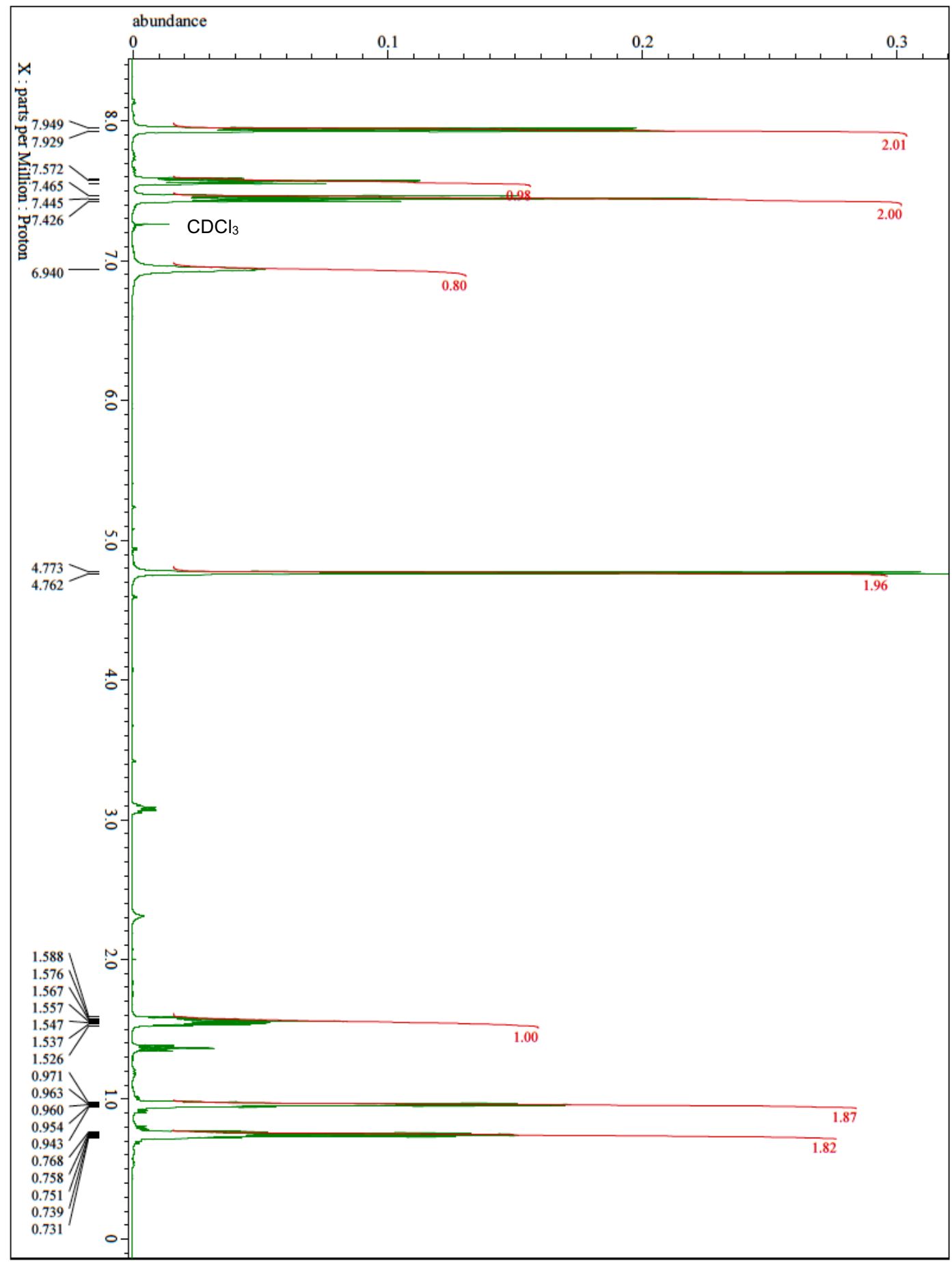


Supporting Information<smiles>O=C(CNC(=O)C1CC1)c1ccccc1</smiles>

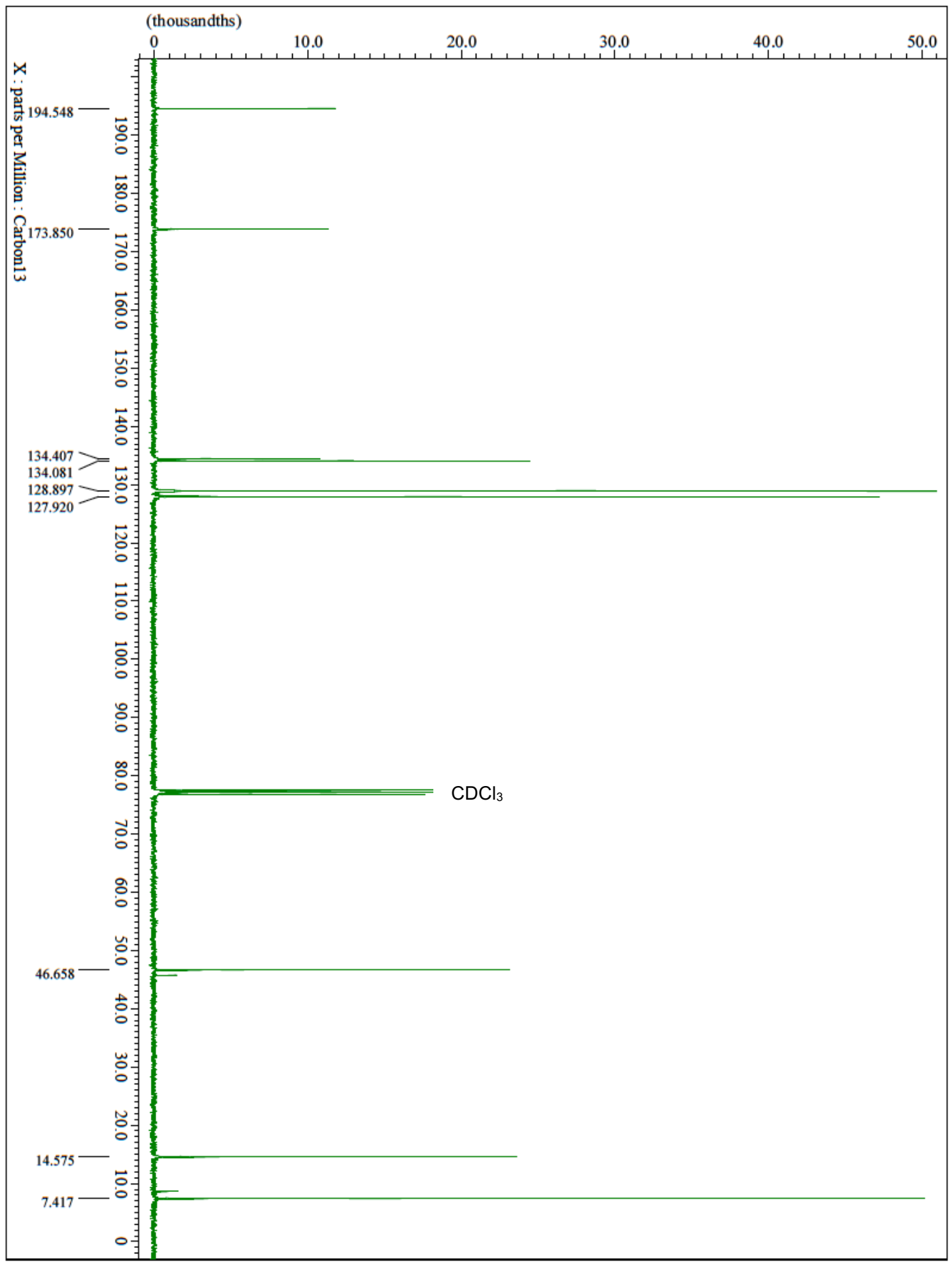


Supporting Information<smiles>c1ccc(-c2cnc(C3CC3)o2)cc1</smiles>

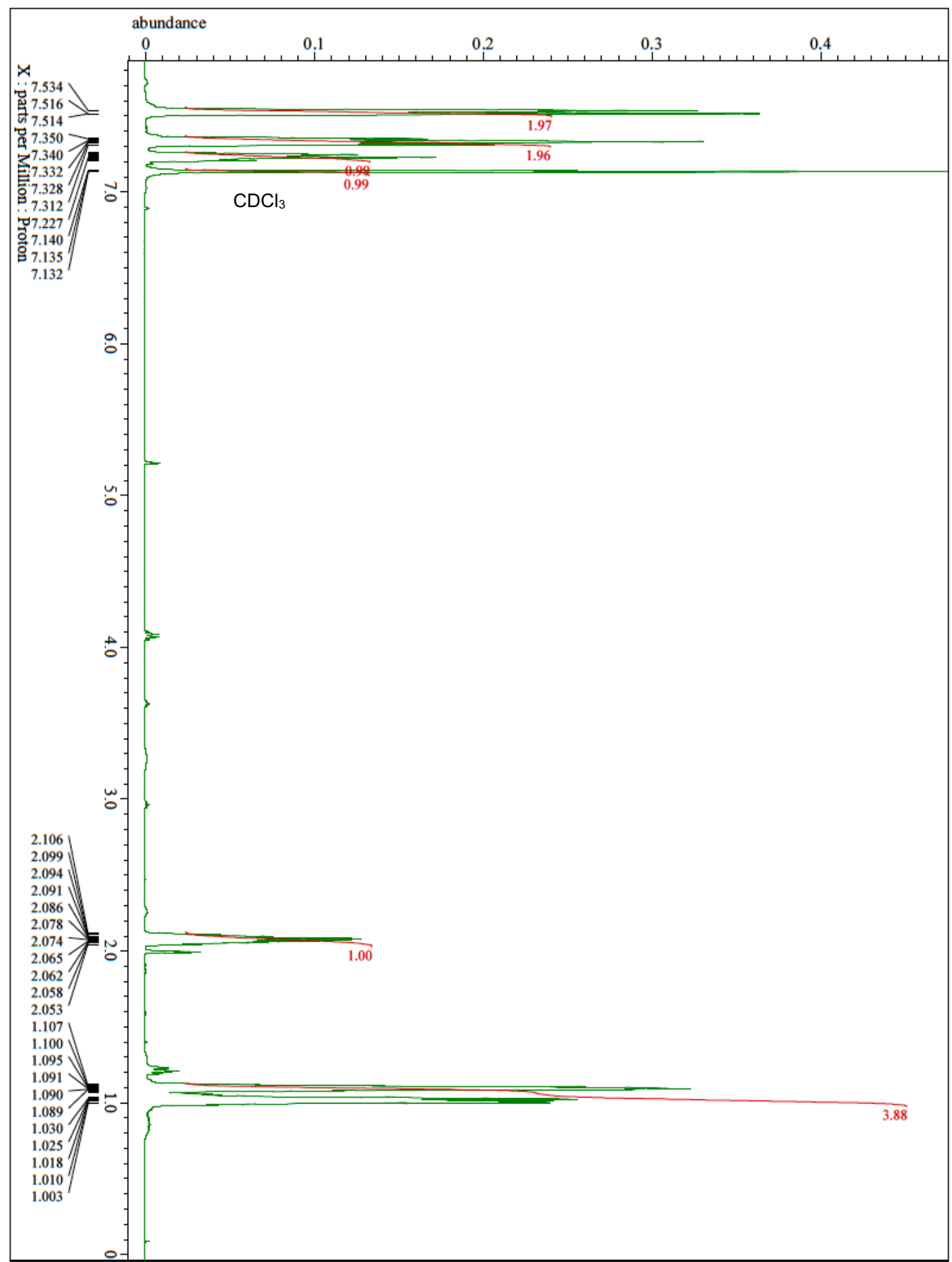


Supporting Information<smiles>c1ccc(-c2cnc(C3CC3)o2)cc1</smiles>

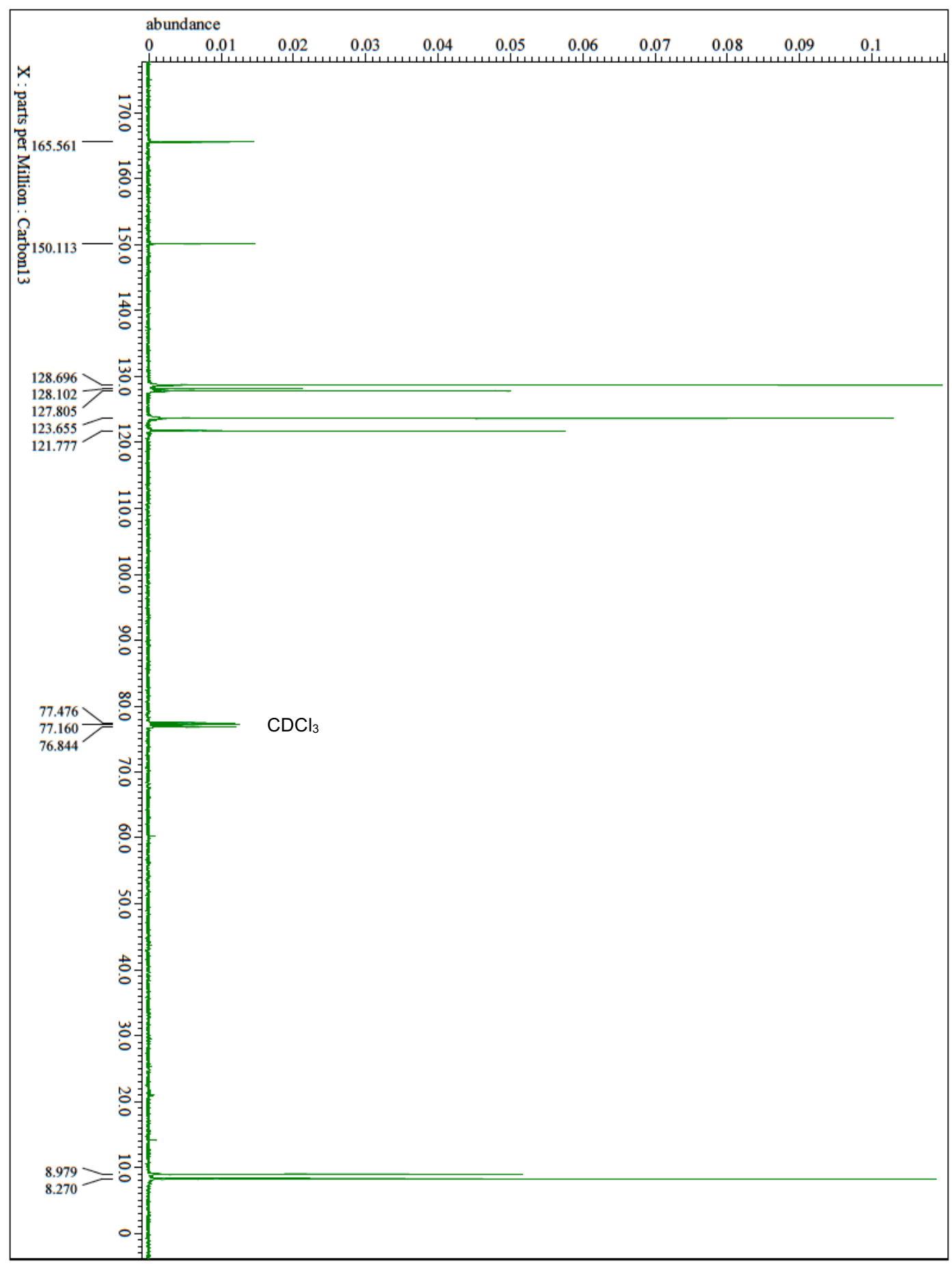


Supporting Information<smiles>O=S(=O)(Cl)c1ccc(-c2cnc(C3CC3)o2)cc1</smiles>

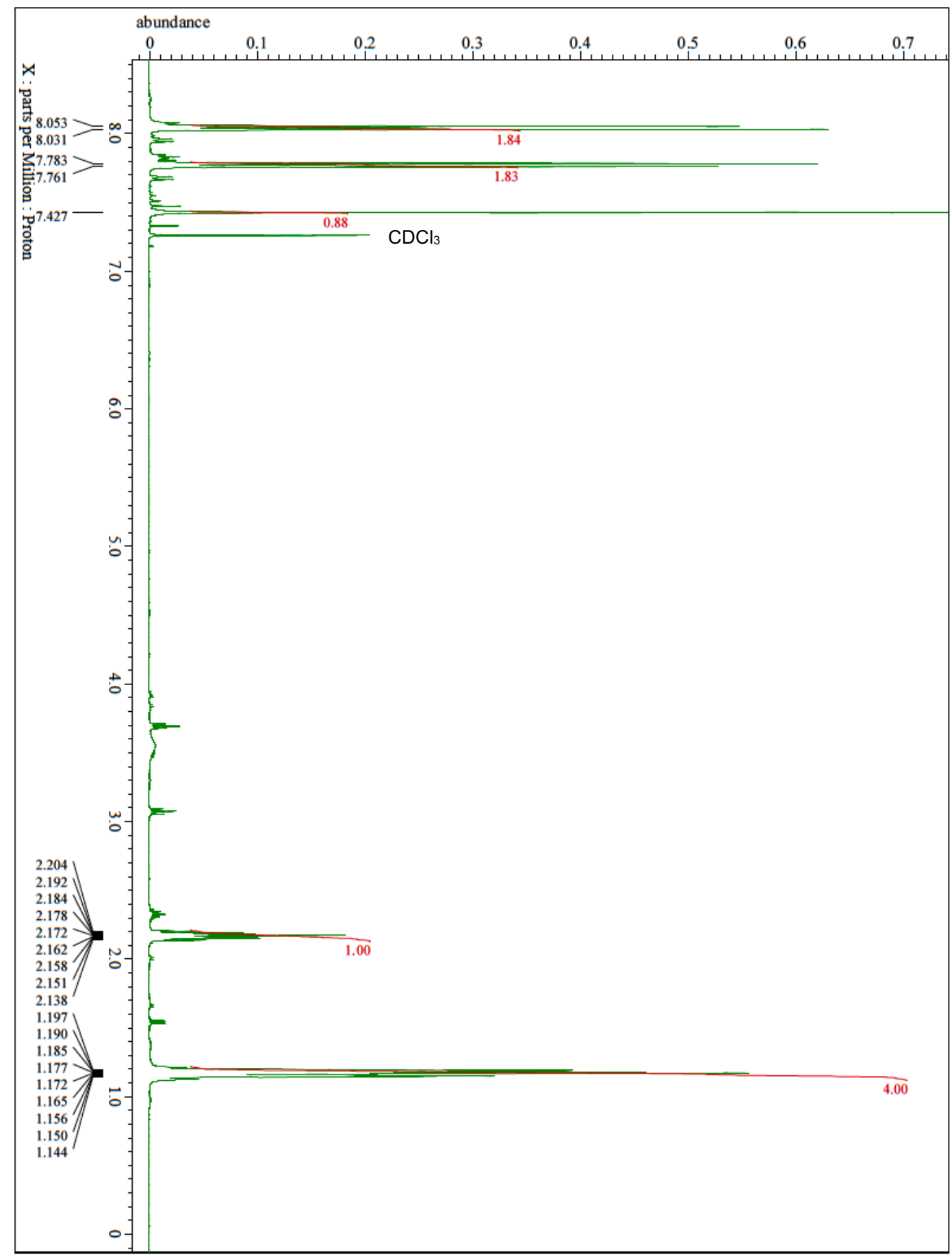


Supporting Information<smiles>O=S(=O)(Cl)c1ccc(-c2cnc(C3CC3)o2)cc1</smiles>

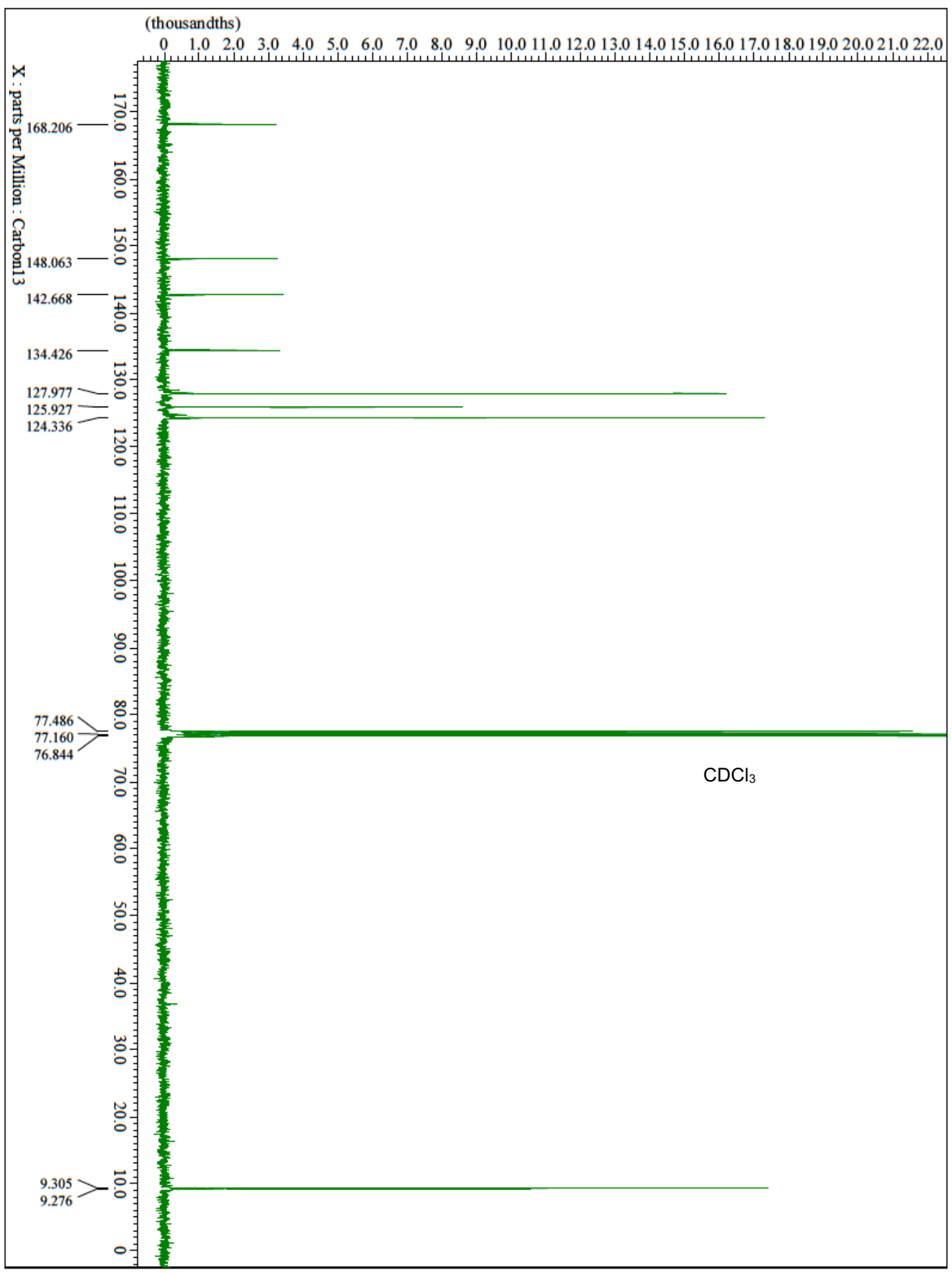


Supporting Information<smiles>O=S(=O)(Nc1ccc(F)cc1)c1ccc(-c2cnc(C3CC3)o2)cc1</smiles>

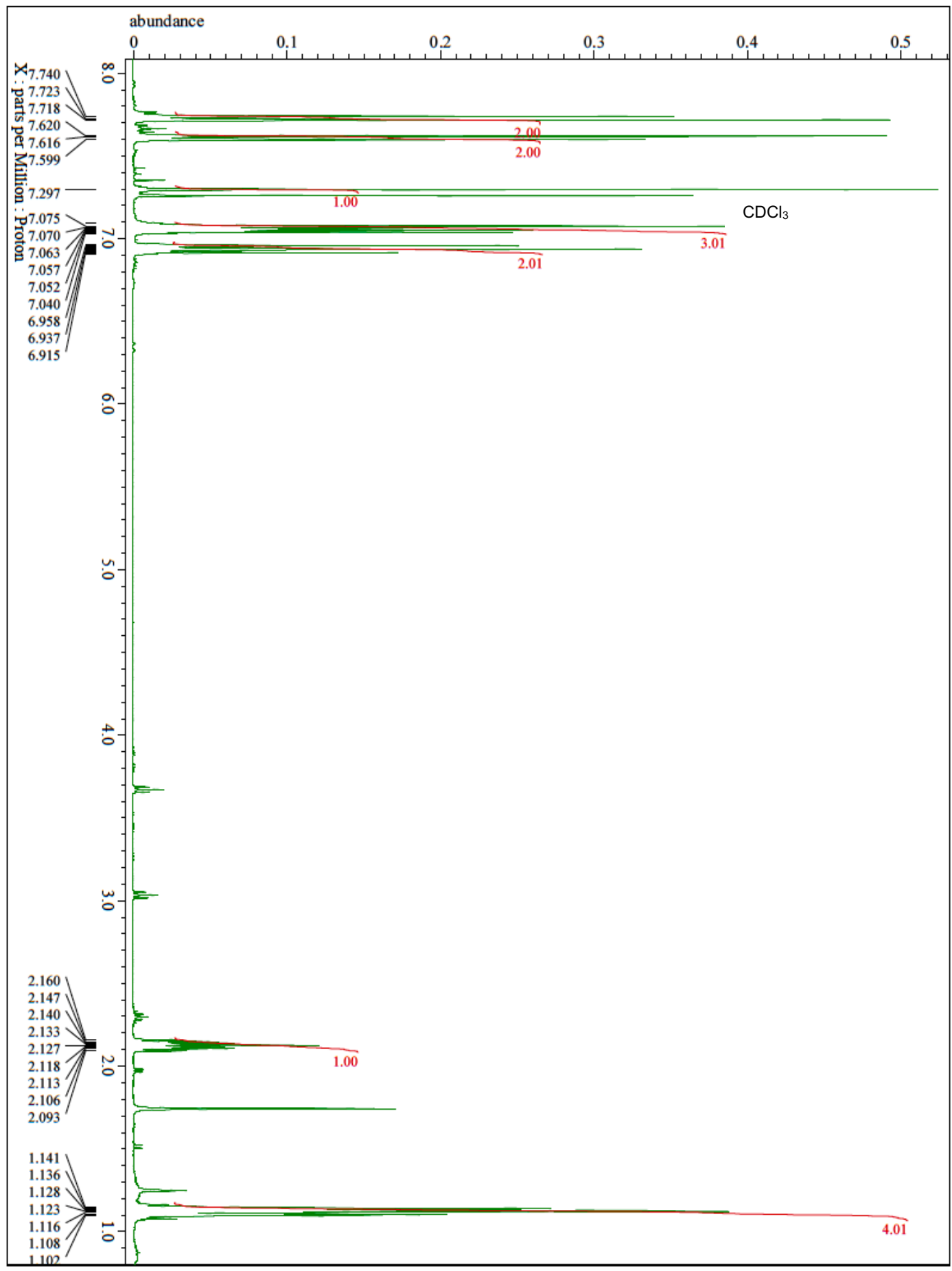


Supporting Information<smiles>O=S(=O)(Nc1ccc(F)cc1)c1ccc(-c2cnc(C3CC3)o2)cc1</smiles>

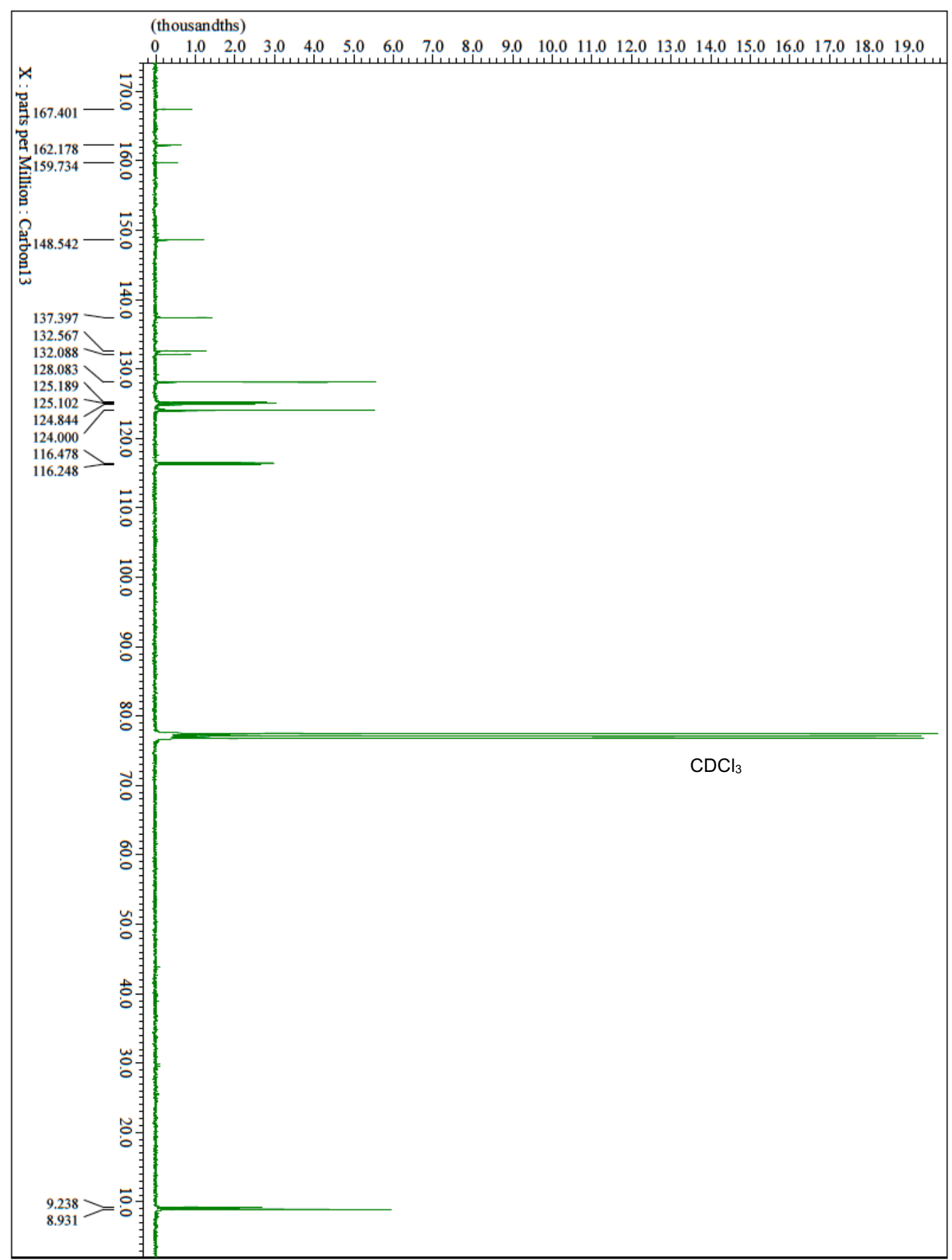


Supporting Information<smiles>O=S(=O)(c1ccc(-c2cnc(C3CC3)o2)cc1)N1CCOCC1</smiles>

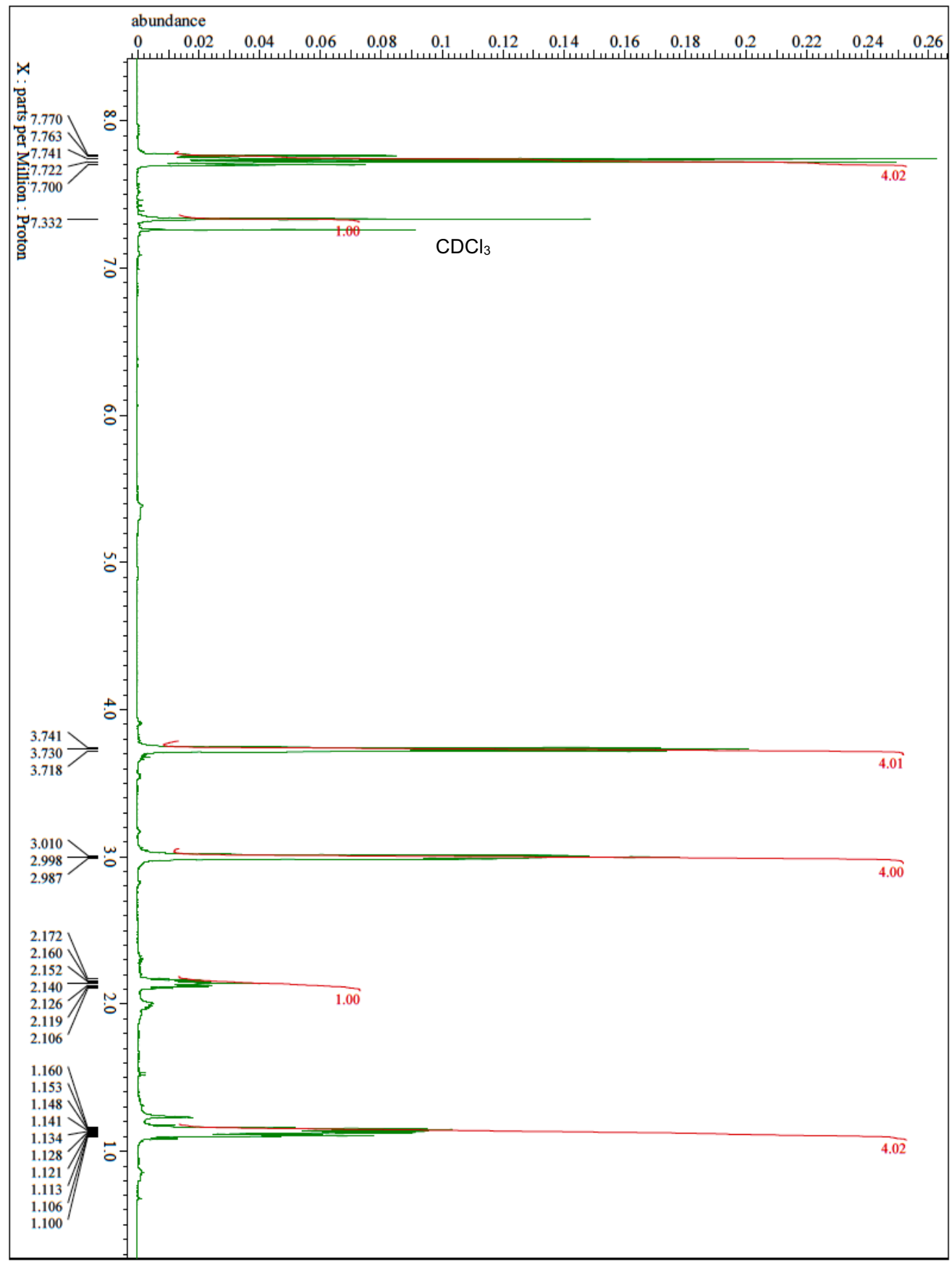


Supporting Information<smiles>O=S(=O)(c1ccc(-c2cnc(C3CC3)o2)cc1)N1CCOCC1</smiles>

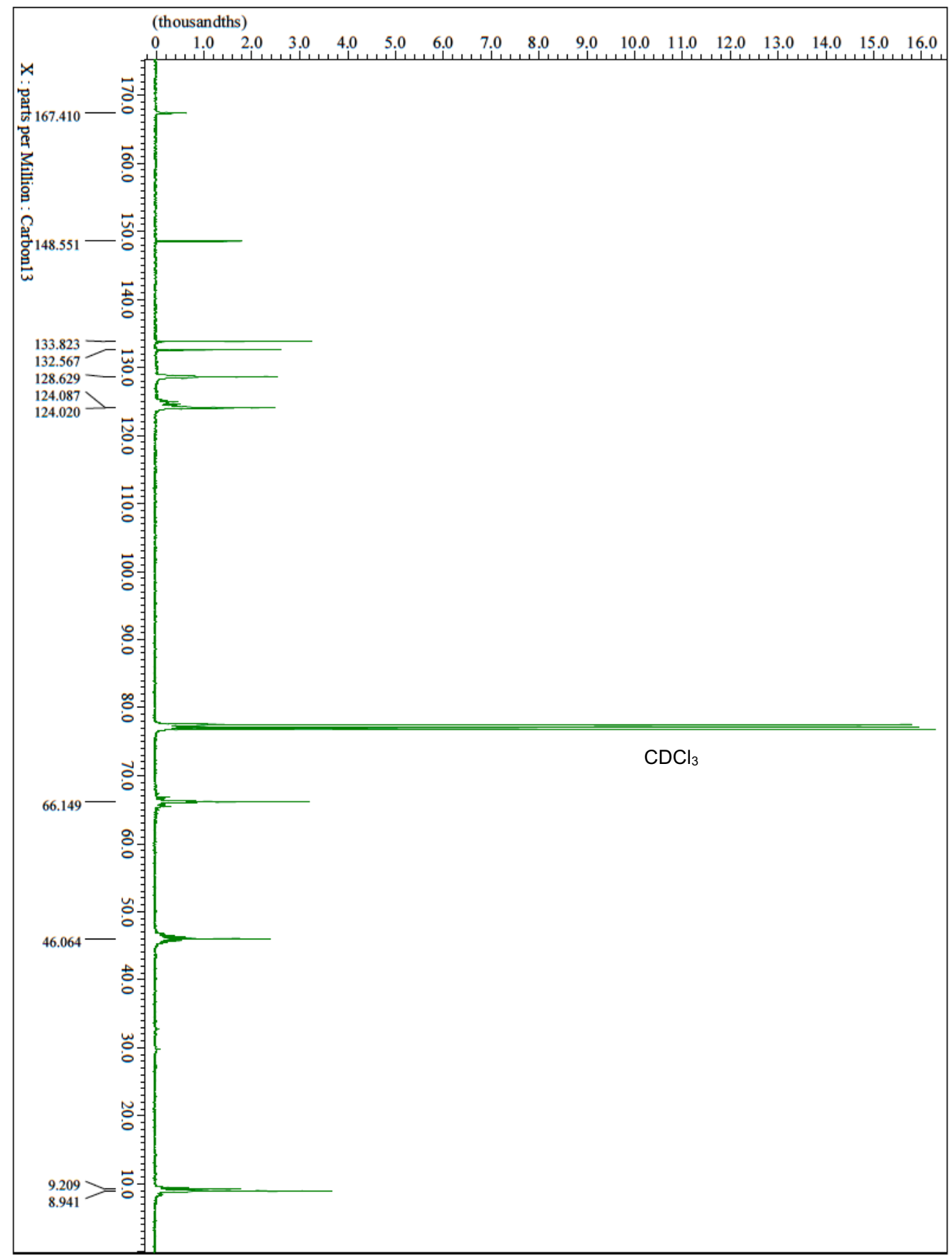


Supporting Information<smiles>O=S(=O)(Nc1ccc(Cl)cc1)c1ccc(-c2cnc(C3CC3)o2)cc1</smiles>

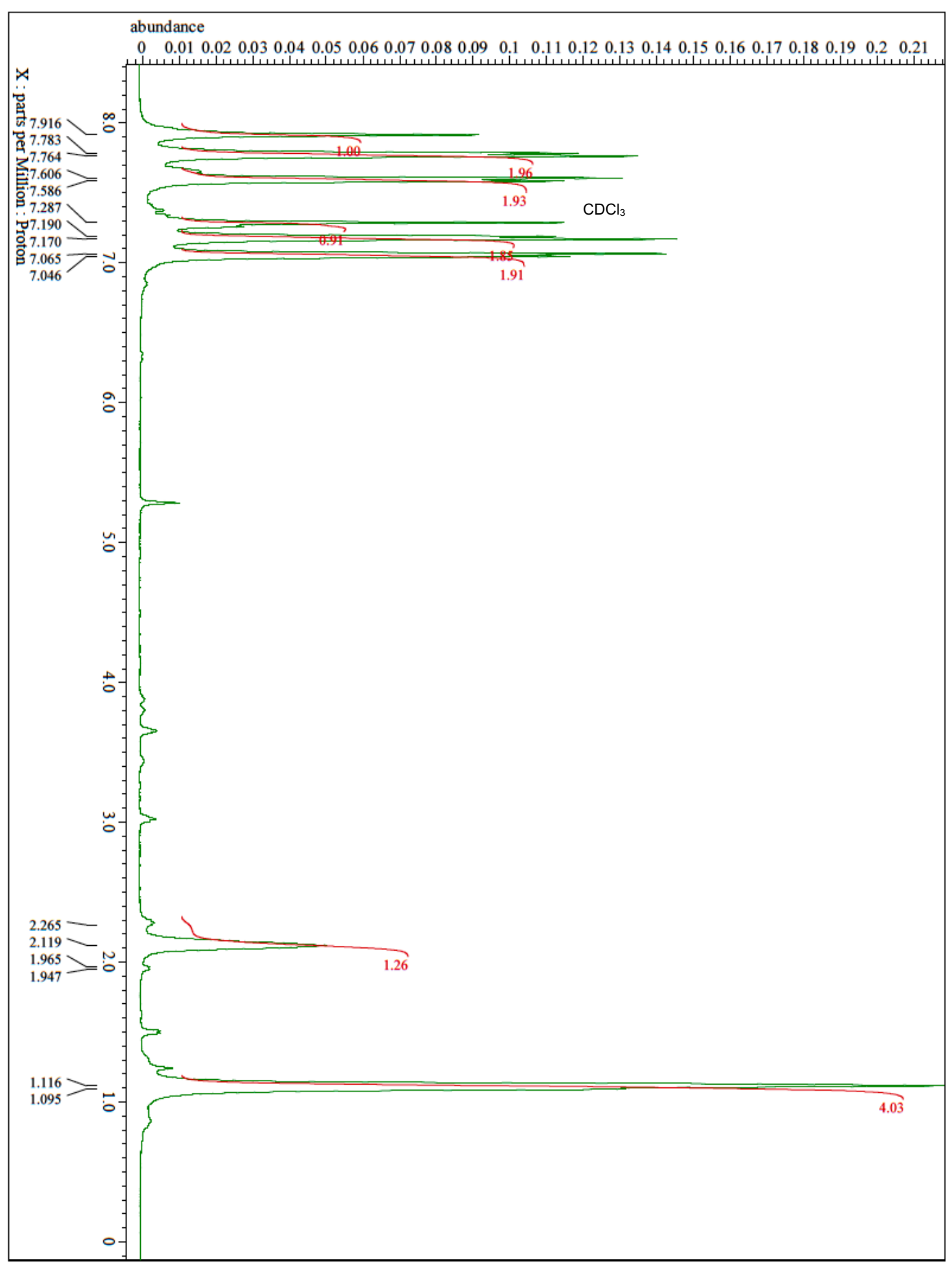


<smiles>O=S(=O)(Nc1ccc(Cl)cc1)c1ccc(-c2cnc(C3CC3)o2)cc1</smiles>

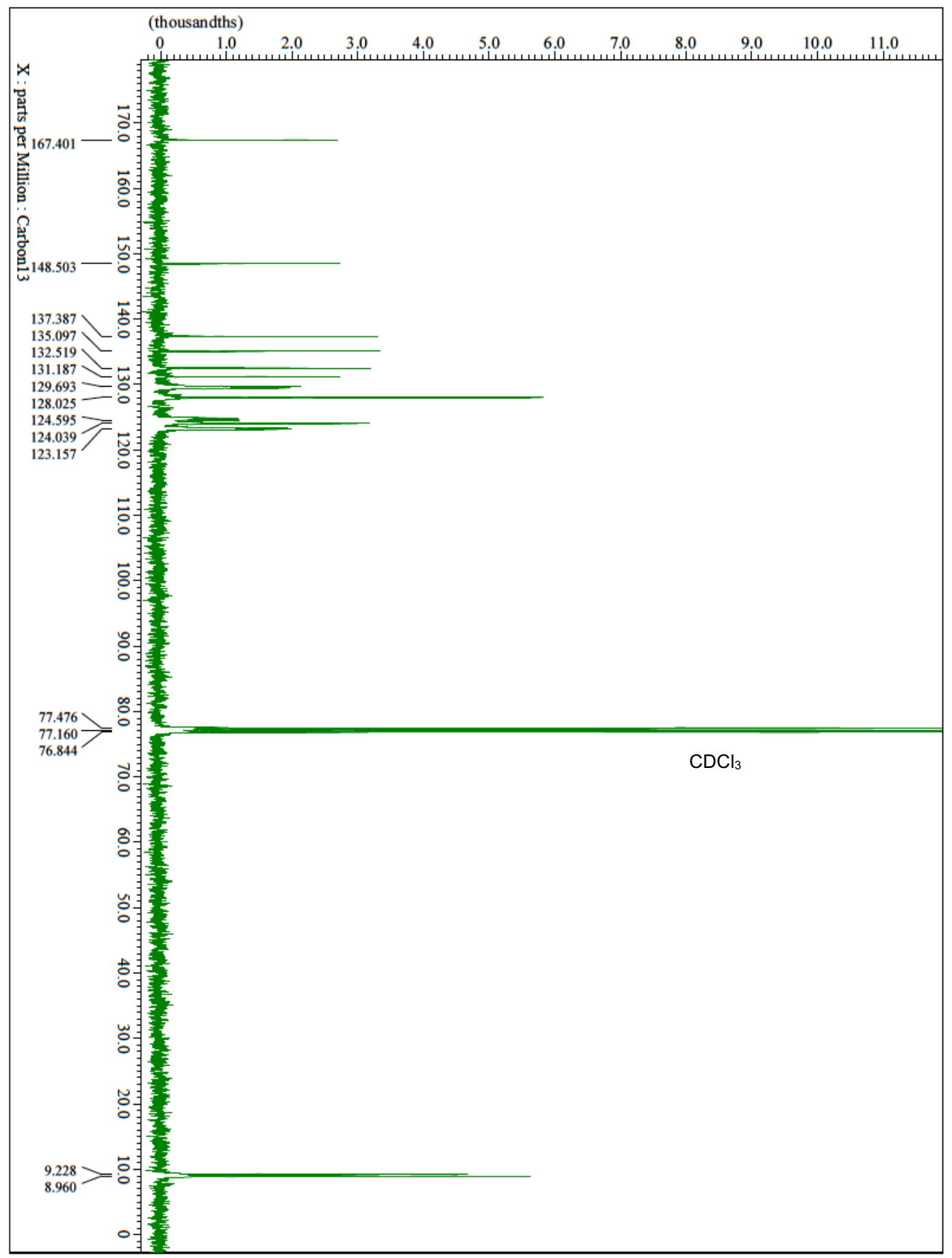


Supporting Information<smiles>O=S(=O)(Nc1ccc(Cl)c(C(F)(F)F)c1)c1ccc(-c2cnc(C3CC3)o2)cc1</smiles>

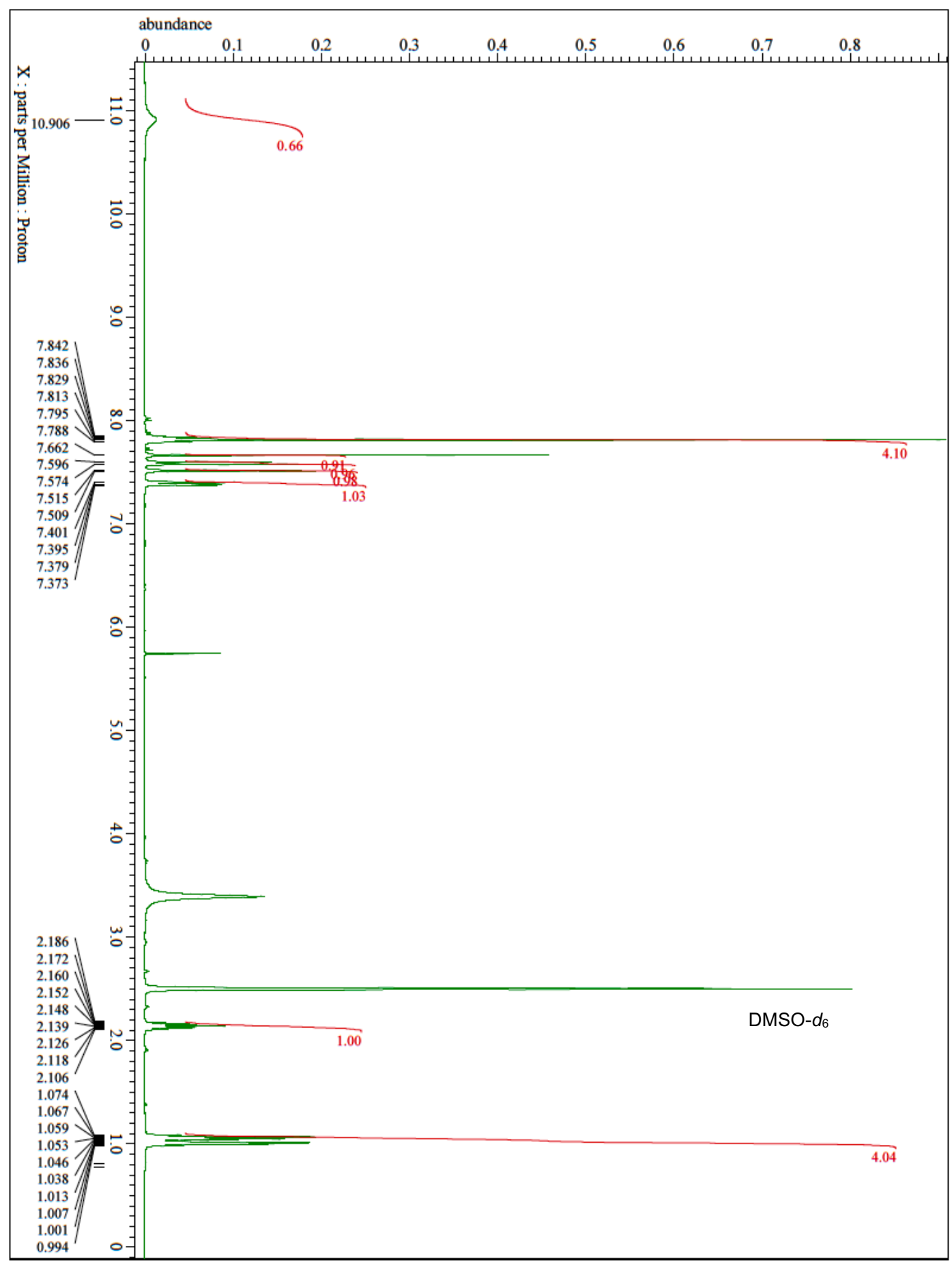


<smiles>O=S(=O)(Nc1ccc(Cl)c(C(F)(F)F)c1)c1ccc(-c2cnc(C3CC3)o2)cc1</smiles>

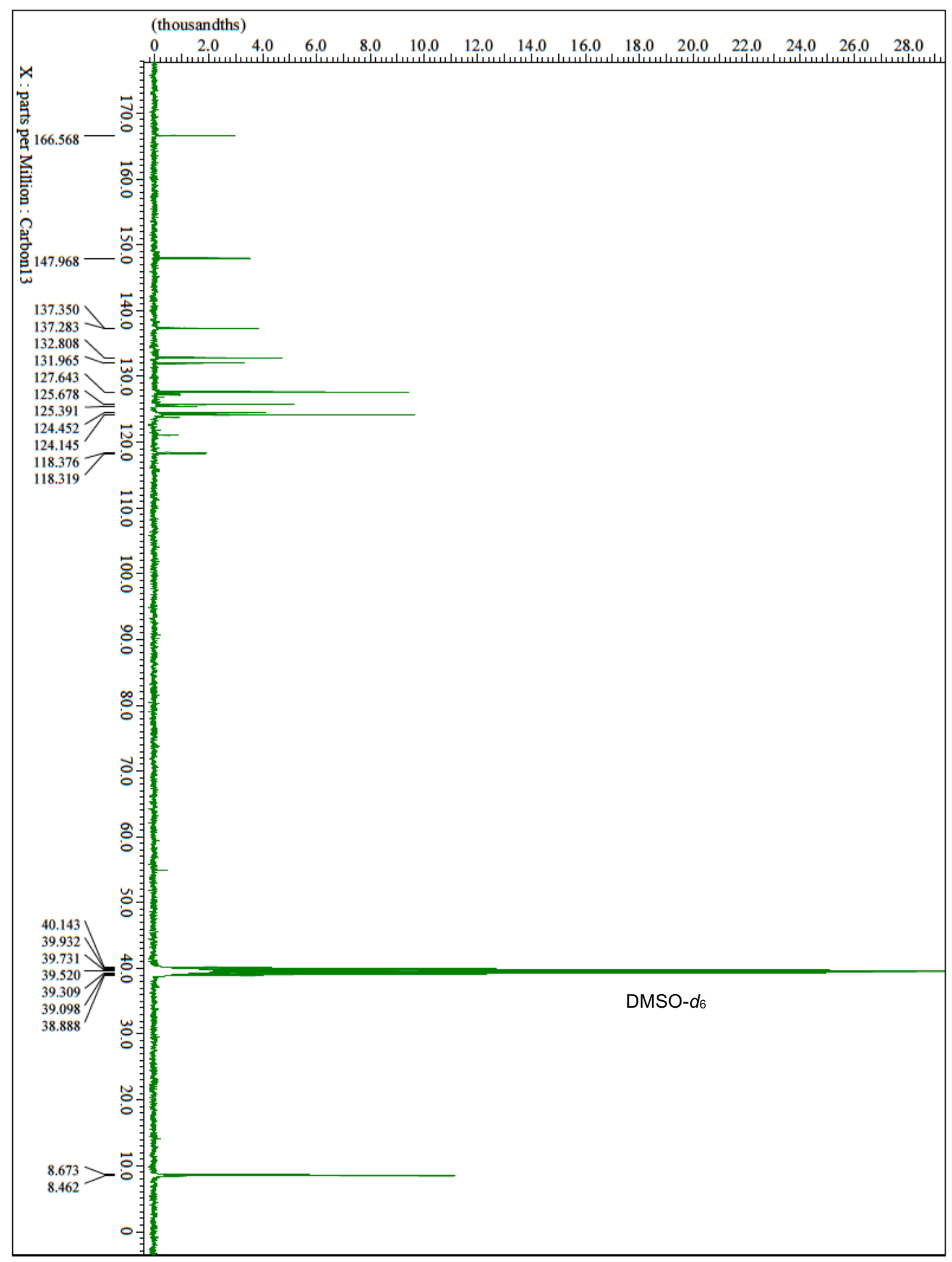


Supporting Information<smiles>O=S(=O)(Nc1ccc2ccccc2c1)c1ccc(-c2cnc(C3CC3)o2)cc1</smiles>

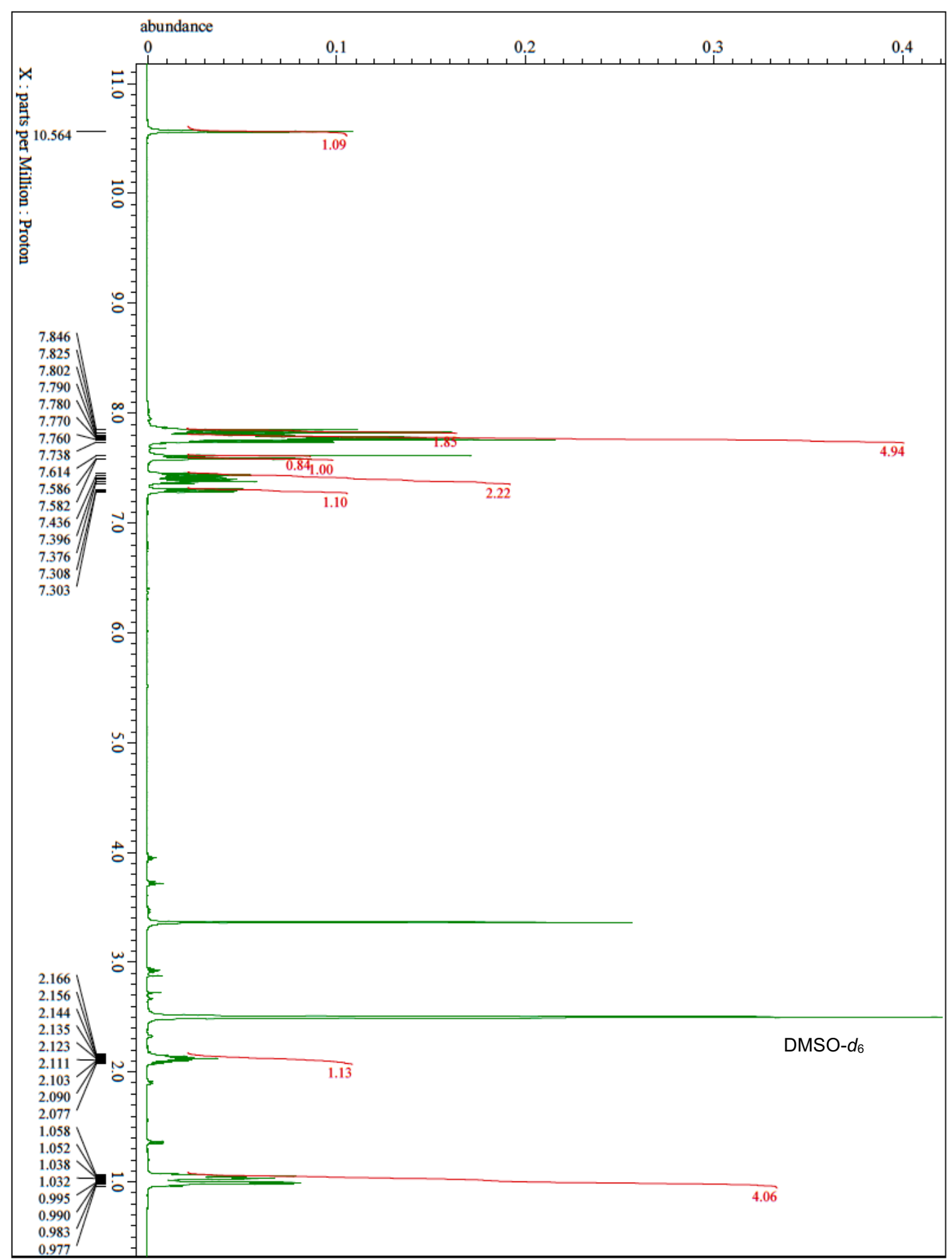


Supporting Information<smiles>O=S(=O)(Nc1ccc2ccccc2c1)c1ccc(-c2cnc(C3CC3)o2)cc1</smiles>

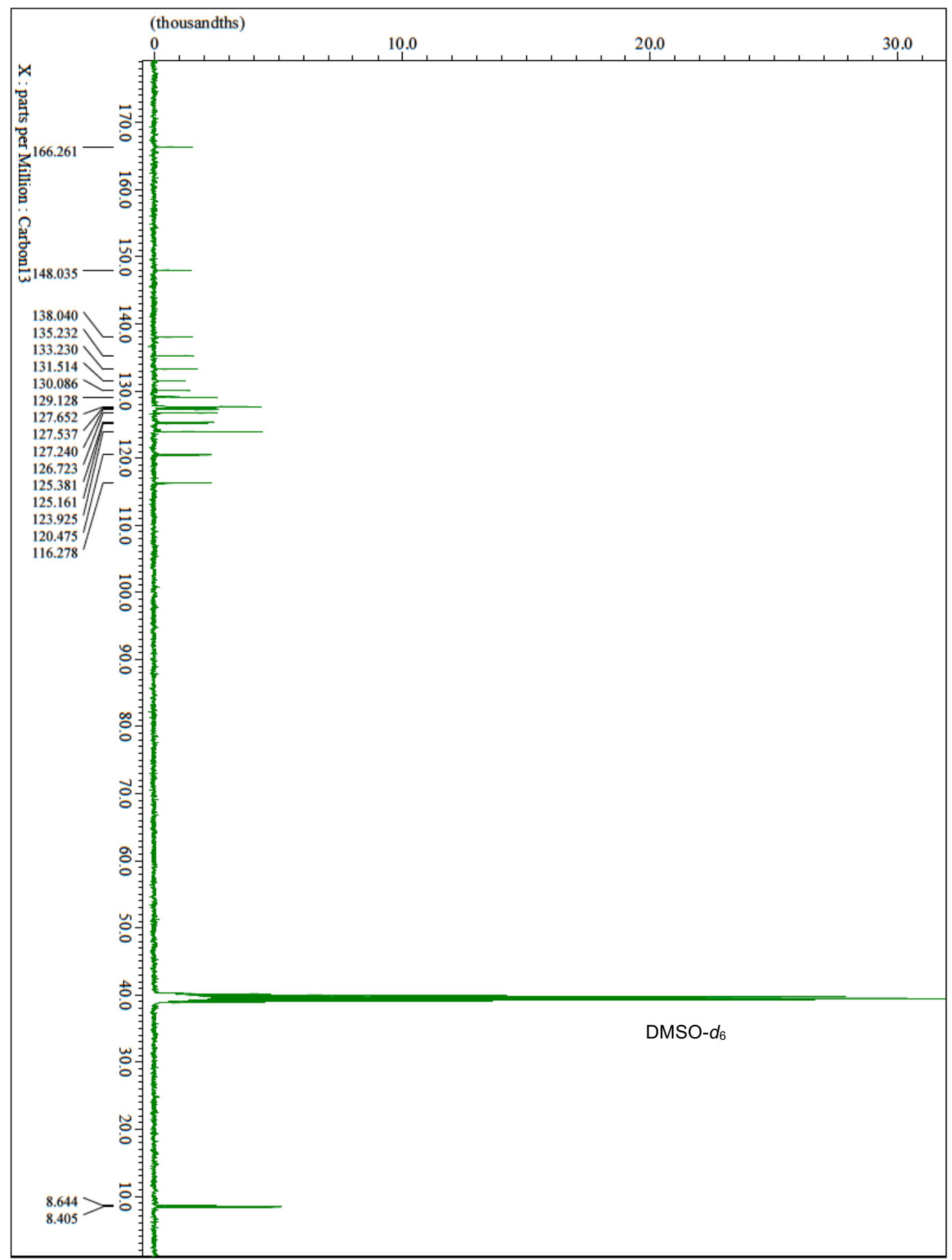


Supporting Information<smiles>COc1ccc(NS(=O)(=O)c2ccc(-c3cnc(C4CC4)o3)cc2)cc1</smiles>

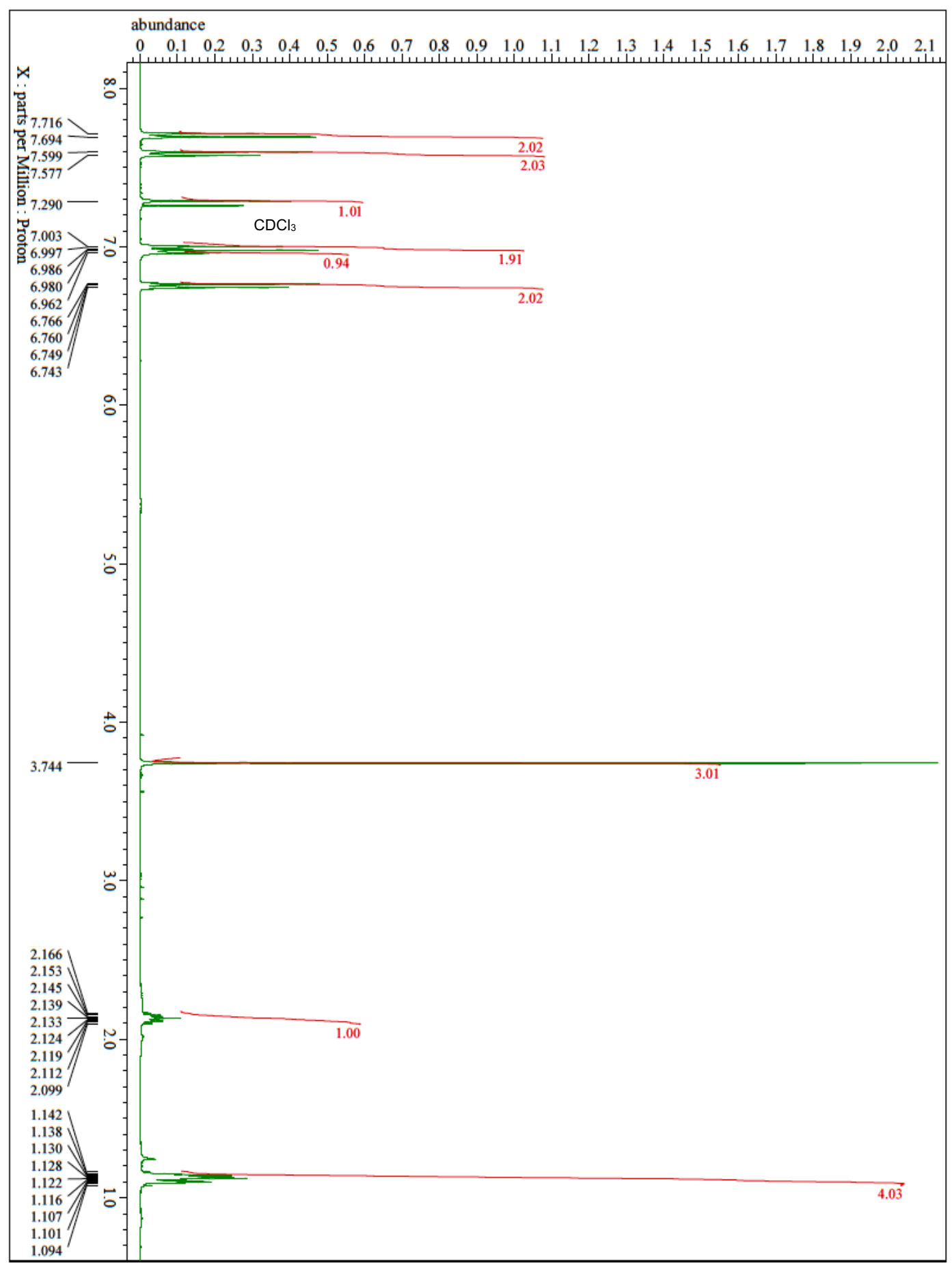


<smiles>COc1ccc(NS(=O)(=O)c2ccc(-c3cnc(C4CC4)o3)cc2)cc1</smiles>

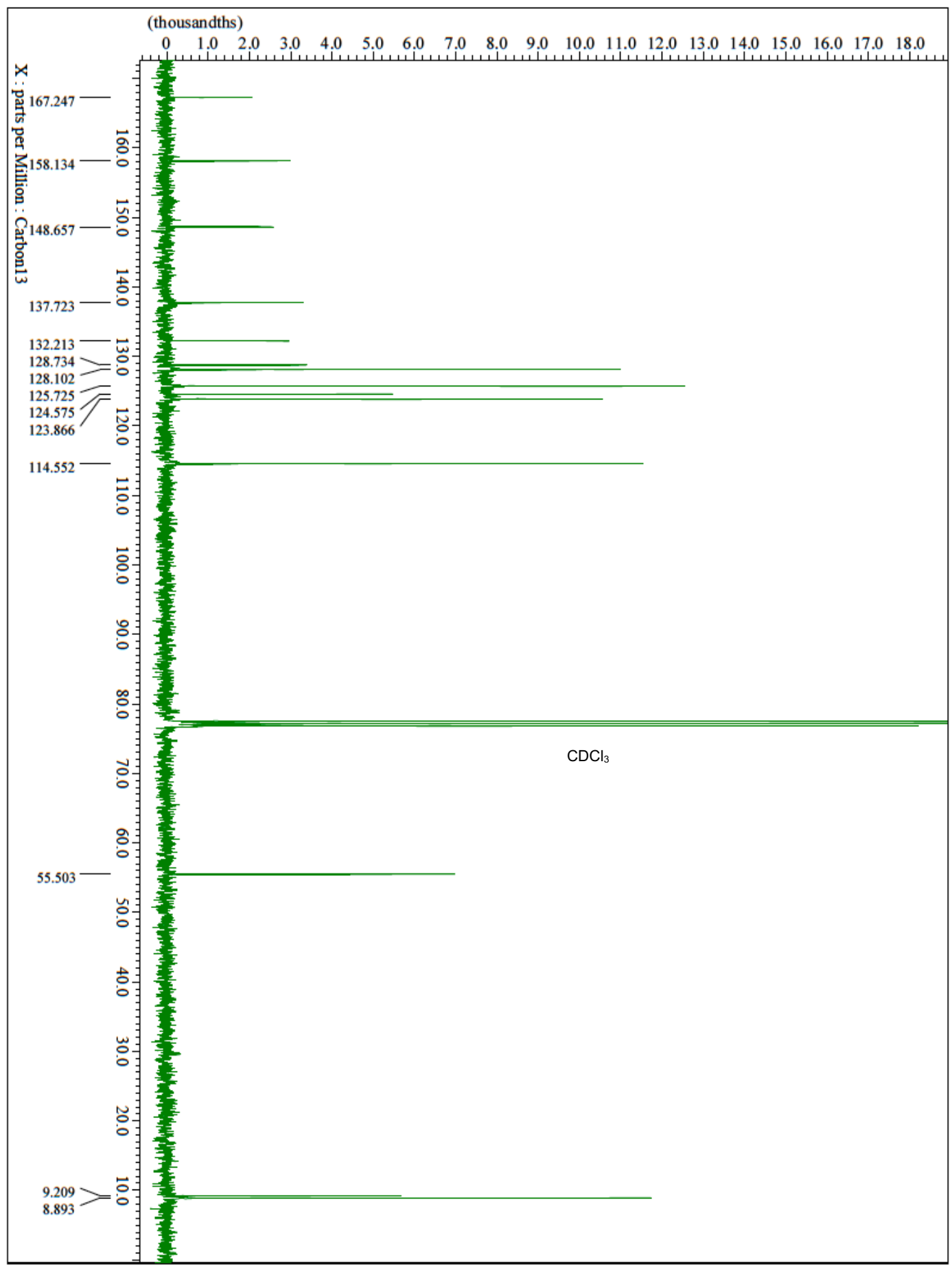


Supporting Information<smiles>O=S(=O)(Nc1ccc(Cl)c(Cl)c1)c1ccc(-c2cnc(C3CC3)o2)cc1</smiles>

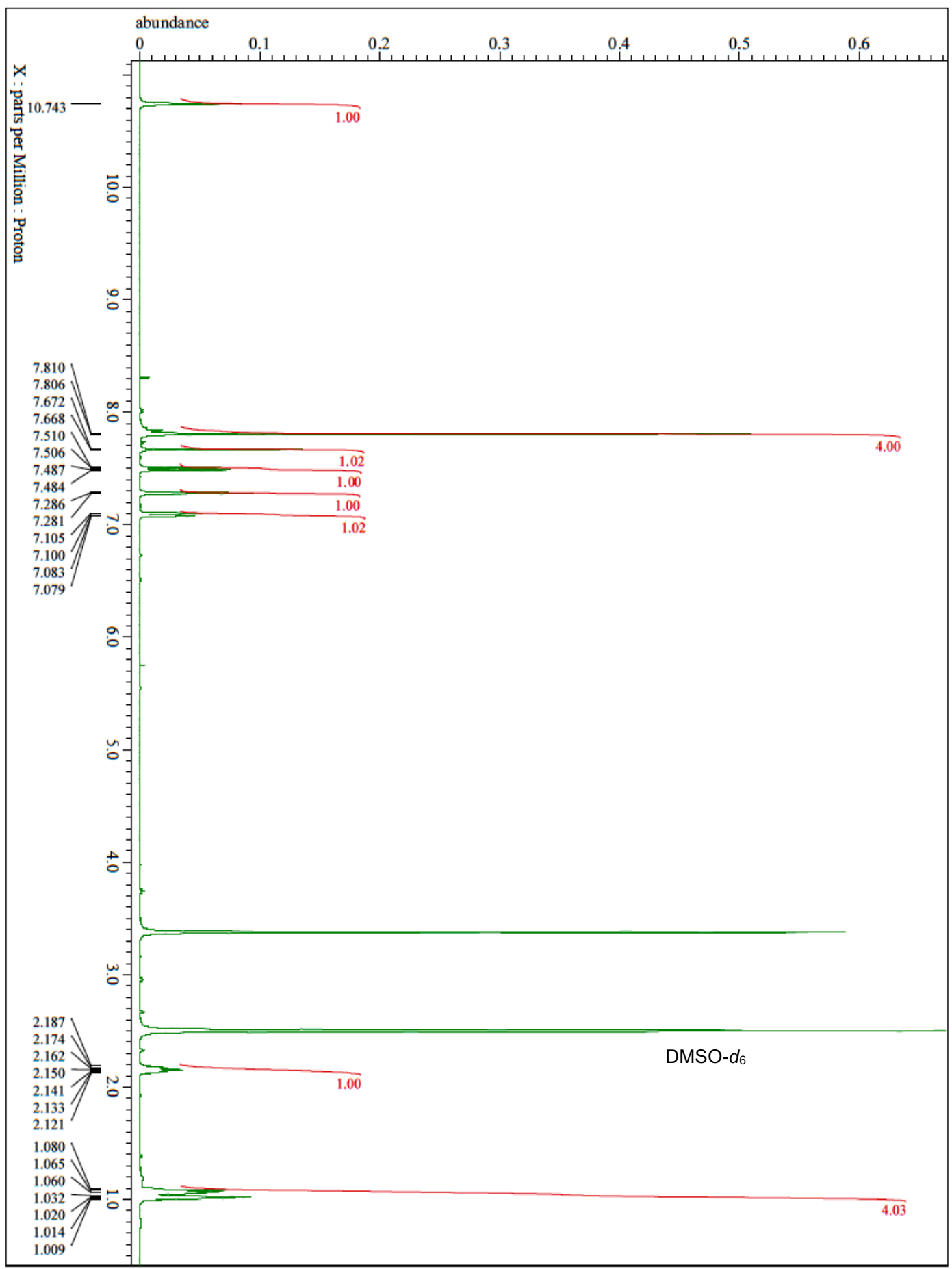


Supporting Information<smiles>O=S(=O)(Nc1ccc(Cl)c(Cl)c1)c1ccc(-c2cnc(C3CC3)o2)cc1</smiles>

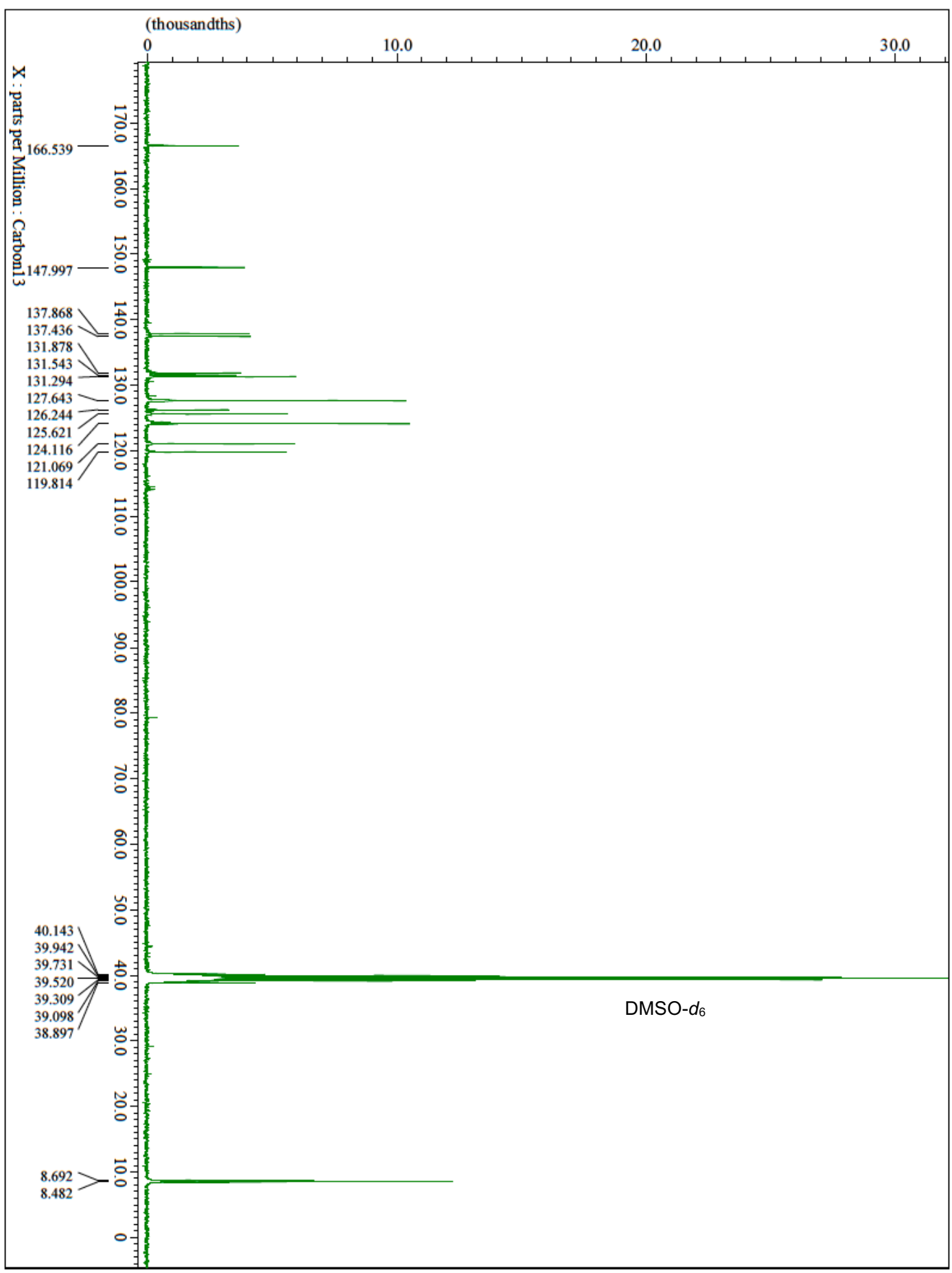


Supporting Information<smiles>O=S(=O)(Nc1ccccc1Cl)c1ccc(-c2cnc(C3CC3)o2)cc1</smiles>

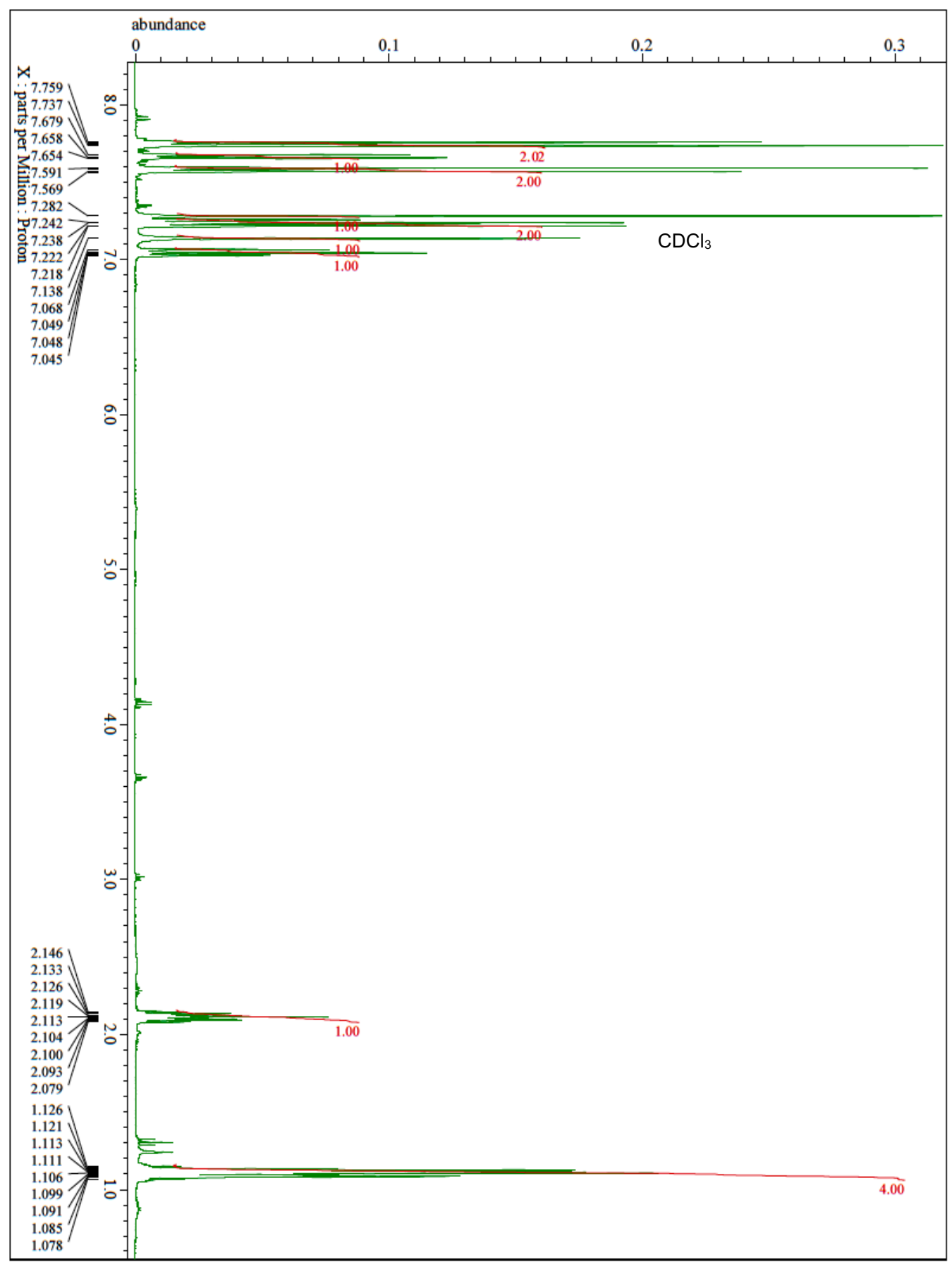


Supporting Information<smiles>O=S(=O)(Nc1ccccc1Cl)c1ccc(-c2cnc(C3CC3)o2)cc1</smiles>

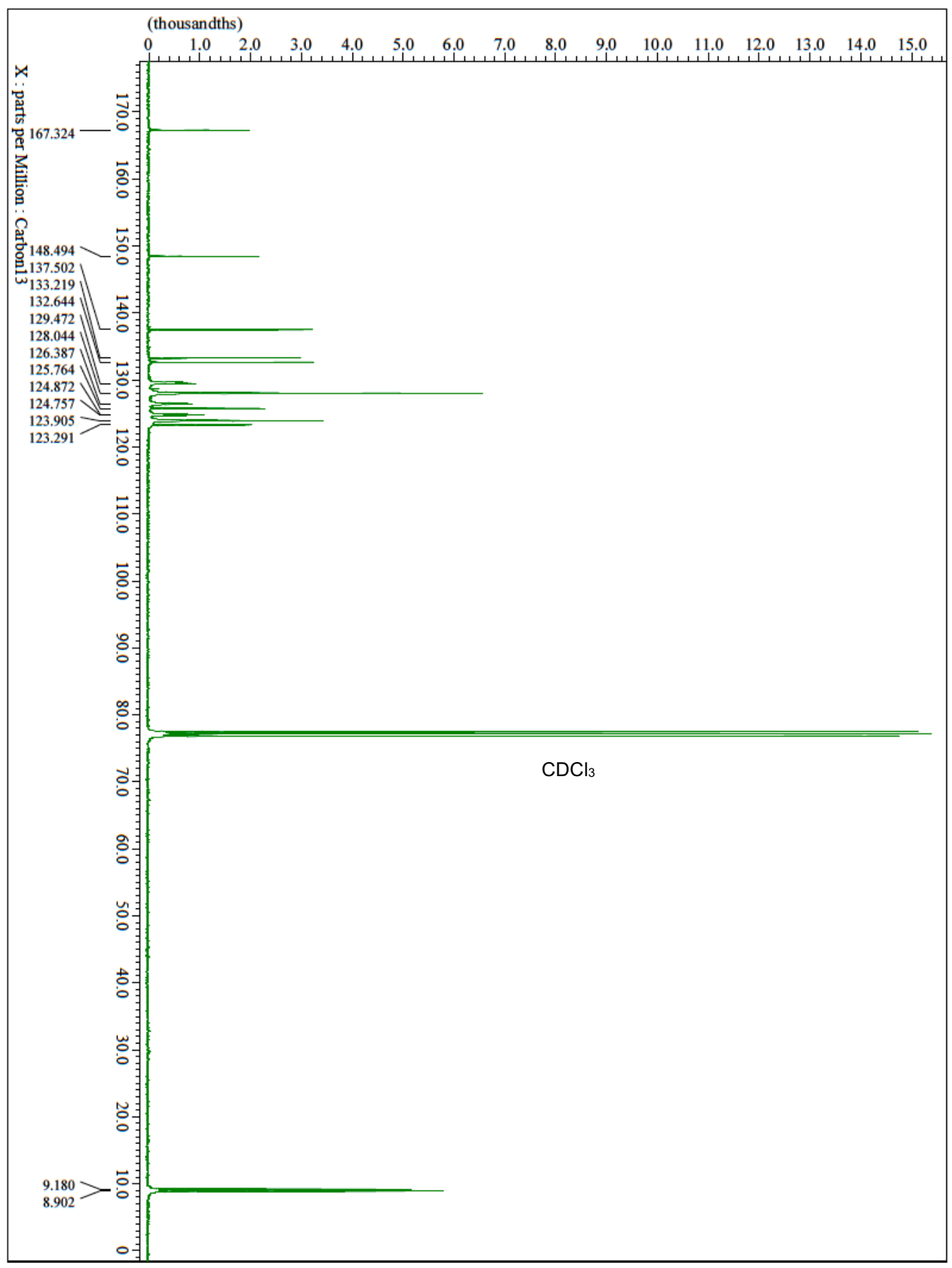


Supporting Information<smiles>O=S(=O)(Nc1ccc(Cl)c(F)c1)c1ccc(-c2cnc(C3CC3)o2)cc1</smiles>

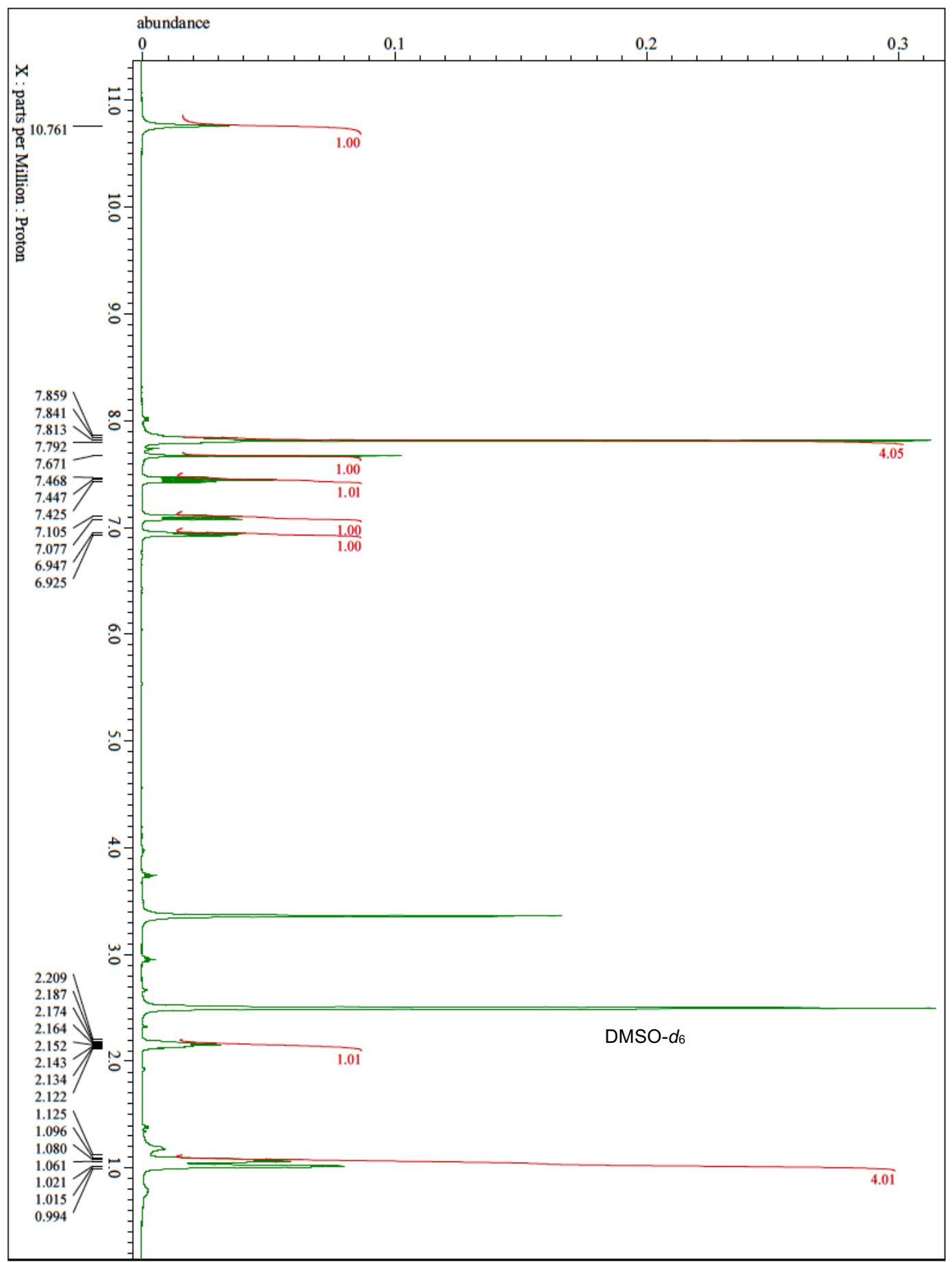


<smiles>O=S(=O)(Nc1ccc(Cl)c(F)c1)c1ccc(-c2cnc(C3CC3)o2)cc1</smiles>

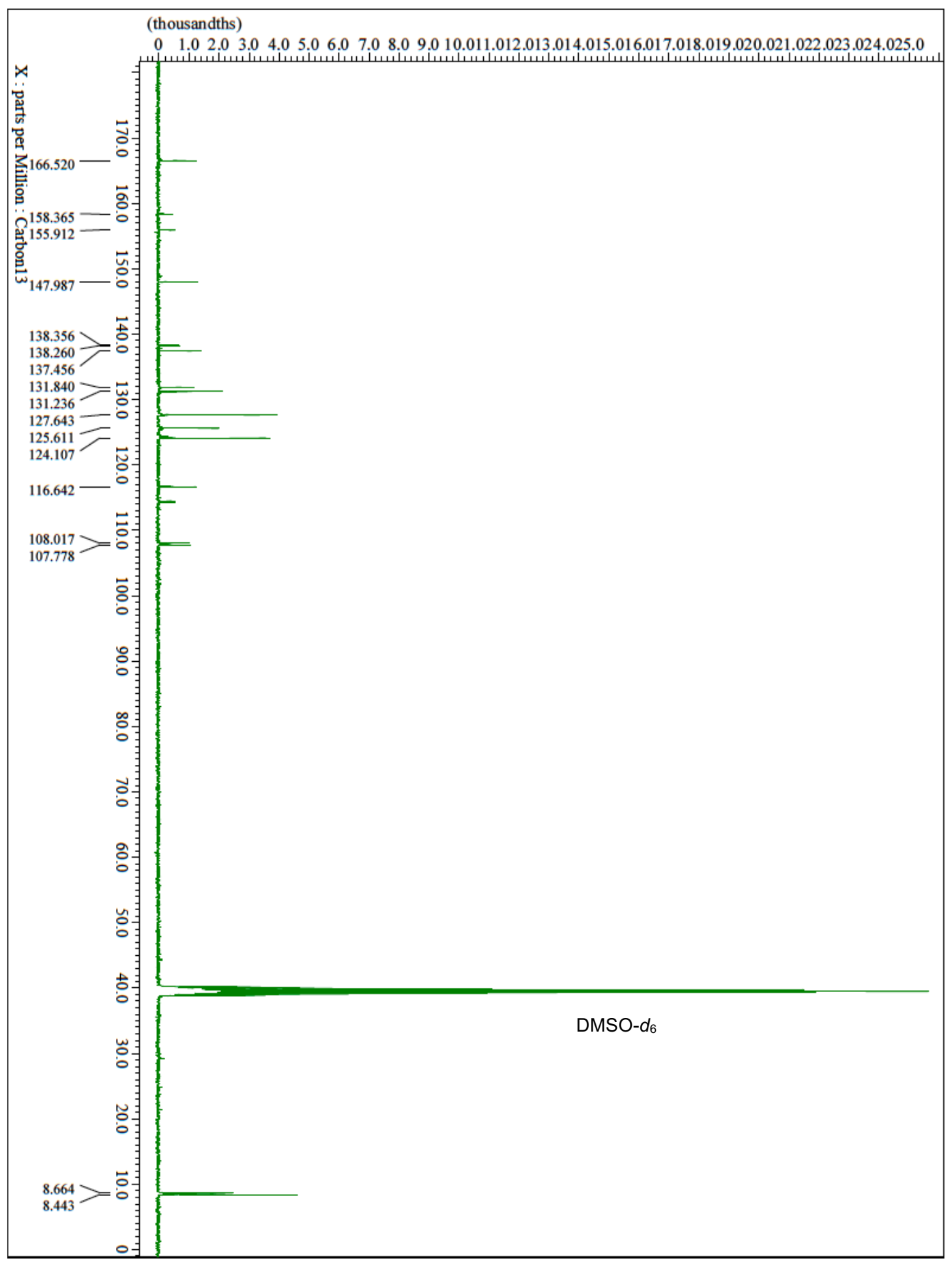


Supporting Information<smiles>O=S(=O)(Nc1cccc(Cl)c1)c1ccc(-c2cnc(C3CC3)o2)cc1</smiles>

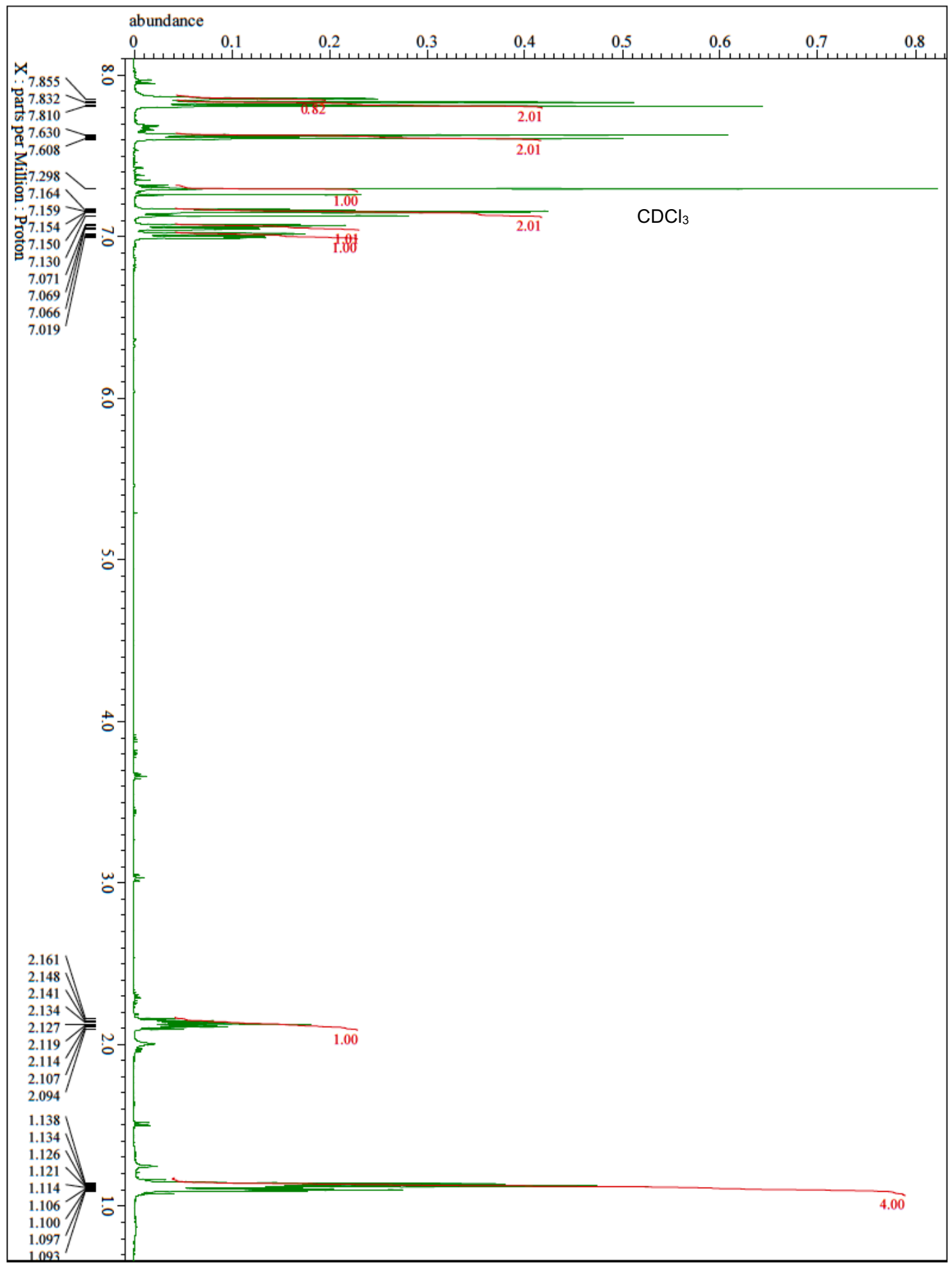


Supporting Information<smiles>O=S(=O)(Nc1cccc(Cl)c1)c1ccc(-c2cnc(C3CC3)o2)cc1</smiles>

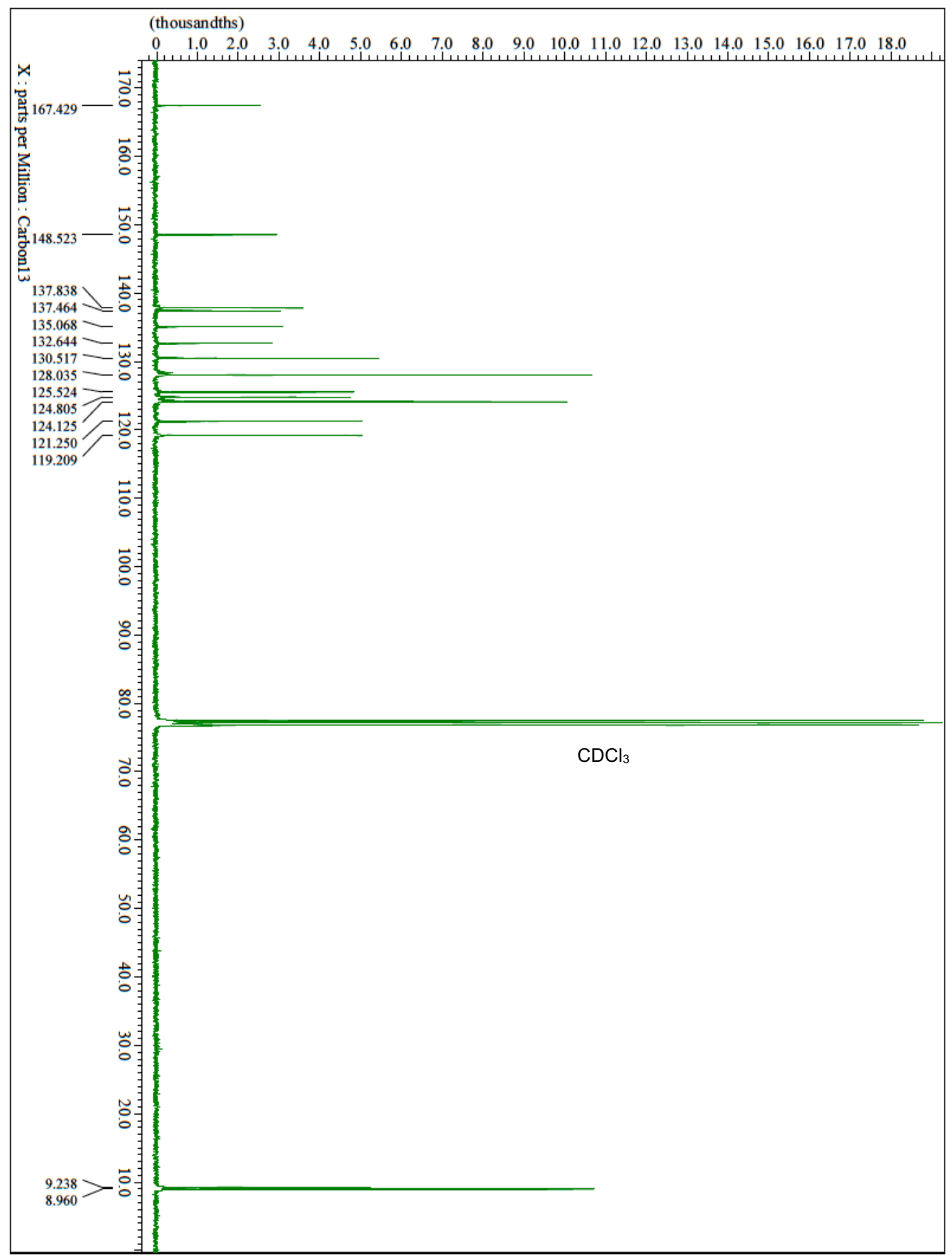


Supporting Information<smiles>Cc1cc(NS(=O)(=O)c2ccc(-c3cnc(C4CC4)o3)cc2)ccc1Cl</smiles>

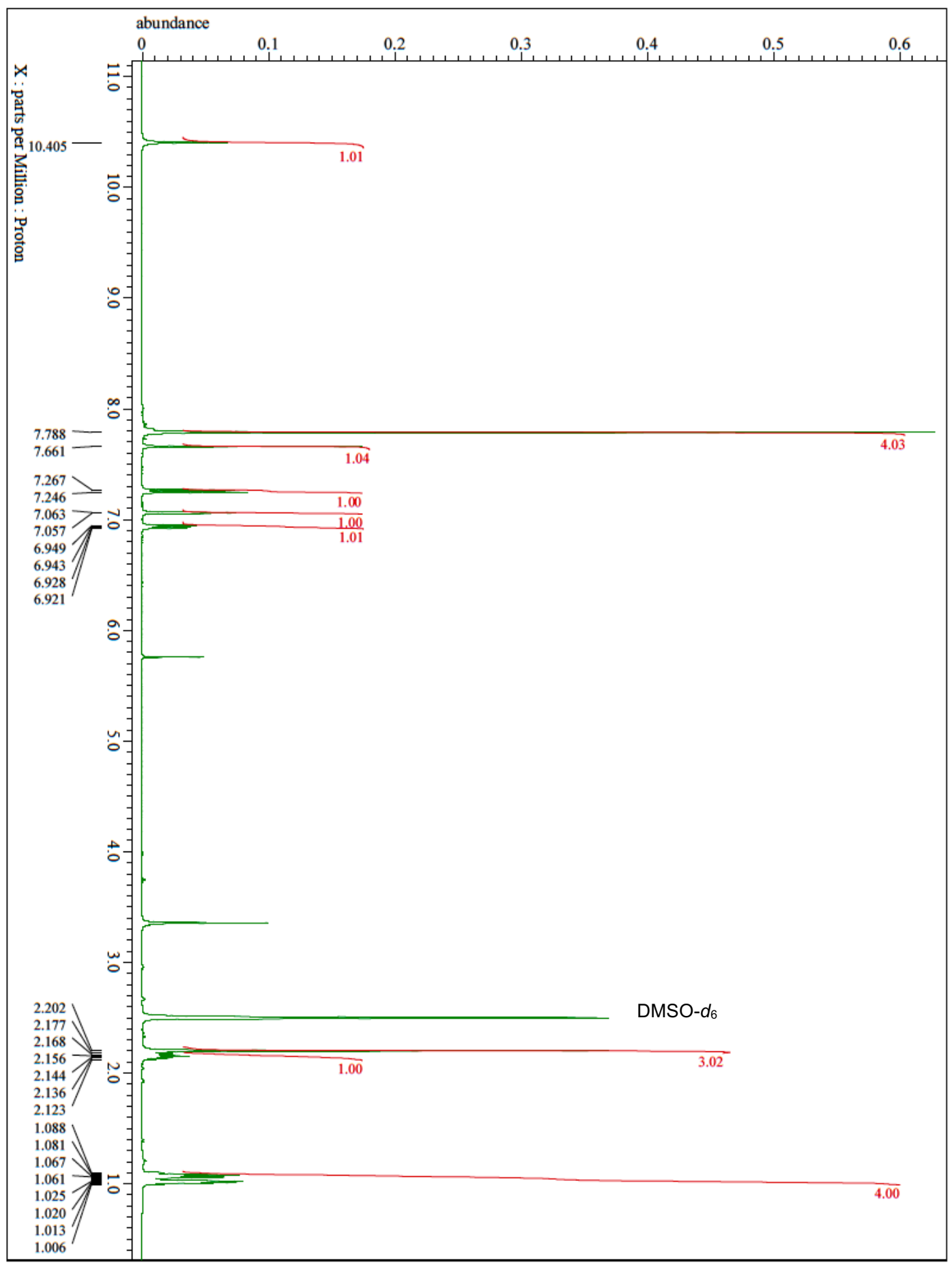


<smiles>Cc1cc(NS(=O)(=O)c2ccc(-c3cnc(C4CC4)o3)cc2)ccc1Cl</smiles>

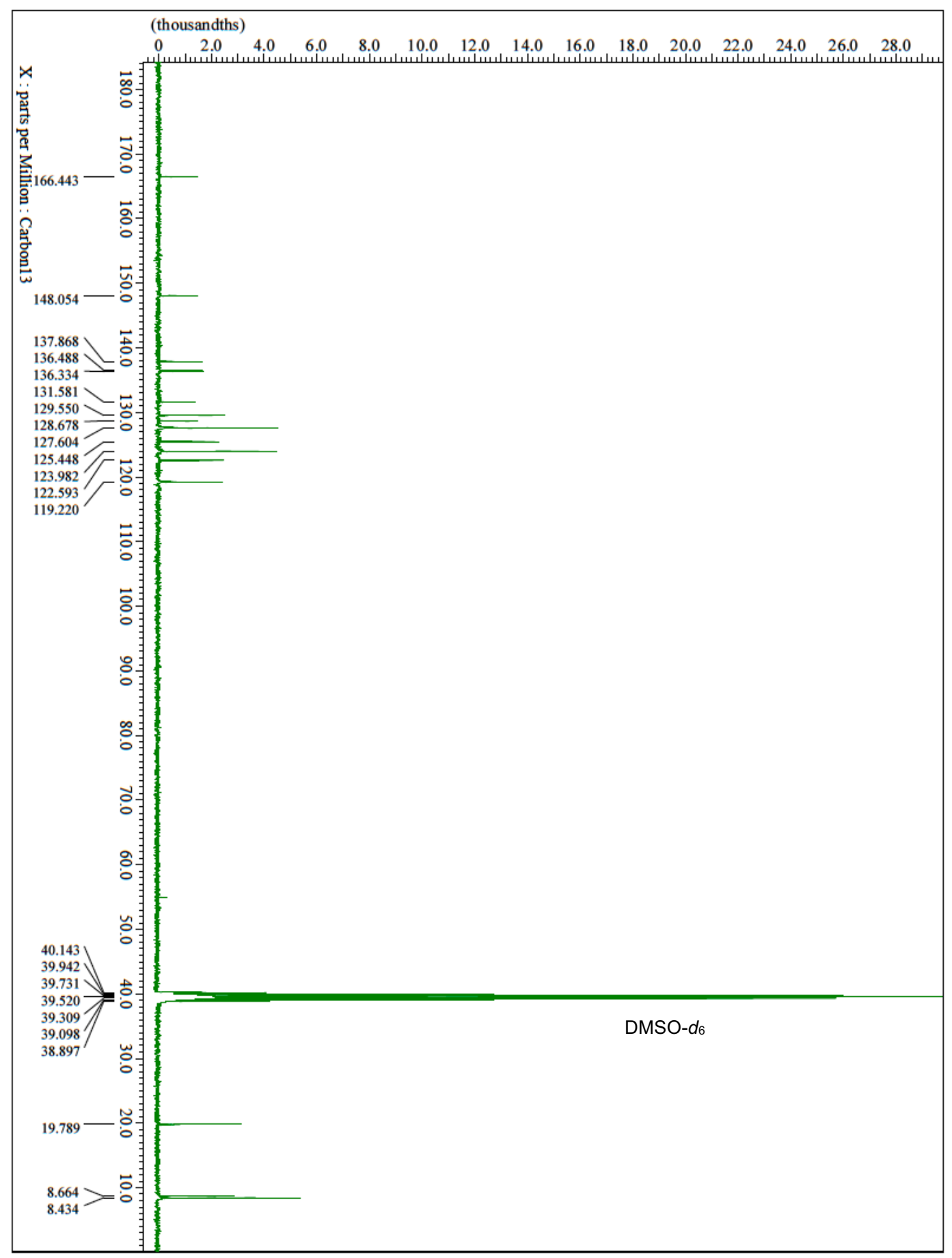


Supporting Information<smiles>O=S(=O)(Nc1cc(Cl)ccc1Cl)c1ccc(-c2cnc(C3CC3)o2)cc1</smiles>

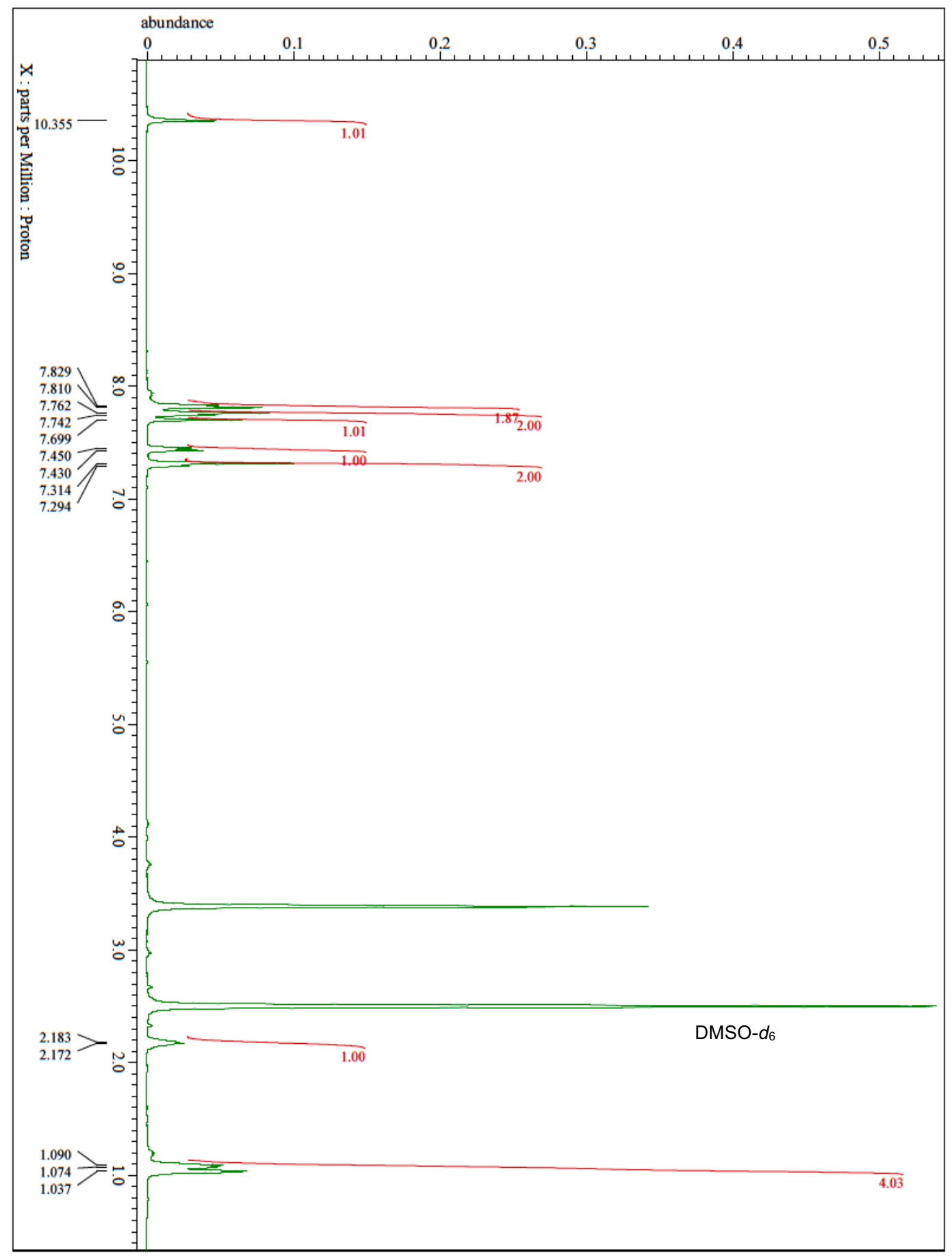


Supporting Information<smiles>O=S(=O)(Nc1cc(Cl)ccc1Cl)c1ccc(-c2cnc(C3CC3)o2)cc1</smiles>

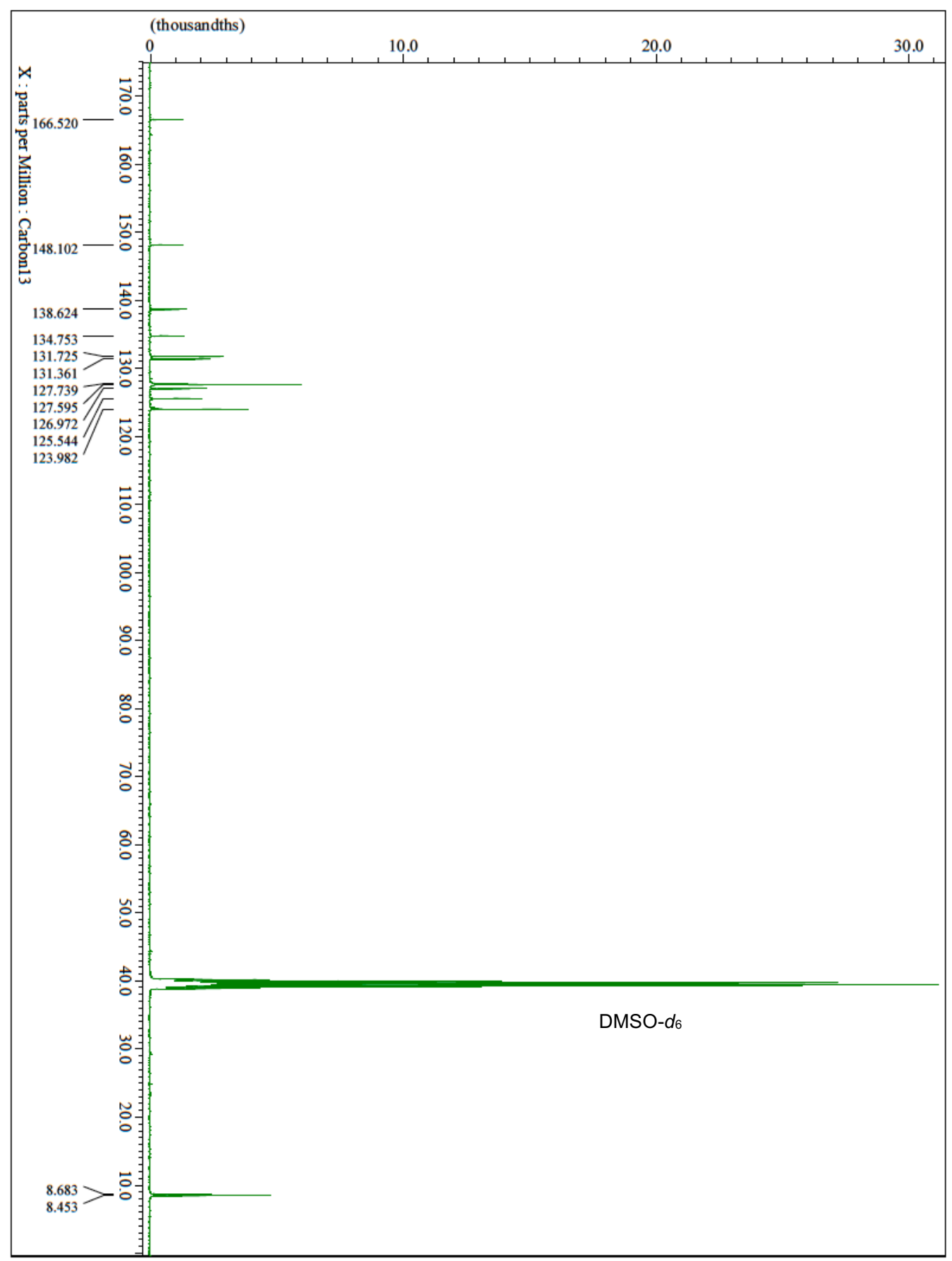


Supporting Information<smiles>Cc1cc(Cl)ccc1NS(=O)(=O)c1ccc(-c2cnc(C3CC3)o2)cc1</smiles>

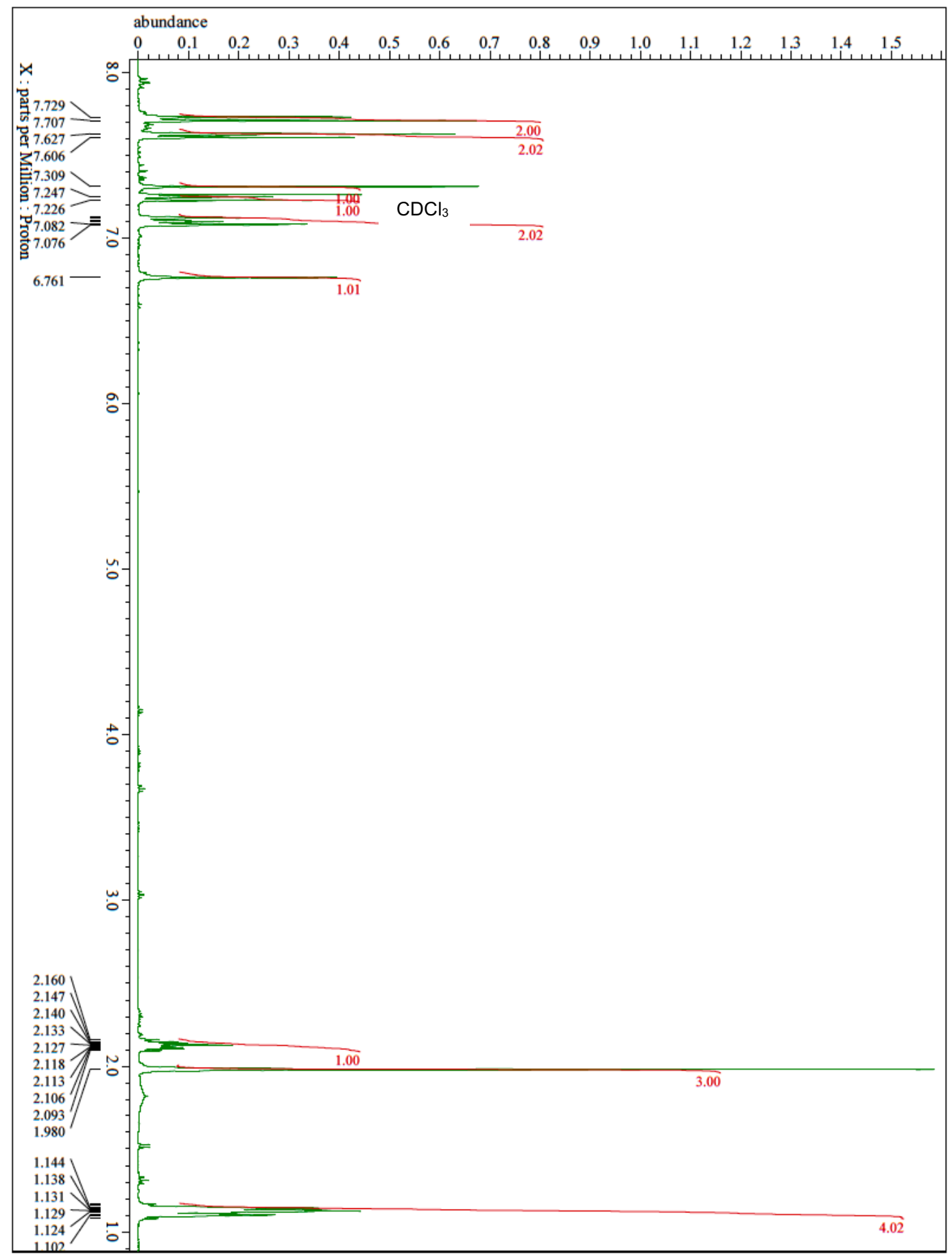


Supporting Information<smiles>Cc1cc(Cl)ccc1NS(=O)(=O)c1ccc(-c2cnc(C3CC3)o2)cc1</smiles>

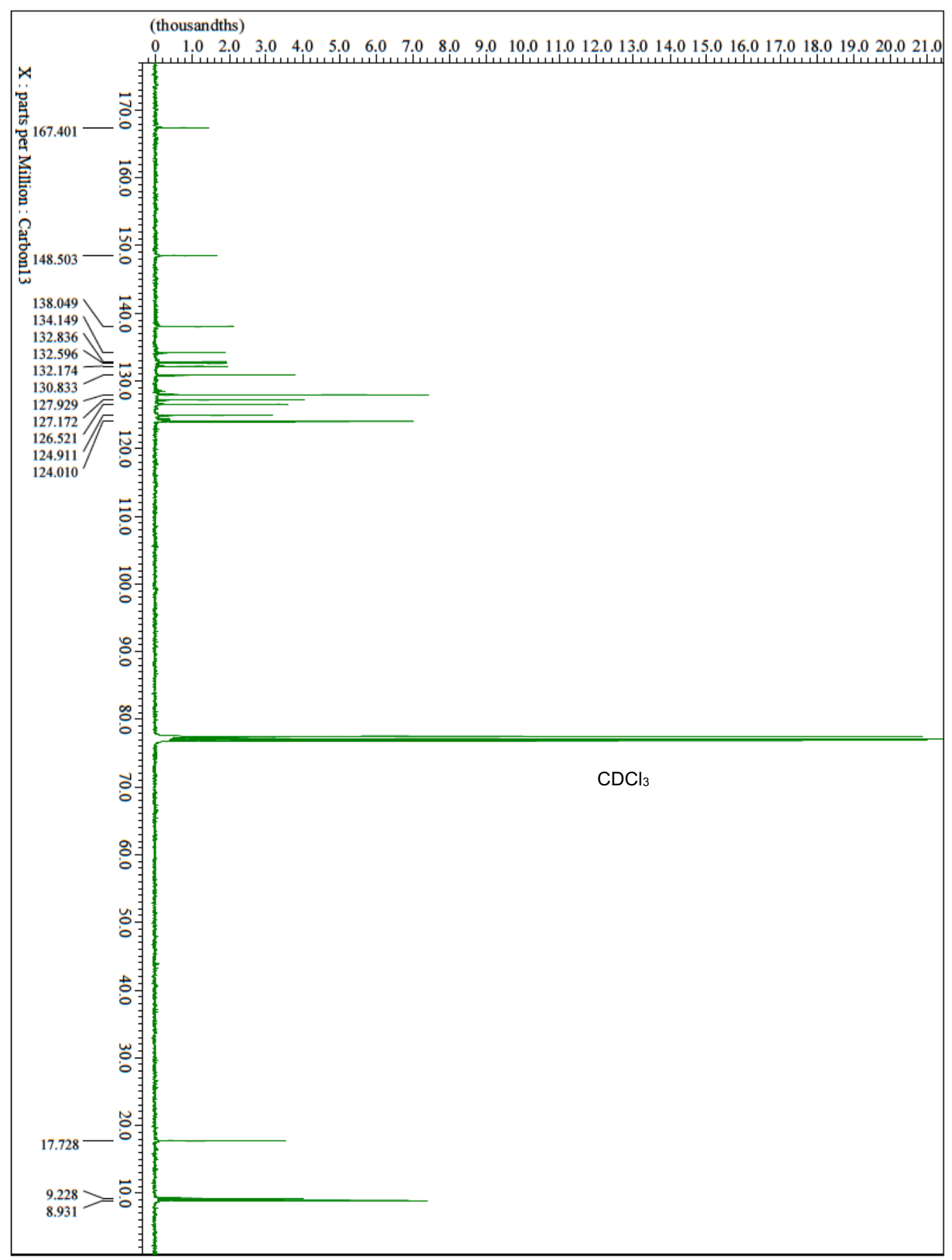


Supporting Information<smiles>O=S(=O)(Nc1ccc(C2CC2)cc1)c1ccc(-c2cnc(C3CC3)o2)cc1</smiles>

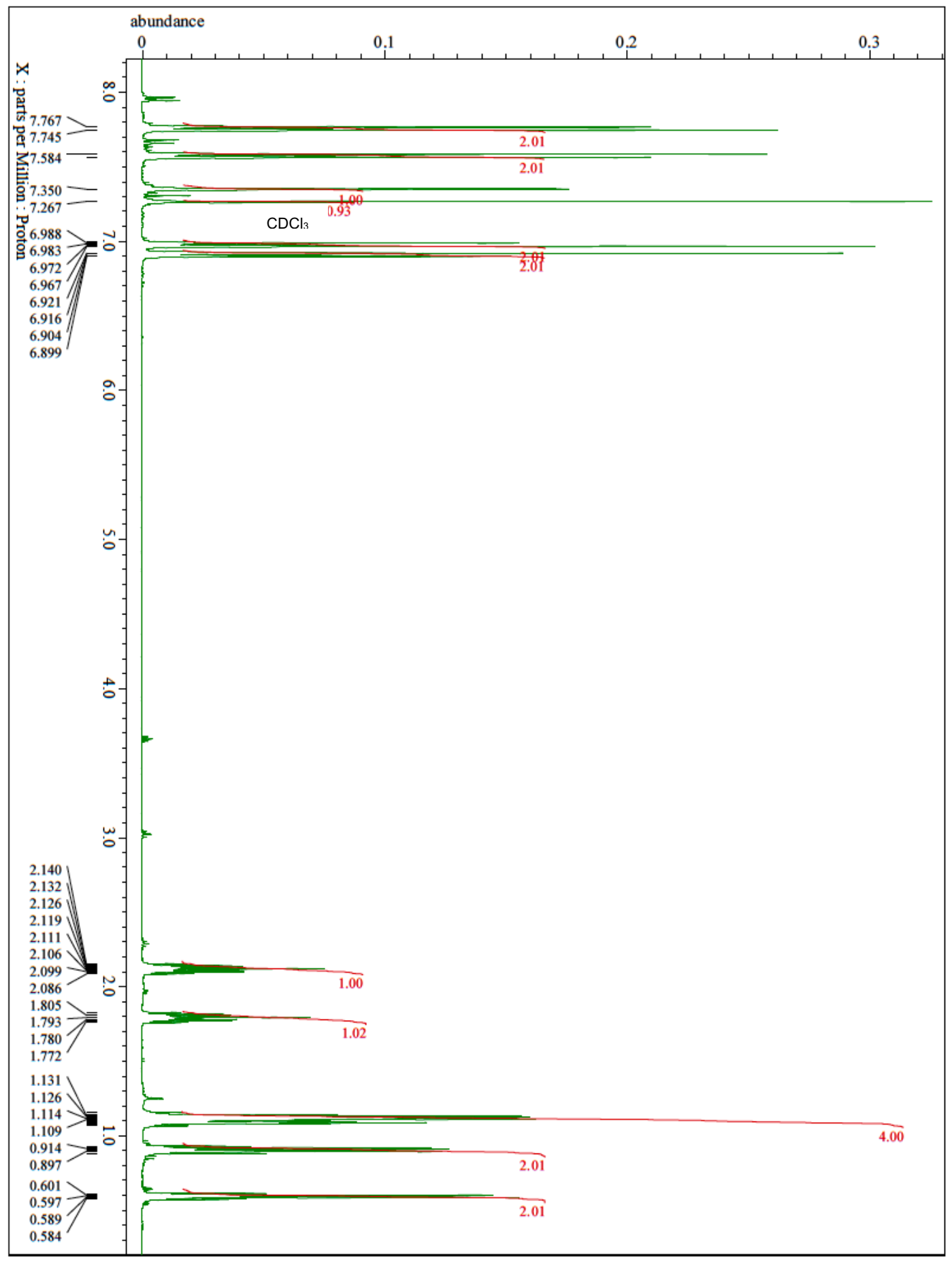


Supporting Information<smiles>O=S(=O)(Nc1ccc(C2CC2)cc1)c1ccc(-c2cnc(C3CC3)o2)cc1</smiles>

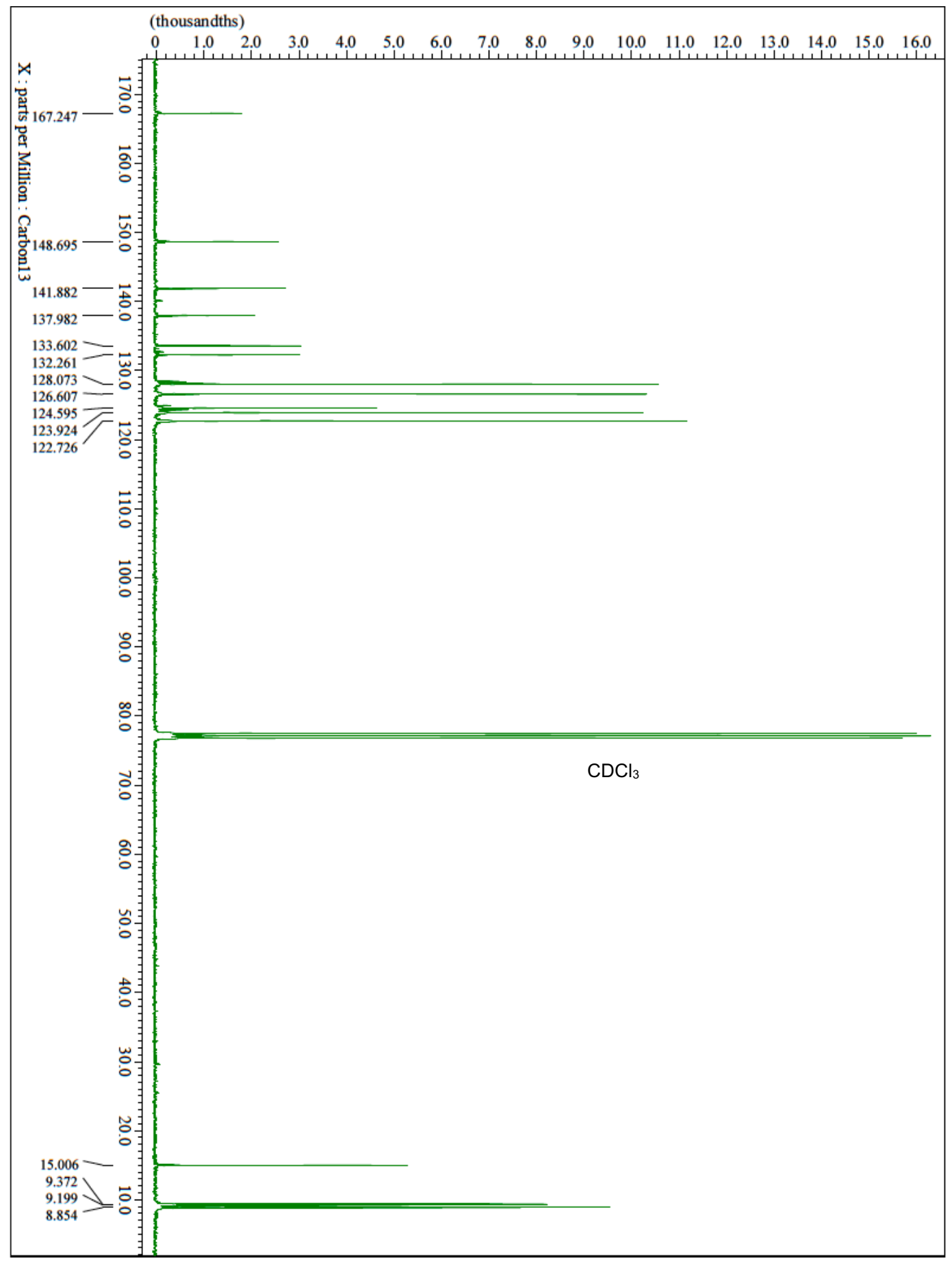


<smiles>Cc1cc(F)cc(NS(=O)(=O)c2ccc(-c3cnc(C4CC4)o3)cc2)c1</smiles>

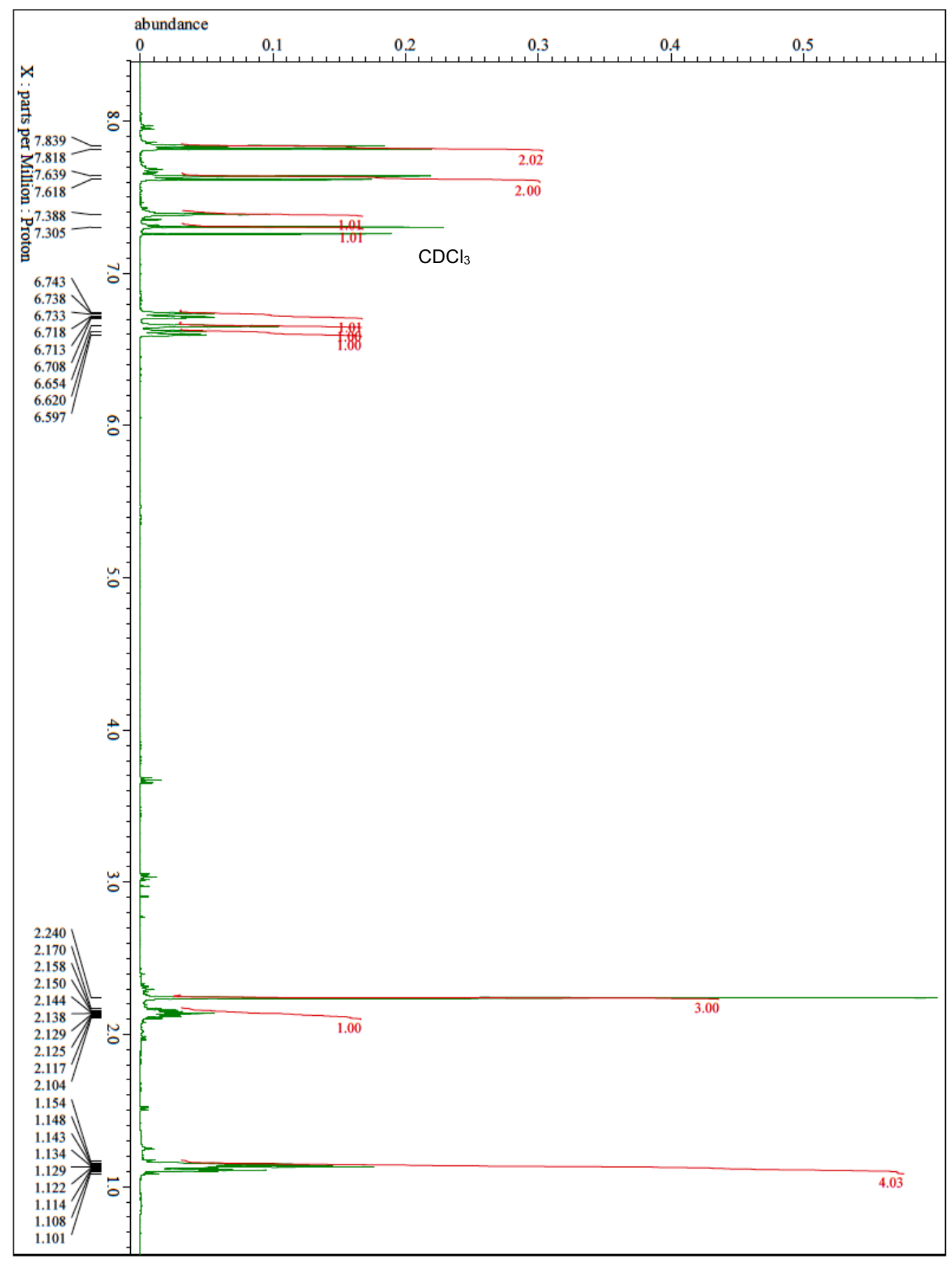


<smiles>Cc1cc(F)cc(NS(=O)(=O)c2ccc(-c3cnc(C4CC4)o3)cc2)c1</smiles>

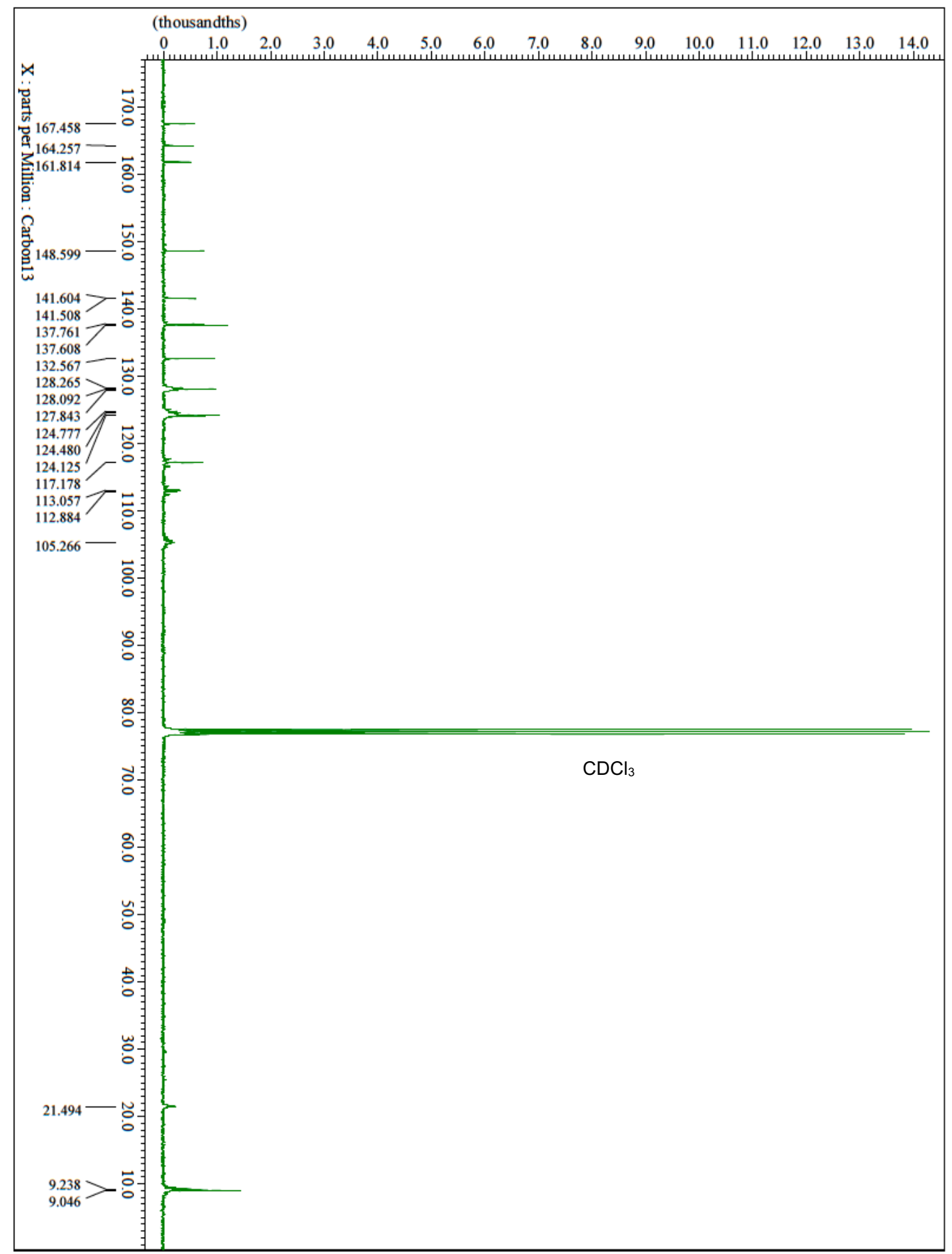


<smiles>O=S(=O)(Nc1cccc2ccccc12)c1ccc(-c2cnc(C3CC3)o2)cc1</smiles>

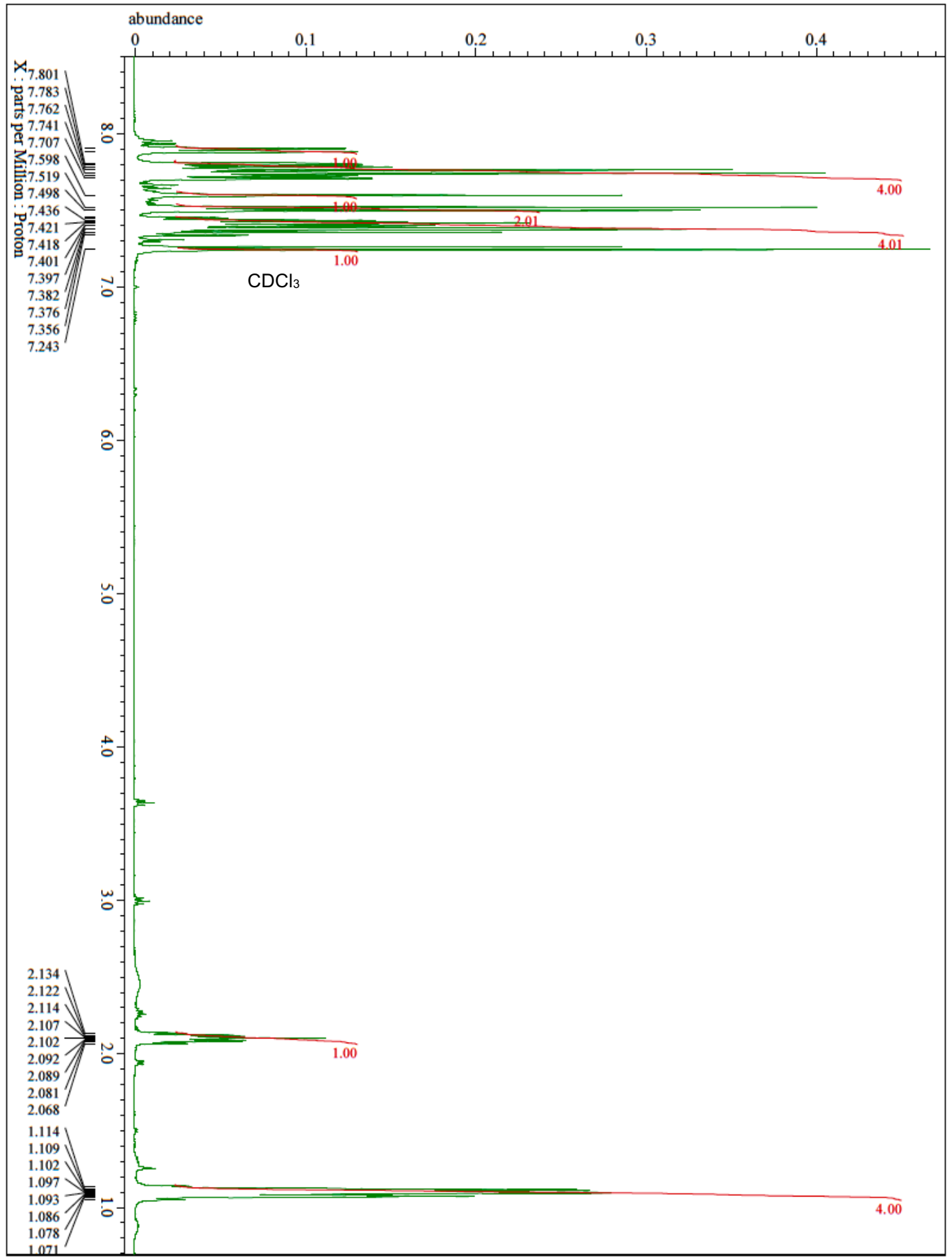


<smiles>O=S(=O)(Nc1cccc2ccccc12)c1ccc(-c2cnc(C3CC3)o2)cc1</smiles>

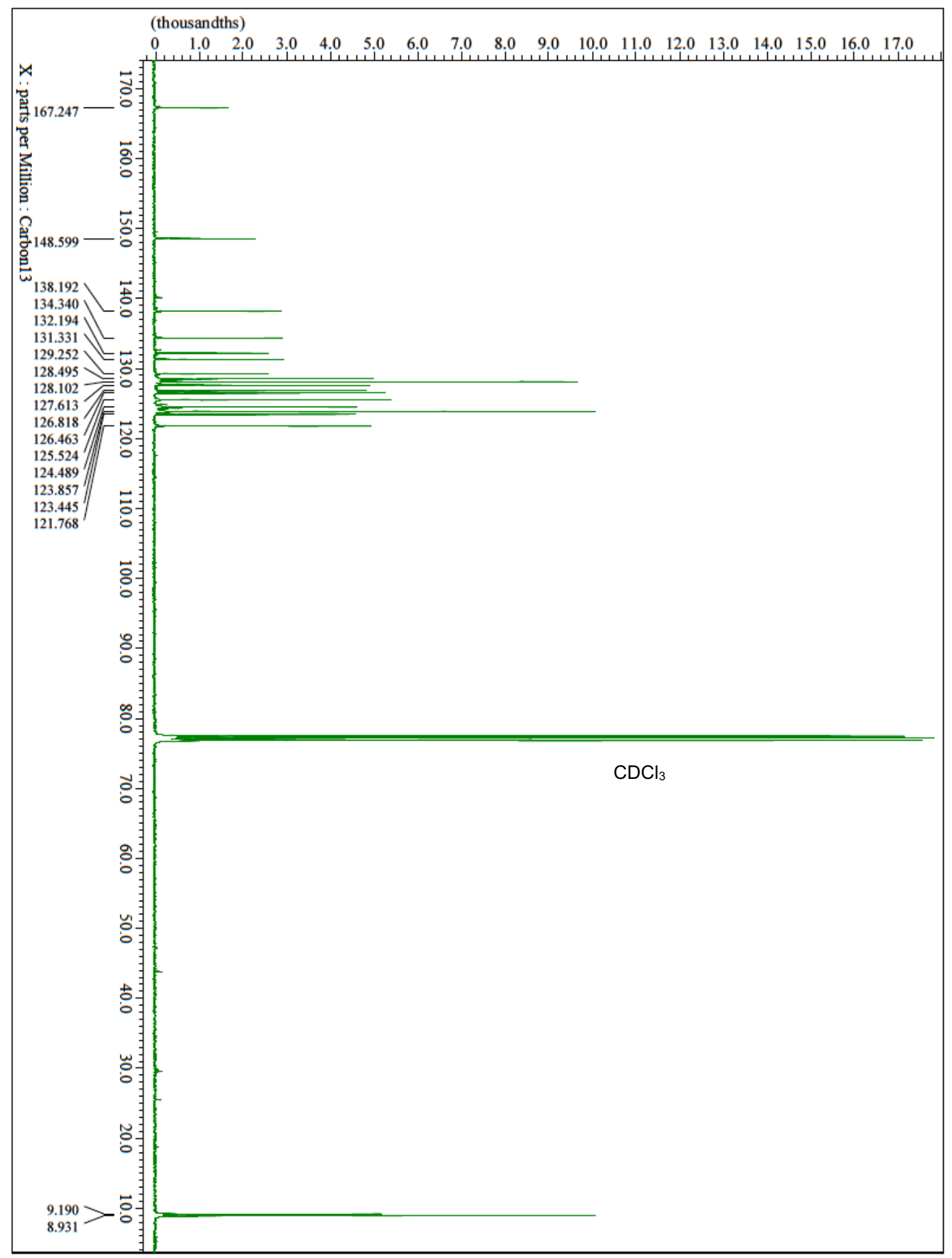


<smiles>CN(c1ccc(F)cc1)S(=O)(=O)c1ccc(-c2cnc(C3CC3)o2)cc1</smiles>

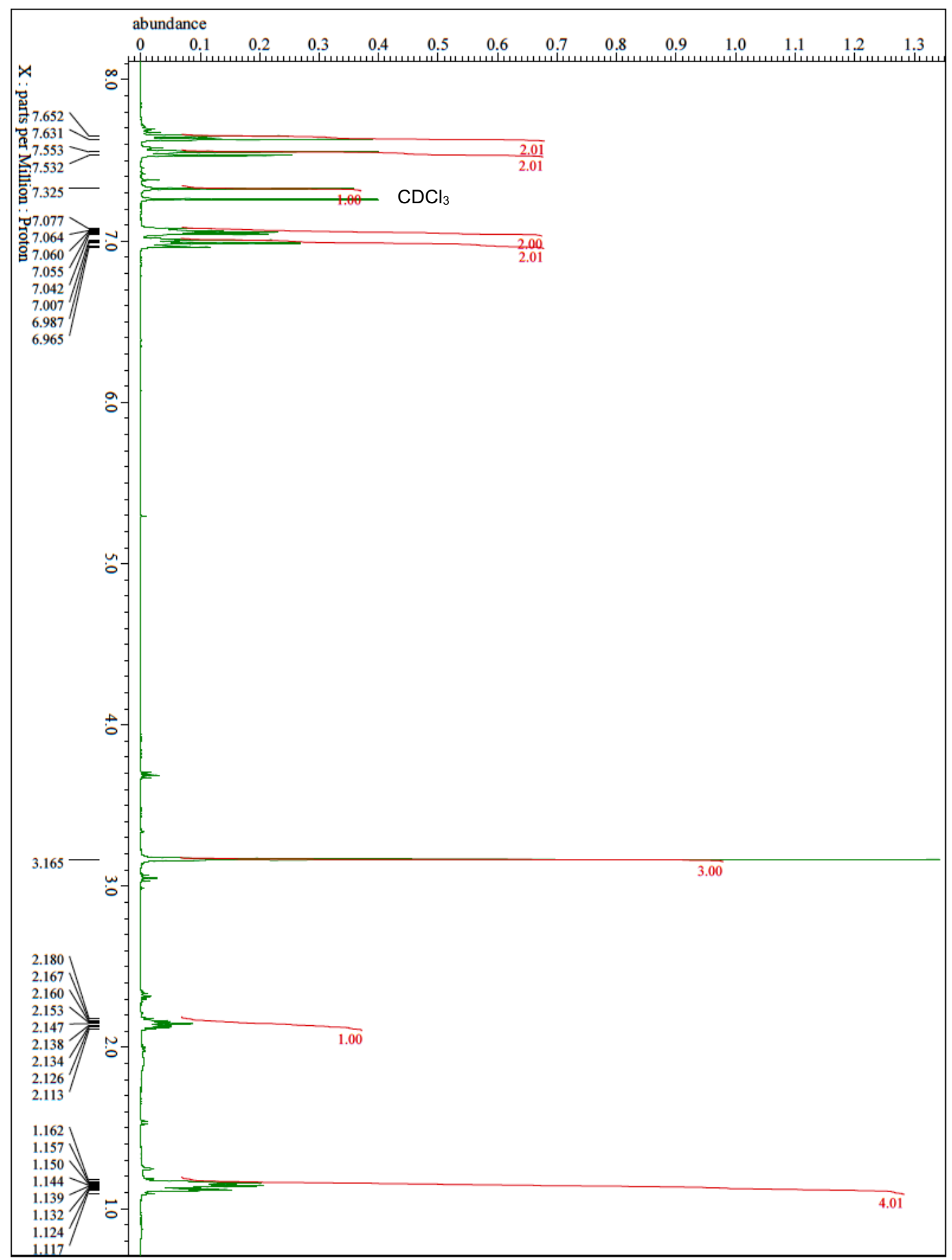


Supporting Information<smiles>CN(c1ccc(F)cc1)S(=O)(=O)c1ccc(-c2cnc(C3CC3)o2)cc1</smiles>

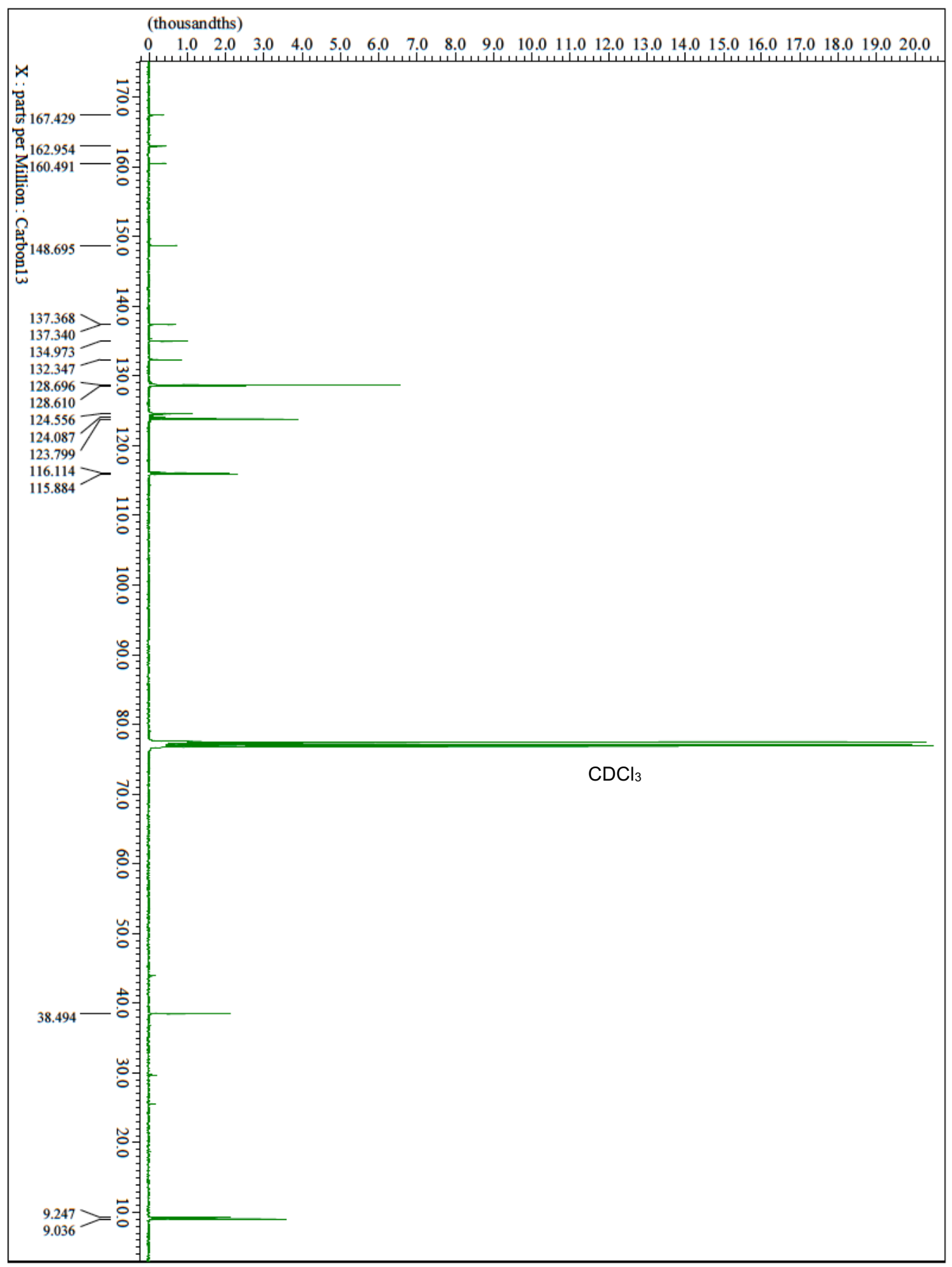




\section{Tubulin Polymerization Assay Information/Data}

Tubulin assay was conducted by ImQuest Biosciences Inc. under project number 532-01-01.

Assay kit

The commercial kit used in the performance of these assays (HTS-Tubulin Polymerization Assay Biochem Kit, catalog number BK004P) was purchased from Cytoskeleton, Inc.

Compounds

Compounds 16, 22, 30, and 32 were solubilized in DMSO at $2 \mathrm{mM}$ and stored at $4{ }^{\circ} \mathrm{C}$ until used. The control compound Paclitaxel was provided with the kit.

Preparation of Reagents

General Tubulin Buffer $80 \mathrm{mM}$ PIPES pH 6.9, 2 mM MgCl $2,0.5 \mathrm{mM}$ EGTA - Lyophilized powder was reconstituted with $10 \mathrm{~mL}$ of distilled water and stored at $4{ }^{\circ} \mathrm{C}$.

GTP $100 \mathrm{mM}$ - each tube was reconstituted with $100 \mu \mathrm{L}$ of ice cold water and aliquoted into $10 \mathrm{x}$ $10 \mu \mathrm{L}$ tubes and stored at $-20^{\circ} \mathrm{C}$.

G-PEM Buffer - ten microliters $(10 \mu \mathrm{L})$ of $100 \mathrm{mM}$ GTP was diluted in $990 \mu \mathrm{L}$ of general tubulin buffer. G-PEM was kept on ice and used within 1 to 2 hours of making.

Tubulin Protein $4 \mathrm{mg} / \mathrm{mL}$ - each vial of tubulin protein was reconstituted with $1 \mathrm{~mL}$ of ice cold GPEM buffer. The tubulin protein was placed on ice and used immediately.

Paclitaxel $2 \mathrm{mM}$ - the paclitaxel included in the kit was reconstituted with $100 \mu \mathrm{L}$ of DMSO.

\section{Tubulin Polymerization Assay Methodology}

Prior to initiating the assay, the spectrophotometer was set to $340 \mathrm{~nm}$ at $37^{\circ} \mathrm{C}$ for performing a kinetic measurement for 61 cycles of 1 reading per minute. The assay plate was warmed at $37^{\circ} \mathrm{C}$ for 30 minutes inside the spectrophotometer. Tubulin buffer was warmed to room temperature and G-PEM buffer was prepared and placed on ice. The compounds 16, 22, 30, and 32 were diluted to 10X the high-test concentration $(10 \mu \mathrm{M})$ in tubulin buffer and three serial 1:5 dilutions were performed. Paclitaxel was only evaluated at 1 concentration per the assay protocol. Ten microliters $(10 \mu \mathrm{L})$ were added to the pre-warmed assay plate and the plate was incubated for 2 minutes at $37^{\circ} \mathrm{C}$. One-hundred microliters $(100 \mu \mathrm{L})$ of tubulin protein was added to each well. The plate was read on the spectrophotometer for 60 minutes and read kinetically. The slope of the curve for each compound at each concentration over 30 minutes was determined and $\mathrm{EC}_{50}$ values were calculated.

$\underline{\text { Results }}$

Compounds 16, 22, 30, and 32 were evaluated for their ability to inhibit tubulin polymerization. Compound 16 had an $\mathrm{EC}_{50}$ value of $0.22 \mu \mathrm{M}$. Compounds 22, 30, and 32 were also active with $\mathrm{EC}_{50}$ values less than $(<) 0.08 \mu \mathrm{M}$. Paclitaxel was evaluated in parallel at one concentration as the assay positive control and resulted in enhancement of polymerization at $10 \mu \mathrm{M}$, which was the expected result. Data is summarized in Figures 1A-1D and Table 1 below. 
Figure S1A: Tubulin Polymerization of 16

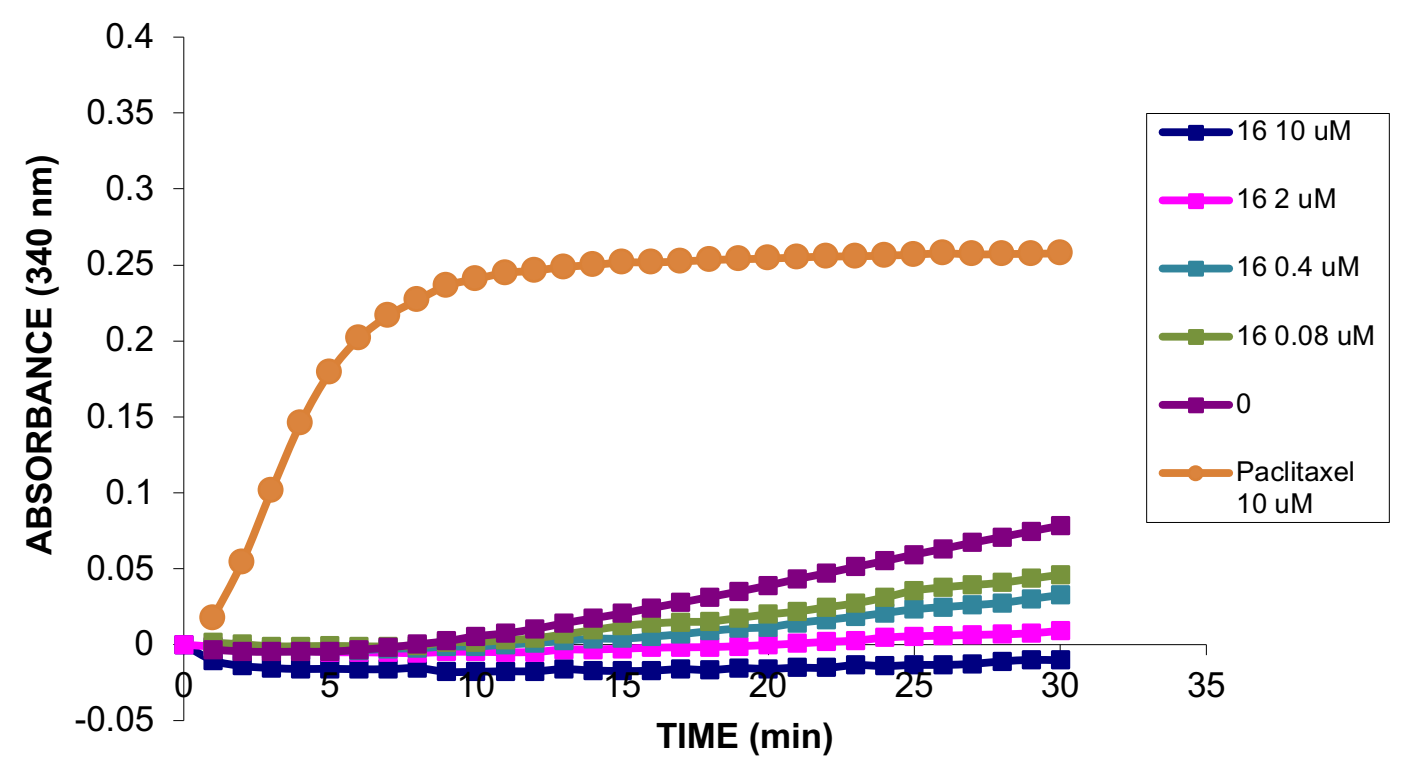

$\begin{array}{cccc}\text { Treatment } & \text { Slope } & \mathbf{R}^{\mathbf{2}} & \text { Time points } \\ \mathbf{1 6} @ 10 \mu \mathrm{M} & 0.000 & 0.890 & 10-30 \\ 16 @ 2 \mu \mathrm{M} & 0.00072 & 0.970 & 10-30 \\ \mathbf{1 6} @ 0.4 \mu \mathrm{M} & 0.0017 & 0.986 & 10-30 \\ \mathbf{1 6} @ 0.08 \mu \mathrm{M} & 0.0023 & 0.987 & 10-30 \\ 0 & 0.0038 & 0.9981 & 10-30 \\ \text { Paclitaxel } 10 \mu \mathrm{M} & 0.0225 & 0.8939 & 2-10\end{array}$


Figure S1B: Tubulin Polymerization of 22

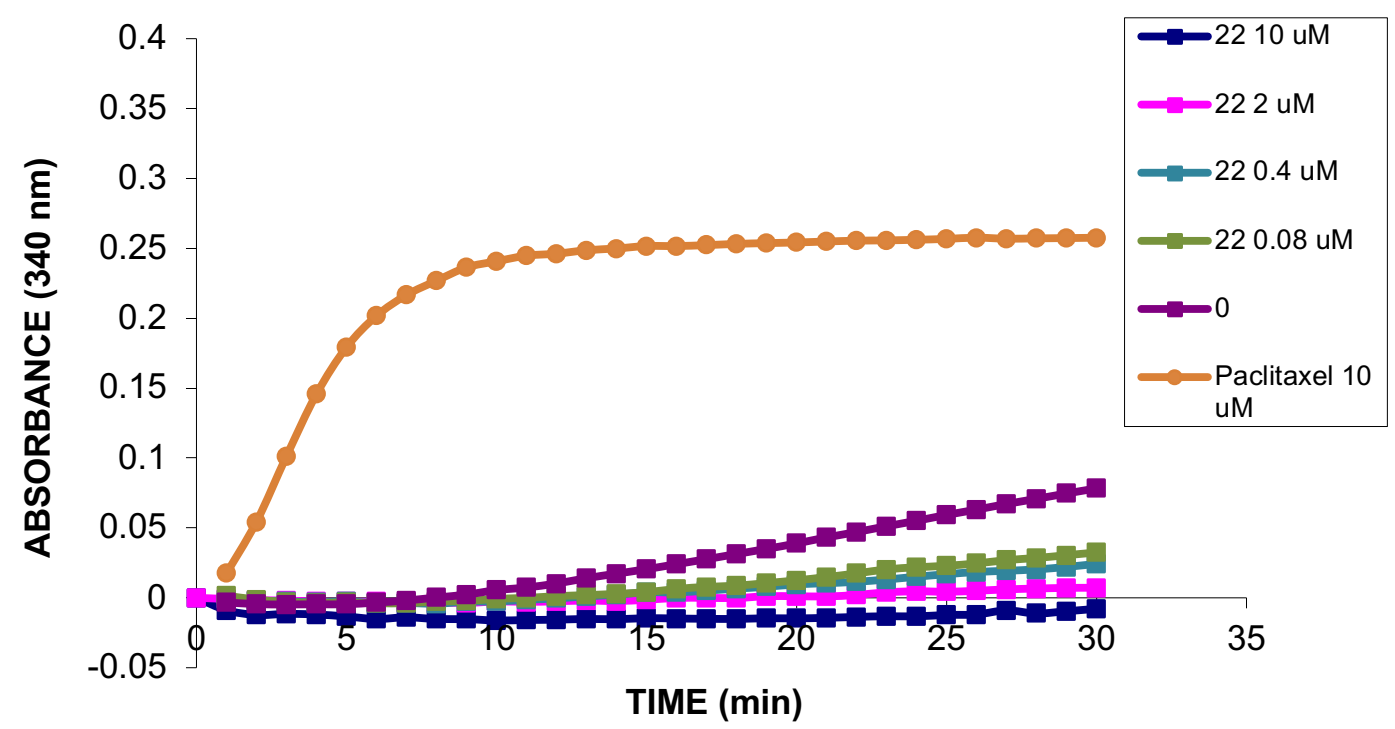

\begin{abstract}
Treatment
$22 @ 10 \mu \mathrm{M}$

$22 @ 2 \mu \mathrm{M}$

$22 @ 0.4 \mu \mathrm{M}$

$22 @ 0.08 \mu \mathrm{M}$

0
\end{abstract}

Paclitaxel $10 \mu \mathrm{M}$

$\begin{array}{ccc}\text { Slope } & \mathbf{R}^{2} & \text { Time points } \\ 0.000 & 0.820 & 10-30 \\ 0.00055 & 0.971 & 10-30 \\ 0.0013 & 0.994 & 10-30 \\ 0.0017 & 0.988 & 10-30 \\ 0.0038 & 0.9981 & 10-30 \\ 0.0225 & 0.8939 & 2-10\end{array}$


Figure S1C: Tubulin Polymerization of $\mathbf{3 0}$

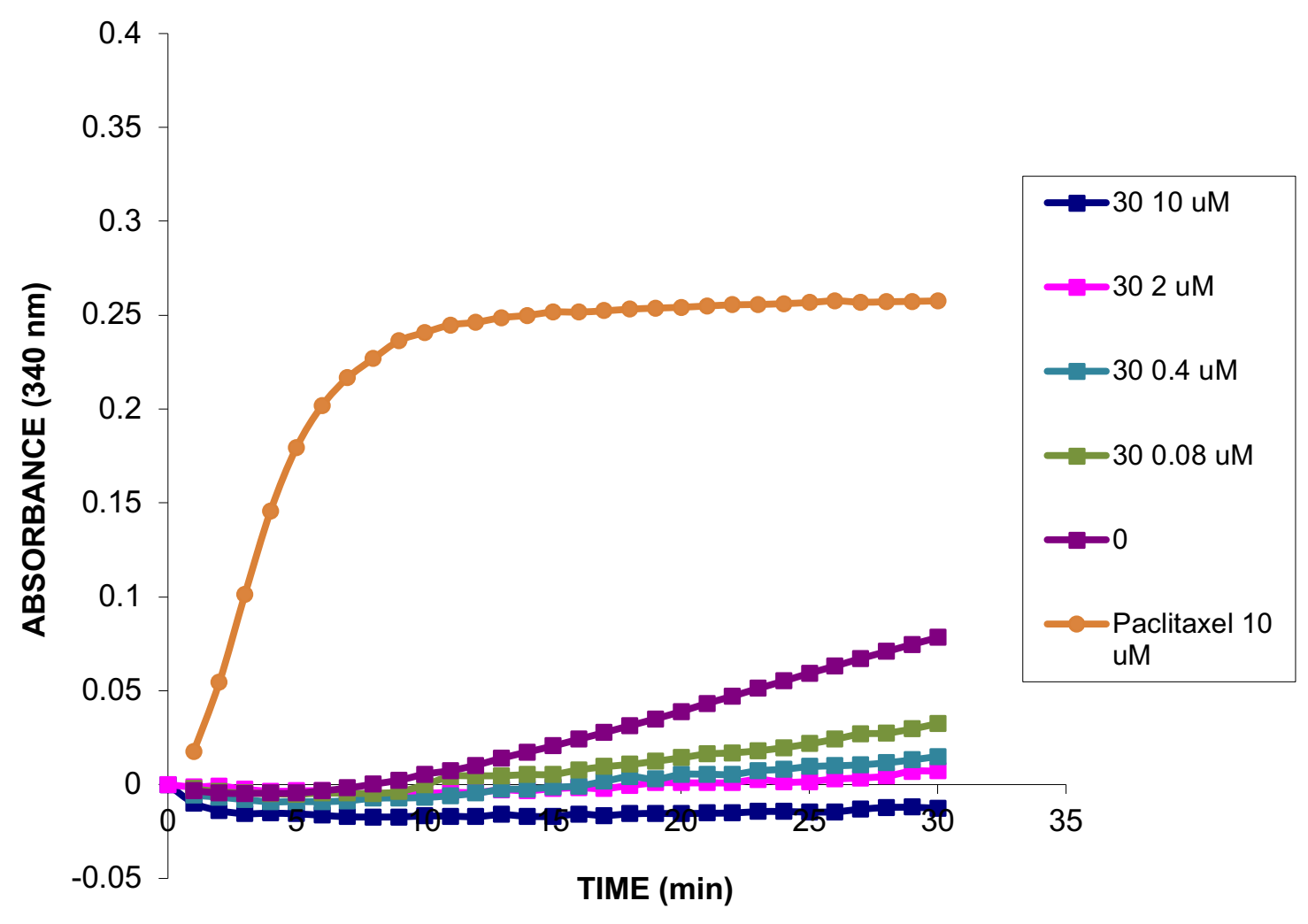

Treatment
$30 @ 10 \mu \mathrm{M}$
$30 @ 2 \mu \mathrm{M}$
$30 @ 0.4 \mu \mathrm{M}$
$30 @ 0.08 \mu \mathrm{M}$
0

Paclitaxel $10 \mu \mathrm{M}$

$\begin{array}{ccc}\text { Slope } & \mathbf{R}^{2} & \text { Time points } \\ 0.000 & 0.873 & 10-30 \\ 0.00054 & 0.943 & 10-30 \\ 0.0010 & 0.986 & 10-30 \\ 0.0015 & 0.980 & 10-30 \\ 0.0038 & 0.9981 & 10-30 \\ 0.0225 & 0.8939 & 2-10\end{array}$


Figure S1D: Tubulin Polymerization of $\mathbf{3 2}$

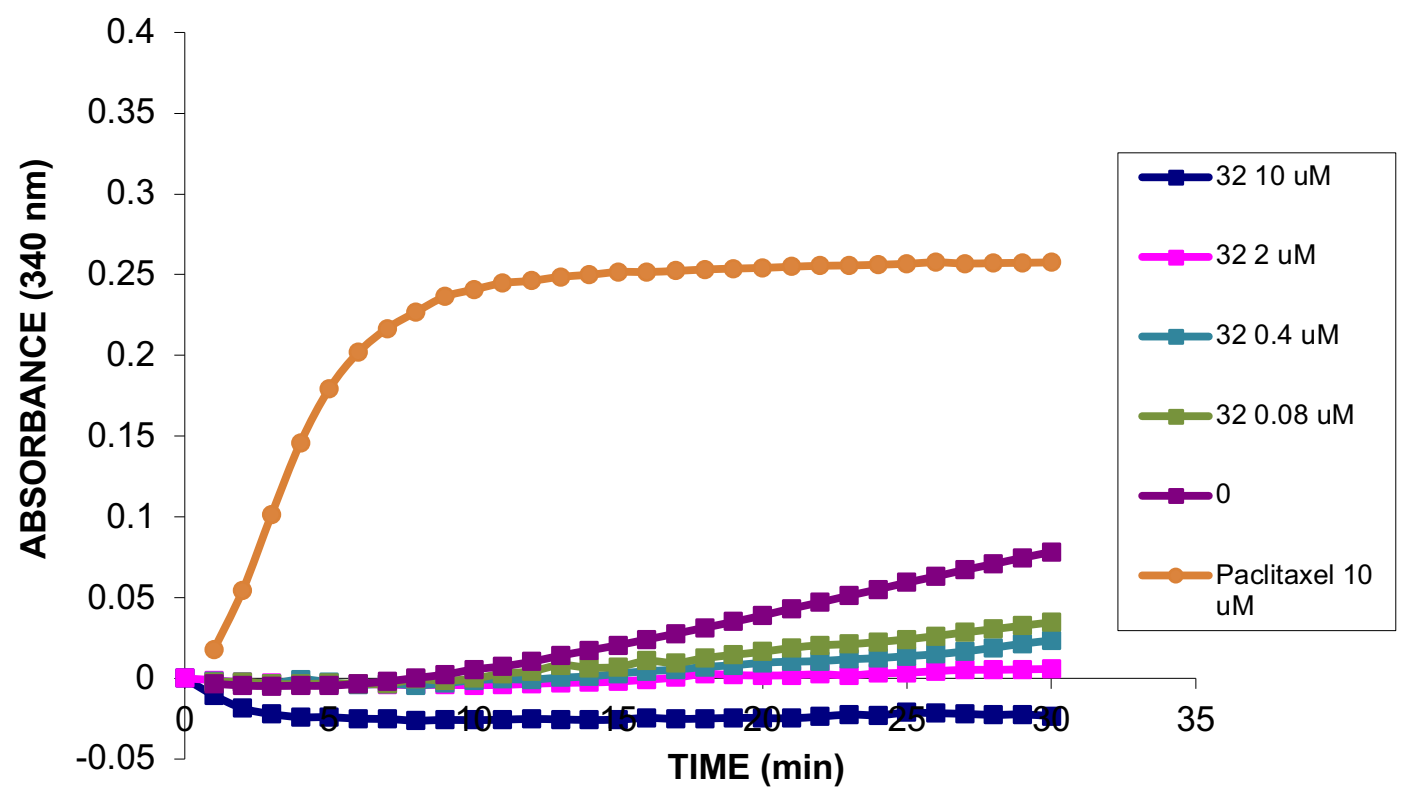

$\begin{array}{cccc}\text { Treatment } & \text { Slope } & \mathbf{R}^{\mathbf{2}} & \text { Time Points (MIN) } \\ \mathbf{3 2} @ 10 \mu \mathrm{M} & 0.000 & 0.761 & 10-30 \\ \mathbf{3 2} @ 2 \mu \mathrm{M} & 0.00052 & 0.943 & 10-30 \\ \mathbf{3 2} @ 0.4 \mu \mathrm{M} & 0.0012 & 0.981 & 10-30 \\ \mathbf{3 2} @ 0.08 \mu \mathrm{M} & 0.0017 & 0.988 & 10-30 \\ 0 & 0.0038 & 0.9981 & 10-30 \\ \text { Paclitaxel } 10 \mu \mathrm{M} & 0.0225 & 0.8939 & 2-10\end{array}$

Table S1. Inhibition of Tubulin Polymerization by 16, 22, 30, and 32.

\begin{tabular}{|c|c|}
\hline Compound & $\mathrm{EC}_{50}(\mu \mathrm{M})$ \\
\hline 16 & 0.22 \\
\hline 22 & $<0.08$ \\
\hline 30 & $<0.08$ \\
\hline 32 & $<0.08$ \\
\hline
\end{tabular}

